University of Louisville ThinkIR: The University of Louisville's Institutional Repository

Electronic Theses and Dissertations

$12-2015$

\title{
The pedagogy of medical humanities : using literature and the visual arts to help future caregivers maintain their compassion and resilience.
}

Lisa Higgins Shugoll

University of Louisville

Follow this and additional works at: https://ir.library.louisville.edu/etd

Part of the Medical Humanities Commons

\section{Recommended Citation}

Shugoll, Lisa Higgins, "The pedagogy of medical humanities : using literature and the visual arts to help future caregivers maintain their compassion and resilience." (2015). Electronic Theses and Dissertations. Paper 2330.

https://doi.org/10.18297/etd/2330

This Doctoral Dissertation is brought to you for free and open access by ThinkIR: The University of Louisville's Institutional Repository. It has been accepted for inclusion in Electronic Theses and Dissertations by an authorized administrator of ThinkIR: The University of Louisville's Institutional Repository. This title appears here courtesy of the author, who has retained all other copyrights. For more information, please contact thinkir@louisville.edu. 
THE PEDAGOGY OF MEDICAL HUMANITIES: USING LITERATURE AND THE VISUAL ARTS TO HELP FUTURE CAREGIVERS MAINTAIN THEIR COMPASSION AND RESILIENCE

\author{
By \\ Lisa Higgins Shugoll \\ B.S., University of North Carolina - Chapel Hill, 1983 \\ M.A., University of Louisville, 2011

\begin{abstract}
A Dissertation
Submitted to the Faculty of the

College of Arts and Sciences of the University of Louisville

in Partial Fulfillment of the Requirements

for the Degree of
\end{abstract}

Doctor of Philosophy in Humanities

Division of Humanities

University of Louisville

Louisville, Kentucky

December 2015 
Copyright 2015 by Lisa Higgins Shugoll

All rights reserved 

THE PEDAGOGY OF MEDICAL HUMANITIES: USING LITERATURE AND THE VISUAL ARTS TO HELP FUTURE CAREGIVERS MAINTAIN THEIR COMPASSION AND RESILIENCE

\author{
By \\ Lisa Higgins Shugoll \\ B.S., University of North Carolina - Chapel Hill, 1983 \\ M.A., University of Louisville, 2011 \\ A Dissertation Approved on
}

November 18, 2015

by the following Dissertation Committee:

Dissertation Director: Annette Allen, PhD

Christopher Fulton, PhD

Stephen Hanson, PhD

Celeste Shawler, PhD, PMHCNS-BC 


\section{DEDICATION}

This dissertation is dedicated to my father

Oswald Kenneth Higgins

His love was constant, no matter what. 


\section{ACKNOWLEDGMENTS}

I would like to thank my mentor and dissertation director, Dr. Annette Allen. I could never have come this far without her kindness, support, and guidance. I am grateful to her for steering me toward medical humanities and I have the deepest respect for the work she has done in this field. Thank you to Dr. Christopher Fulton, an extraordinary teacher whose passion for art led me toward many life-enhancing discoveries. Thank you to Dr. Stephen Hanson, whose willingness to grapple with life's most difficult questions is an inspiration. And, thank you to Dr. Celeste Shawler for bringing her clinical expertise to the table and for asking the perfect questions.

I am deeply grateful to Andrew Marsh, whose moving story and powerful art so beautifully demonstrate the importance of medical humanities. I have not done justice to his creativity or his indefatigable nature, but I am honored to share a part of them here.

I would also like to thank my daughters, Lara and Anna, two remarkably kind and intelligent young women. They are the reason for everything. Thank you to the rest of my family; I hope I am worthy of your pride in my accomplishments. And thank you to the ladies of my book groups - those strong, generous women I have the good fortune of calling dear friends. Your accomplishments inspire me, your encouragement motivates me, and our laughter makes everything fine. 


\section{ABSTRACT \\ THE PEDAGOGY OF MEDICAL HUMANITIES: USING LITERATURE AND THE VISUAL ARTS TO HELP FUTURE CAREGIVERS MAINTAIN THEIR COMPASSION AND RESILIENCE}

\section{Lisa Higgins Shugoll}

November 18, 2015

In this dissertation I argue that medical humanities education for students considering careers in healthcare should begin at the general undergraduate level and should have two primary objectives, (1) providing tools that will help students foster therapeutic, compassionate relationships with their patients, and (2) providing strategies that will help students maintain healthy habits of mind that afford resilience against compassion fatigue. I assert that in order for students to practice compassion for themselves and others three core objectives must be met. (1) Students must be exposed to the fundamentals of bioethics in order to understand the virtue of compassion itself, (2) they must develop expertise in the tenets of narrative medicine in order to fully comprehend the causes of suffering in their patients, and (3) they must be introduced to the practice of mindfulness as a means of self-care. The following chapters suggest that literature and the visual arts offer the most effective means of teaching these concepts and 
present a pedagogy that incorporates traditional academic theory as well as practical application of knowledge.

Chapter one introduces the tenets of narrative medicine through the study of Frida Kahlo’s 1932 painting, Henry Ford Hospital. This chapter considers the formal, contextual, and expressive elements of Kahlo's painting as they are related to Rita Charon's concepts of narrative competence and narrative practice. Chapter two explores the concept of empathy, a prerequisite to compassion, using short stories by Eudora Welty and Richard Selzer. This chapter addresses the problems of alterity and the presence of unconscious biases that create obstacles to empathy. Chapter three uses ancient and modern dramatic literature to introduce the fundamentals of bioethics. This chapter argues that virtue, as well as principles, can be taught in the classroom and suggests a process for moral reflection. Chapter four introduces the concepts of mindfulness and creative "flow" and suggests that engagement with and creation of fully abstract visual art helps students experience and practice the healthy states of mind that provide resilience against compassion fatigue. Chapter five presents a case study that attests to the importance of the medical humanities pedagogy described in this dissertation. 


\section{TABLE OF CONTENTS}

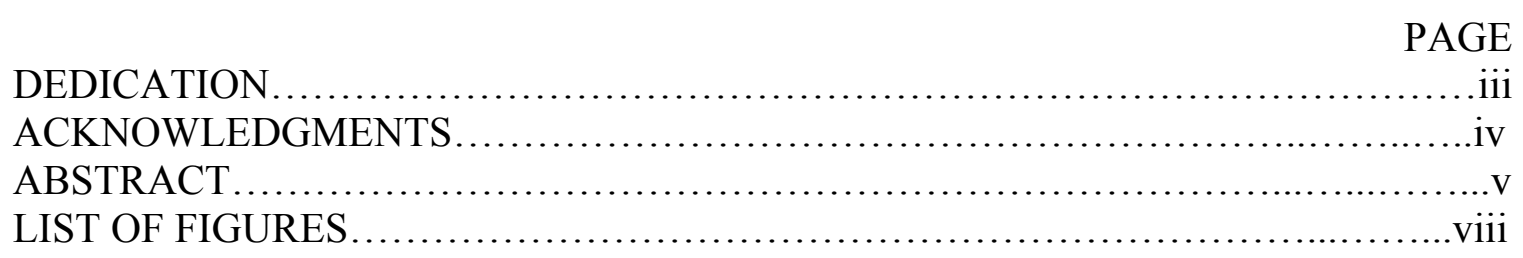

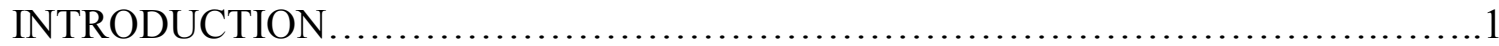

CHAPTER ONE: The Pedagogy of Narrative Competence and Mindful Empathy......13

CHAPTER TWO: The Pedagogy of Self-Awareness - Using Literature to Explore Alterity and Address Healthcare Disparities................................41

CHAPTER THREE: The Pedagogy of Bioethics - Using Dramatic Literature to Introduce Virtues and Principles

CHAPTER FOUR: The Art of Mindfulness - Helping Caregivers Care for Themselves.....................................................106

CHAPTER FIVE: The Importance of Medical Humanities Pedagogy - A

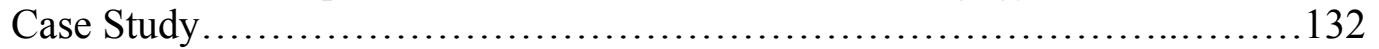

REFERENCES......................................................... 162

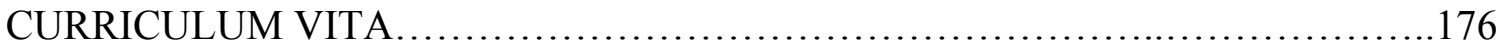




\section{LIST OF FIGURES}

FIGURE PAGE

1. Frida Kahlo, Henry Ford Hospital (1932).....................................41

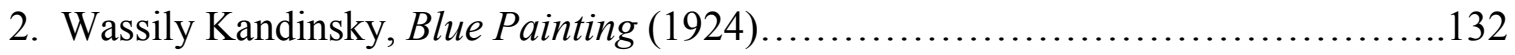

3. Visual Analog Scale (VAS) for pain measurement.......................... 143

4. McGill Pain Questionnaire (MPQ) .......................................... 156

5. MPQ completed by Andrew Marsh on 11/25/12 ............................ 157

6. Andrew Marsh, Pain Trophy 13 - Pattern in Progress (2007)....................158

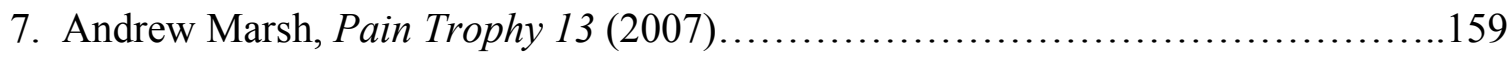

8. Andrew Marsh, Make it Writhe (2012)..................................... 160

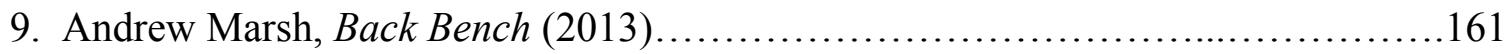

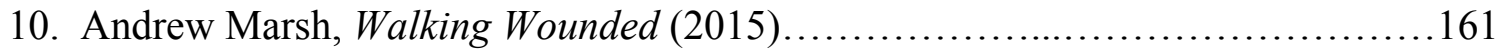

11. Andrew Marsh, Walking Wounded Casting Performance (2015)..................162 


\section{INTRODUCTION}

Medical Humanities is a relatively new academic field that seeks ways of integrating the humanities into a medical education curriculum that is, of necessity, increasingly scientific and technological. The perceived benefits of a more inclusive education for healthcare practitioners are myriad, but there is little agreement among scholars about specific goals and objectives of medical humanities pedagogy. ${ }^{1}$ Originally developed for medical students, the scope of medical humanities education has expanded to include practitioners in all aspects of healthcare. For this reason the terms Medical Humanities, Humanities and Healthcare, and Health Humanities are often used interchangeably. For the purposes of this dissertation, the traditional and more familiar nomenclature of Medical Humanities will be employed even though the suggestions for pedagogy are intended for students interested in any type of caregiving profession. This dissertation affirms that Medical Humanities education should, in fact, begin at the general undergraduate level and be available to any student considering a career in healthcare.

\footnotetext{
${ }^{1}$ Robert Martensen, “Thought Styles among the Medical Humanities: Past, Present, and Near-Term
} 
The field of Medical Humanities is, by definition, a multidisciplinary domain. For this reason, there is little in the way of cohesive ideology or suggested pedagogy, especially at the general undergraduate level. In my own work I have come to regard providing students with the tools to develop and maintain a sense of compassion for their patients and themselves as the most important objective for undergraduate medical humanities education. In this regard it is important to understand compassion as something more than a vague, ill-defined feeling, and instead consider it a skill that must be practiced and carefully maintained by all who choose to enter the field of healthcare.

Understanding and maintaining the virtue of compassion is imperative for the formation of therapeutic caregiving relationships and also for preventing caregiver burnout. This dissertation asserts that in order for students to practice compassion for themselves and others three core objectives must be met. (1) Students must be exposed to the fundamentals of bioethics in order to understand the virtue of compassion itself, (2) they must develop an expertise in the tenets of narrative medicine in order to fully comprehend the causes of suffering in their patients, and (3) they must be introduced to the practice of mindfulness as a means of self-care. The following chapters suggest that literature and the visual arts offer the most effective means of teaching these concepts and present a pedagogy that incorporates traditional academic theory as well as practical application of knowledge.

The primary sources explored in this dissertation have been selected for their effectiveness in demonstrating various elements of narrative, bioethics, and mindfulness, while simultaneously addressing many areas of healthcare in which there is dissatisfaction among both consumers and practitioners. This selection does not represent 
the entire reading and viewing list for an introductory medical humanities course, which would certainly include factual, evidence-based texts in addition to the sources discussed here. Many of the literary and artistic works discussed in this dissertation are familiar to scholars of medical humanities and are included because the current discourse contains lacunae or misinformation that warrant further study and clarification.

There is much debate among scholars of medical humanities about the difficulties in evaluating the effectiveness of programs designed to teach behaviors and virtues generally considered unquantifiable. Some scholars and clinicians believe demonstrating positive outcomes in a quantitative empirical manner is the only way to make medical humanities fully acceptable to clinicians, ${ }^{2}$ while others find such attempts to measure outcomes reductive and not particularly informative. ${ }^{3}$ Because most undergraduate students are not yet practicing caregivers, we must assess their understanding of the concepts presented and their ability to relate those concepts to lived experience. In this regard, I concur with the conclusions of Shapiro et al., who posit, "students' increasing emotional awareness, self-reflection, and capacity to grasp ambiguity might be considered as proxy outcomes for actual patient interaction skills." 4

The formation of therapeutic relationships between caregivers and their patients is likely the single most important aspect of healthcare, not only in terms of making sound clinical decisions that truly benefit the patient, ${ }^{5}$ but also in preventing malpractice

\footnotetext{
${ }^{2}$ Catherine Belling, "Sharper Instruments: On Defending the Humanities in Undergraduate Medical Education," Academic Medicine June 2010 85, no. 6 (2010): 938.

${ }^{3}$ Ayelet Kuper, "Literature and Medicine: A Problem of Assessment," Academic Medicine Academic Medicine 81, no. Suppl (2006): S133.

${ }^{4}$ Johanna Shapiro et al., "Medical Professionalism: What the Study of Literature Can Contribute to the Conversation," Philosophy, Ethics \& Humanities in Medicine 10, no. 1 (June 2015): 6, doi:10.1186/s13010-015-0030-0.

${ }^{5}$ Samantha A. Batt-Rawden et al., "Teaching Empathy to Medical Students," Academic Medicine 88, no. 8 (2013): 1171.
} 
lawsuits and caregiver burnout. ${ }^{6}$ At the core of such relationships is the virtue of compassion, defined by researchers at Stanford University as:

A complex multidimensional construct that is comprised of four key components: (1) an awareness of suffering (cognitive component), (2) sympathetic concern related to being emotionally moved by suffering (affective component), (3) a wish to see the relief of that suffering (intentional component), and (4) a responsiveness or readiness to help relieve that suffering (motivational component). ${ }^{7}$

This definition is useful to the pedagogy of medical humanities because each component of compassion presents a unique educational opportunity and objective. The cognitive and intentional components, an awareness of suffering and a wish to see it relieved, ask that the caregiver go beyond what is initially apparent and seek to understand the causes of suffering that may not be evident in the physical exam (PE) or history of present illness (HPI). This type of attention requires an expertise in the elements of narrative. The affective component is predicated upon an emotional response that has traditionally been discouraged in medical caregivers. ${ }^{8}$ Genuine emotional connection is crucial to the creation of therapeutic relationships, however, and part of medical humanities pedagogy must consist of helping students explore and understand their own capacities for emotional response. (I will argue that an empathetic concern is preferable to a sympathetic concern, and the subtle differences between these terms will be explored later in this introduction.) The motivational component of compassion,

\footnotetext{
${ }^{6}$ Mark Crane, "Why Burned-out Doctors Get Sued More Often," Medical Economics 75, no. 10 (May 26, 1998): 210-18.

${ }^{7}$ Hooria Jazaieri et al., "A Randomized Controlled Trial of Compassion Cultivation Training: Effects on Mindfulness, Affect, and Emotion Regulation," Motivation and Emotion 38, no. 1 (February 1, 2014): 23. Italics original. 8 Jodi Halpern, From Detached Concern to Empathy: Humanizing Medical Practice (Oxford: Oxford University Press, 2001), 17; Rita Charon, Narrative Medicine: Honoring the Stories of Illness (Oxford: Oxford University Press, 2006), 6.
} 
responsiveness and readiness to relieve suffering, requires caregivers to have confidence in their ability to mitigate a patient's suffering. This confidence should extend beyond technical or scientific expertise and include a caregiver's willingness and ability to remain emotionally present without sacrificing his or her own well-being.

The dictionary definitions of empathy, sympathy, and compassion are all remarkably similar, but for the purposes of this dissertation, and for medical humanities in general, it is important to clarify the terms. Compassion has previously been defined, but empathy and sympathy need further specification. As Dr. Jodi Halpern has noted, physicians have been attempting to differentiate these terms since the 1950's, at which time sympathy was considered a misguided impulse to "conflate self and other," whereas empathy was seen as intellectual concern without emotional involvement. ${ }^{9}$ This distinction persists in modern healthcare where conventional wisdom encourages "an intellectual rather than emotional form of knowing". ${ }^{10}$ Halpern disagrees with that precept, however, and states, "[T]he function of empathy is not merely to label emotional states, but to recognize what it feels like to experience something."11 Halpern refers to the practice of clinical empathy as "emotional attunement" and stresses that this is not simply a vicarious experiencing of the patient's emotions, but rather an imaginative reconstruction of the patient's situation that allows and encourages emotional resonance between caregiver and patient. ${ }^{12}$ Sympathy, on the other hand, has been described as "feeling 'for' another person rather than feeling 'with' another person," which places emphasis on the feelings of the observer (or caregiver) rather than those of the other (or

\footnotetext{
${ }^{9}$ Halpern, From Detached Concern to Empathy: Humanizing Medical Practice, 18.

10 Jodi Halpern, "What Is Clinical Empathy?," JGI Journal of General Internal Medicine 18, no. 8 (2003): 670.

${ }^{11}$ Ibid., 671.

12 Ibid.
} 
patient). ${ }^{13}$ In these terms, sympathy emphasizes the difference between self and other rather than attempting to form a mutual understanding. In the pedagogy suggested by this dissertation, empathy will be understood as a prerequisite to compassion.

Pellegrino and Thomasma consider compassion "a virtue of special importance in the medical relationship," and define it as "the capacity of physicians to feel something of the unique predicament of the patient, to enter into the patient's experience of illness and, as a result, to suffer vicariously the patient's anxiety, pain, fear (and so on)."14 This definition primarily addresses the affective, or empathetic, component of compassion, but is illuminating because it confirms that Pellegrino and others consider this aspect critically important. ${ }^{15}$ Unfortunately, this aspect of compassion is also the one most often avoided and least often taught.

The idea of suffering as the patient is suffering is frightening to many caregivers who worry that such an emotional response will compromise objective decision-making. Pellegrino argues, however, that "objective medical good" is "the lowest order of patient good," and that only decisions made with compassion will be truly beneficial to the patient. ${ }^{16}$ Caregivers may also fear that such deep emotional engagement with patients will lead to compassion fatigue and emotional exhaustion on the part of the caregiver. This dissertation suggests that cultivating a practice of present moment awareness helps maintain a healthy emotional well-being in caregivers.

\footnotetext{
13 Jane Stein-Parbury, Patient \& Person: Interpersonal Skills in Nursing, 4th ed. (London: Churchill Livingstone, 2009), 141.

${ }^{14}$ Edmund D. Pellegrino and David C. Thomasma, The Virtues in Medical Practice (Oxford: Oxford University Press, 1993), 25.

${ }^{15}$ Howard M. Spiro et al., eds., Empathy and the Practice of Medicine: Beyond Pills and the Scalpel (New Haven: Yale University Press, 1993); Halpern, From Detached Concern to Empathy: Humanizing Medical Practice; Batt-Rawden et al., "Teaching Empathy to Medical Students."

${ }^{16}$ Pellegrino and Thomasma, The Virtues in Medical Practice, 25.
} 
The skilled practice of narrative medicine, the tenets of which have been developed primarily by Rita Charon, is the cornerstone to compassionate caregiving. Caregivers who are able to elicit a patient's narrative, empathize with the patient in a healthy and productive manner, and verify their understanding of the patient's story are able to ascertain causes of suffering that may not be readily apparent. While the precepts of narrative competence have traditionally been explicated using literary texts, chapter one of this dissertation offers Frida Kahlo's 1932 painting, Henry Ford Hospital, as a means of exploring both the intellectual and affective elements of narrative engagement.

This chapter considers the formal, contextual, and expressive elements of Kahlo's work as they are related to Charon's concepts of narrative competence and narrative practice. The ideas of David Freedberg, Walter Benjamin, Roland Barthes, and Alain de Botton provide theoretical frameworks that explore the power of visual art to elicit an emotional response in the viewer, and this emotional response is discussed as a means of allowing students to reflect on the process of empathic engagement.

Chapter two continues the discussion of empathetic engagement, but considers the concept of alterity and the presence of unconscious biases that create obstacles to empathy and subsequently affect the quality of healthcare in the United States. This chapter acknowledges issues of healthcare disparity, specifically the presence of a "status syndrome" 17 affecting the overall health of certain segments of the population, and the continued presence of racial bias and microaggression that affect healthcare delivery. ${ }^{18}$ I

\footnotetext{
17 M. G. Marmot, “Status Syndrome: A Challenge to Medicine," JAMA 295, no. 11 (March 15, 2006): 1304-7, doi:10.1001/jama.295.11.1304.

${ }^{18}$ Joshua Miller and Ann Marie Garran, Racism in the United States: Implications for the Helping Professions (Belmont, CA: Thompson Brooks/Cole, 2008).
} 
propose that education of individual caregivers should provide tools for recognizing unconscious biases and countering attitudes that perpetuate status syndrome.

The critical theories of Hans Georg Gadamer and Louise M. Rosenblatt offer useful insights for literary exploration and are presented in chapter two as justification for a pedagogy that encourages close reading and self-reflection rather than structural analysis of a text. In addition, Peggy McIntosh's ideas regarding white privilege and willful ignorance ${ }^{19}$ are used to consider the ethical implications of this type of narrative engagement.

The primary sources examined in this chapter are two short stories, Eudora Welty’s 1941, “A Worn Path,” and Richard Selzer’s, “Imelda,” first published in 1982. "A Worn Path" is explored as a metanarrative exemplifying the practical differences between sympathy and empathy, and an unconventional interpretation of "Imelda" is suggested, one in which allegory and myth are used to illuminate the presence of hubris in otherwise altruistic caregivers. Both works allow readers to reconsider initial interpretations in which unconscious biases and paternalism may be present.

Chapter three uses two works of dramatic literature, one ancient and the other modern, to introduce the fundamentals of bioethics. The study and practice of bioethics utilizes the tenets of philosophical inquiry to address the myriad dilemmas induced by extraordinary developments in modern medical treatment and research. There are multiple theoretical approaches to bioethics, and this chapter considers four in particular. Virtue ethics places premium importance on the moral character of medical practitioners, arguing that caregivers should possess specific virtues such as compassion, discernment,

\footnotetext{
${ }_{19}$ Peggy McIntosh, “White Privilege: Unpacking the Invisible Knapsack," Independent School 49, no. 2 (Winter 1990): 31.
} 
trustworthiness, integrity, and conscientiousness, in order to provide competent, ethical care. ${ }^{20}$ Principlism, arguably the theory most often taught and applied, ${ }^{21}$ proposes four principles - autonomy, nonmaleficence, beneficence, and justice - that should guide ethical decision making in healthcare. ${ }^{22}$ Casuistry rejects the idea that a single unified theory can be applied to all ethical dilemmas, and suggests a case-by-case approach that relies on precedents and previously established paradigms. ${ }^{23}$ Narrative Ethics argues that proficient use of any ethical theory requires narrative competence, best learned from the study of literature. ${ }^{24}$

This chapter affirms, "To teach ethics is not to teach the difference between right and wrong, but to make students feel more comfortable facing complex moral decisions," 25 and argues that virtue, as well as principles can be taught in the classroom. Sophocles' Greek tragedy, Philoctetes, first performed in $409 \mathrm{BCE},{ }^{26}$ provides an excellent vehicle for exploring the concept of duty, and the presence of conflicting moral obligations. This play also introduces students to the concept of a moral exemplar, and allows them to consider the attributes they will seek in caregiver role models. Margaret Edson's 1999 Pulitzer Prize winning drama, $W$; $t$, provides a stunning example of nonethical behavior, and asks students to consider the consequences of the absence of compassion in healthcare. I will argue that $W$; $t$ contains inconsistencies and inaccuracies

\footnotetext{
20 Tom L. Beauchamp and James F. Childress, Principles of Biomedical Ethics, 6th ed. (New York: Oxford University Press, 2009), 40.

${ }^{21}$ Bernard Gert, Charles M. Culver, and K. Danner Clouser, Bioethics: A Systematic Approach (New York: Oxford University Press, 2006), 17.

22 Beauchamp and Childress, Principles of Biomedical Ethics, 12-3.

${ }^{23}$ David DeGrazia, Thomas A. Mappes, and Jeffrey Brand-Ballard, Biomedical Ethics, 7th ed. (New York: McGraw Hill, 2011), 33.

${ }^{24}$ Howard Brody, Stories of Sickness, 2nd ed. (Oxford: Oxford University Press, 2003), 175, 179.

${ }^{25}$ Eunice Kapplinger and Susan Ray-Degges, “Can Ethics Be Taught or Is It Too Late?," Journal of Interior Design 24, no. 1 (1998): 49.

${ }^{26}$ John Carlevale, "Education, Phusis, and Freedom in Sophocles' Philoctetes," Arion: A Journal of Humanities and the Classics 8, no. 1 (2000): 28.
} 
in its portrayal of modern healthcare, but that it nevertheless contains important lessons for caregivers. Both dramas provide consummate opportunities for students to practice moral reflection and to consider what might constitute a personal reflective equilibrium in the presence of a complex moral dilemma.

Chapter four addresses the high rate of burnout and compassion fatigue in healthcare workers by first distinguishing between burnout and compassion fatigue and then suggesting methods for teaching healthy habits of mind that have been shown to mitigate compassion fatigue. I argue that simple stress reduction is not sufficient to combat the emotional and psychological effects of compassion fatigue and that attention must be paid to healthy mental processes that can prevent maladaptive coping mechanisms. This chapter introduces key concepts of mindfulness - present moment awareness, non-judgment, and sustained attention - using Dr. Ronald Epstein's " 8 -fold teaching method to improve the capabilities of health professionals by fostering four key habits of mind."27 Epstein's methodology is adapted for the classroom and used to elicit contemplation of Wassily Kandinsky’s 1924 Blue Painting. Attention to Kandinsky's use of color and form allow a type of metacognition in which students consider their own thought processes and emotional reactions to the work.

Psychology professor Mihaly Csikszentmihalyi has described a beneficial state of mind called "flow," in which a person becomes so deeply engaged in an activity that time is distorted, attention is fully focused, and "there is order in consciousness." ${ }^{8}$ The creation of nonrepresentational works of art often allows students to experience this state

\footnotetext{
27 Ronald M. Epstein, "Mindful Practice in Action (II): Cultivating Habits of Mind.," Families, Systems \& Health: The Journal of Collaborative Family HealthCare 21, no. 1 (2003): 11.

${ }^{28}$ Mihaly Csikszentmihalyi, Flow: The Psychology of Optimal Experience (New York: Harper Perennial Modern Classics, 2008), 6. Italics original.
} 
of flow. Once the characteristics of this state are experientially understood and its therapeutic value realized, students might feel encouraged to find activities that allow them to access this state on a regular basis. Specific practices that maintain a healthy state of mind are crucial for caregivers hoping to remain compassionate throughout their careers and this chapter suggests ways of allowing students to personally experience the beneficial practices of mindfulness and flow.

Chapter five presents the artwork and healthcare narrative of Andrew Marsh, a gifted artist who suffers chronic pain as a result of damaged discs in the cervical, thoracic, and lumbar regions of his spine. His experience with the healthcare community demonstrates the profound necessity for healthcare practiced with narrative competence and compassion, particularly in the case of chronic pain and other conditions for which traditional medicine still has surprisingly little to offer. The treatment of chronic pain relies heavily on opioid (narcotic) medications, which raises ethical concerns about the relationship between physicians and the pharmaceutical industry.

Marsh's case also represents a situation in which caregivers are faced with the challenge of developing a beneficial relationship with a patient whose thoughts on his own well-being are often in conflict with the recommendations of the medical community. A scenario in which medical options for the relief of suffering are limited and the patient's lifestyle choices seem risky is one that many caregivers would find frustrating. Developing healthy habits of mind allows caregivers to remain emotionally present in a therapeutic way while simultaneously preventing compassion fatigue.

Finally, Marsh's artwork offers the viewer a brilliant visual representation of physical pain, thereby providing caregivers with some means of understanding an 
experience that "does not simply resist language, but actively destroys it." 29 This chapter suggests the use of standardized pain assessment forms constrain patient narratives and may therefore subvert the practice of narrative medicine.

The overall goal of this dissertation is to demonstrate the ways in which literature and the visual arts can be used to teach the fundamentals of narrative medicine, bioethics, and mindful self-care to general undergraduate students considering careers in the demanding field of healthcare. It seeks to provide tools that help future caregivers form therapeutic relationships with their patients and care for themselves in ways that prevent compassion fatigue. The field of healthcare changes moment by moment with new advances in technology and pharmacology, exponentially increasing the vast amount of knowledge healthcare providers must absorb and retain. If we begin by teaching future caregivers to place equal value on knowledge that promotes healthy relationships and mindful self care, we stand a much greater chance of imbuing the healthcare community with compassionate, resilient practitioners who enjoy their work and make a positive difference in the lives of their patients.

\footnotetext{
${ }^{29}$ Elaine Scarry, The Body in Pain: The Making and Unmaking of the World (Oxford: Oxford University Press, 1985), 4.
} 


\section{CHAPTER ONE}

\section{THE PEDAGOGY OF NARRATIVE COMPETENCE AND MINDFUL EMPATHY}

"Along with their growing scientific expertise, doctors need the expertise to listen to their patients, to understand as best they can the ordeals of illness, to honor the meanings of their patients' narratives of illness, and to be moved by what they behold so that they can act on their patients' behalf." 30

Rita Charon, $M D, P h D$

In the above quotation, Rita Charon describes a particular kind of expertise, one that encompasses each of the four components of compassion - cognitive, affective, intentional, and motivational. It is an imperative of medical humanities education to help students develop the kind of expertise she describes. Narrative medicine, "medicine practiced with the narrative competence to recognize, absorb, interpret, and be moved by the stories of illness," 31 is a prerequisite for healthcare practiced with compassion because it is through the patient's narrative that the caregiver comes to understand the true nature of the patient's suffering. The compassionate caregiver must be skilled at eliciting and interpreting such narratives, but must also experience an empathetic response to that narrative. As mentioned in the introduction, it is an empathetic, rather

${ }^{30}$ Charon, Narrative Medicine: Honoring the Stories of Illness, 3.

${ }^{31}$ Ibid., vii. 
than sympathetic concern that should comprise the affective component of compassion.

Like compassion, empathy can be seen as having more than a single component.

Roughly speaking, the cognitive component of empathy involves understanding another's perspective and being aware of his or her feelings, and the affective component involves sharing in those feelings. ${ }^{32}$ In a study of the practice and efficacy of teaching empathy to medical students, Batt-Rawden et al., have noted that most attempts focus on the cognitive component of empathy, viewing it as a skill that can be developed and measured. ${ }^{33}$ This chapter argues that the affective component of empathy is equally important and can also be taught. Without the affective component, empathy is nothing more than "detached concern," 34 which is the traditional, and poorly functioning, model for patient-caregiver relationships. ${ }^{35}$ The affective component of empathy is often a spontaneous response, but it can also be intentionally cultivated. Either way, the emotional aspect of empathy requires mindful awareness and attention on the part of the caregiver if it is to be used on the patient's behalf.

This chapter offers suggestions for teaching the elements of narrative competence and the cultivation of mindful empathy using Frida Kahlo’s 1932 painting, Henry Ford Hospital [Figure 1]. It begins with a brief synopsis of the origins of narrative medicine, and then explores the work of David Freedberg and other theorists who have studied the power of visual art to evoke an empathetic response. It examines key theories of narrative in general, and finally considers Rita Charon's elements of narrative medicine

\footnotetext{
32 Mohammadreza Hojat et al., "Physician Empathy: Definition, Components, Measurement, and Relationship to Gender and Specialty," American Journal of Psychiatry 159, no. 9 (September 1, 2002): 1563, doi:10.1176/appi.ajp.159.9.1563.

33 Batt-Rawden et al., "Teaching Empathy to Medical Students," 1173.

34 Ibid., 1171.

${ }^{35}$ Halpern, From Detached Concern to Empathy: Humanizing Medical Practice, 15.
} 
as they are represented in Kahlo's painting. Close engagement with this work of art allows students to examine the nature of their own empathetic response and to understand the elements of narrative as universal in nature while simultaneously unique to every patient.

The genesis of narrative medicine can be dated to 1972, when Joanne Trautmann Banks was appointed professor of Literature and Medicine at the Hershey Medical Center of Pennsylvania State University. ${ }^{36}$ Banks was a literature professor and Virginia Woolf scholar who believed the study of literature had "life enhancing" benefits. Perhaps because she was the mother of a disabled son who spent a great deal of time in the varied environments of healthcare, Banks wished to share these benefits with students of medicine..$^{37}$ The purpose of Banks's course, and of similar courses later instituted at medical schools throughout the country, was to provide future doctors with some means of understanding pain and suffering from the patients' perspective. ${ }^{38}$

Rita Charon expanded upon Bank's original intentions for the study of literature, and in 2000 founded the Narrative Medicine program at Columbia University. Charon is a professor of clinical medicine at Columbia, and also holds a $\mathrm{PhD}$ in English Literature. What began as a way of allowing young medical students some means of understanding the patient's experience of illness and suffering, now includes the development of "narrative competence ... a sophisticated knowledge of how stories work" that enables a caregiver to "follow the patient's narrative thread, identify the metaphors or images used

${ }^{36}$ Jones, Anne Hudson, "Reflections, Projections, and the Future of Literature-and-Medicine," in Literature and Medicine: A Claim for a Discipline, eds. Delese Wear, Martin Kohn, and Susan Stocker (McLean, VA: Society for Health and Human Values, 1987).29.

37 Oransky, Ivan "Joanne Trautmann Banks," The Lancet, vol. 370 no. 9584 (2007). http://www.thelancet.com/journals/lancet/article/PIIS0140-6736(07)61148-9/fulltext

${ }^{38}$ Charon, Rita. "Literature and Medicine: Origins and Destinies," Academic Medicine vol. 75, no. 1 (2000). 23. 
in the telling, tolerate ambiguity and understand the story in light of others told by this teller."39

Like Rita Charon, Howard Brody holds both an $\mathrm{MD}$ and $\mathrm{PhD}$. He is a professor of philosophy and family practice medicine at Michigan State University and has also made significant contributions to the theory and praxis of narrative medicine. Brody has noted that the relationship between caregiver and patient is inherently narrative in nature, often beginning with a "chief complaint" or "chief concern" (CC) as related by the patient, ${ }^{40}$ and culminating in a case history, which is the story of disease as seen from the caregiver's perspective. ${ }^{41}$ Narrative medicine is a means of practice that mandates attention to the narratives of both patient and caregiver, and considers these narratives the primary means through which diagnoses are made and treatment is offered. This type of practice does not, in any way, exclude the scientific and technological aspects of medicine that continue to create enormous strides in the reduction of disease and promotion of health, but simply asserts that unless a healthcare practitioner understands what a specific illness or injury actually means to the patient, it is almost impossible to deliver care that promotes the well-being of the patient and, consequently, of the caregiver.

Frida Kahlo lived within a physical body that betrayed her at every turn, and images of her own body figure prominently in many of her paintings. Sidonie Smith has suggested, "Life writing about the body has also enabled people to confront the destiny of

\footnotetext{
39 Ibid., 4.

${ }^{40}$ Charlie Goldberg, "History of Present Illness," A Practical Guide to Clinical Medicine, August 16, 2008, https://meded.ucsd.edu/clinicalmed/history.htm.

${ }^{41}$ Brody, Stories of Sickness, 8.
} 
the ill or impaired body, their own or someone else's," ${ }^{42}$ and it seems evident that Kahlo created her autobiographical paintings as a means of confronting her own failing body and of expressing the ways in which being embodied in an unreliable and pain-riddled physical self complicates the quest for identity and wholeness.

When she was six years old, Kahlo contracted polio, and although she recovered, her right leg atrophied and she walked with a limp for the rest of her life. ${ }^{43}$ When she was eighteen, Kahlo was badly injured in a bus accident. A medical report from 1926 lists the following injuries and complications resulting from the accident, "fracture of the third and fourth lumbar vertebrae, triple fracture to pelvis, approximately eleven fractures to right leg, dislocation of left shoulder, stomach wound due to metal rod entering left side and exiting by the vagina, causing damage to the left lip of vulva. Acute peritonitis. Cystitis.... Three months in Red Cross Hospital. ... [immobilized] for nine months in a plaster corset." ${ }^{\prime 4}$

The medical record, an impersonal catalog of injuries and illnesses, does not begin to express the emotional suffering that accompanied Kahlo's physical trauma. Kahlo spoke of the accident as the moment she lost her virginity. ${ }^{45}$ It is unlikely Kahlo was simply referring to a physical change caused by the horrific injury; she is certainly lamenting the loss of innocence, and loss of the future she had planned. After spending one month in the hospital, Kahlo spent three additional months on bed rest at her home. Kahlo had hoped to become a doctor, but began painting during this period of

\footnotetext{
${ }^{42}$ Sidonie Smith and Julia Watson, Reading Autobiography: A Guide for Interpreting Life Narratives, 2nd ed. (Minneapolis: University of Minnesota Press, 2010), 53.

${ }^{43}$ Christina Burrus, Frida Kahlo: Painting Her Own Reality (New York: Abrams, 2008), 16.

${ }^{44}$ Ibid., 122.

${ }^{45}$ Martha Zamora, Frida Kahlo: The Brush of Anguish, trans. Marilyn Sode Smith (San Francisco: Chronicle Books, 1990), 26.
} 
convalescence. Her bed was affixed with a canopy that held a mirror as well as an easel, and some of her earliest paintings were self-portraits. ${ }^{46}$

In 1931, after years of chronic pain, Kahlo's doctors recorded evidence of a previously undiagnosed congenital spinal malformation such as scoliosis, or perhaps spina bifida occulta. ${ }^{47}$ Kahlo wore spinal corsets, both plaster and metal, off and on in an effort to ease the pain and also underwent a series of lumbar punctures with injections of Lipidol, a contrast agent injected into the spinal fluid in order to make it visible on x-ray. Evidently these procedures were done in an effort to obtain some sort of concrete diagnosis. In 1946 four lumbar vertebrae were fused using bone from her pelvis and a metal rod. ${ }^{48}$

Kahlo married the artist Diego Rivera on August $21^{\text {st }}, 1929 .{ }^{49}$ Later that year she underwent an abortion due to the "unfavorable position" of her pelvis, which doctors believed made it impossible for her to carry an infant to term..$^{50}$ In spite of her tumultuous relationship with Rivera, or perhaps because of it, Kahlo eventually wished to have a child with her husband. ${ }^{51}$ By the time she became pregnant again in 1932, Kahlo had worked through some of the ambivalence she had long felt regarding motherhood and later told her doctor, "At that time I was enthusiastic about having the child after having thought of all the difficulties that it would cause me." ${ }^{52}$ Kahlo was placed on strict bed rest in an effort to maintain the pregnancy, but she miscarried after four months. ${ }^{53}$

\footnotetext{
${ }^{46}$ Andrea Kettenmann, Frida Kahlo: Pain and Passion (Los Angeles: Taschen, 1992), 18.

${ }^{47}$ Burrus, Frida Kahlo: Painting Her Own Reality, 122.

48 Ibid., 124.

49 Ibid., 36.

50 Ibid., 122.

51 Zamora, Frida Kahlo: The Brush of Anguish, 40.

${ }^{52}$ Kettenmann, Frida Kahlo: Pain and Passion, 32.

${ }^{53}$ Burrus, Frida Kahlo: Painting Her Own Reality, 122.
} 
While still hospitalized after the miscarriage, Kahlo began preliminary sketches for Henry Ford Hospital. The artist depicts herself lying in a hospital bed incongruously placed in a desolate landscape. In the distant background she has rendered the Ford Motor Company plant where her husband was working on sketches for the murals he would later paint for the Detroit Institute of Arts. ${ }^{54}$ The focal point of the painting is the hospital bed, isolated in the midst of a barren landscape and giving visual form to the loneliness and isolation often experienced in times of illness. Kahlo lies naked and completely exposed on the bed; her physical frame is very small in relation to the bed frame and the surrounding environment. Her nakedness and her smallness present the viewer with a portrait of complete vulnerability; Kahlo seems at the mercy of the elements both within and outside the hospital. The bed is tilted at an odd angle and Kahlo lies very close to the near edge. This distortion of the picture plane places the patient in a precarious position and conveys the fear of being at the edge of a precipice both physically and emotionally. It is a visual rendering of disorientation, fear, and grief.

An empathetic understanding of the emotions conveyed in Kahlo's painting requires students to become deliberately and intentionally engaged with the work, accepting it as a means of gaining insight into the patient experience. Some familiarity with the details of Kahlo's life, both medical and personal, may be helpful in forming an empathetic connection to the painting, but are probably not necessary for all students because the work alone is visually captivating.

\footnotetext{
${ }^{54}$ Hayden Herrera, Frida: A Biography of Frida Kahlo (New York: Harper Perennial, 2002), 70.
} 


\section{In The Power of Images: Studies in the History and Theory of Response, David}

Freedberg considers the "psychological and behavioral" responses to art, ${ }^{55}$ and provides a strong theoretical framework for understanding the emotional power of Kahlo's painting. Throughout the text Freedberg explores three factors he sees as essential to the affective power of an image: familiarity, particularity, and vividness. ${ }^{56}$

In his discussion of familiarity, Freedberg examines the use of art in the middle ages to influence the attitudes and behavior of young children, an effect he attributes to the children's ability to identify with, or see themselves "mirrored" in the works of art. ${ }^{57}$ He continues this discussion by analyzing the use of images to connect earthly and divine realms, and notes that when such images take human form, "worshipers may as a consequence venerate the object and confuse it with what it stands for ... what is familiarly known cannot be invested with powers that are proper to the sphere of transcendence." 58 In such cases a strong empathetic connection to an image may become idolatrous, but human forms are nevertheless used to "shape the divine" because the human form is "most intimately known to us." ${ }^{99}$ Freedberg cites Freud's concept of transference in explaining the human tendency to feel an emotional connection to both objects and beings in which we perceive qualities with which we are familiar. ${ }^{60}$ The simple presence of the human form in a work of art might engender only the barest sense of empathy, but Kahlo's rendition may evoke an immediate and much stronger response in students who have undergone similar experiences of fear or grief in the face of illness

\footnotetext{
55 David Freedberg, The Power of Images: Studies in the History and Theory of Response (Chicago: University of Chicago Press, 1991), xix.

56 Ibid., 196.

57 Ibid., 5.

58 Ibid., 65.

${ }^{59}$ Ibid., 190.

60 Ibid., 191.
} 
or injury. For those who have not, a closer exploration of the painting offers much to consider.

Kahlo invites familiarity by painting a single, large tear near her left eye. As with all of her self-portraits, Kahlo's facial expression is rather stoic and enigmatic. Kahlo removes whatever questions might arise about her emotional state, however, with the presence of a universal symbol of sadness. The tear is familiar to any viewer who has ever cried, and thus it elicits immediate comprehension. It is also stylized, however, larger and whiter than would be realistic. This draws the viewer's attention to its importance in the painting and to the fact that we are being asked to pay particular attention to Kahlo's grief.

Freedberg describes particularity as those elements of a work of art that remove it from the realm of the general, and make it utterly unique and distinctive. ${ }^{61}$ In considering the influence of particularity, Freedberg discusses the art form of ex votos, works created as expressions of gratitude for divine intervention. He notes, "In every case, manufacture and figuration is predicated on a strict concept of distinctiveness and accuracy." 62 Victims of severe illness or injury offer votive works as visual representations of the gratitude they feel toward divine forces or beings that intervened and enabled the victim to survive. These works are meant as gifts of thanks to the intercessor, and also as reminders that gratitude is owed and should be continuously felt. In order to generate this emotion of thankfulness, the votive must represent the "event from which the devotee was saved" as accurately as possible. ${ }^{63}$

\footnotetext{
61 Ibid., 117.

62 Ibid., 155.

63 Ibid.
} 
Henry Ford Hospital is not an ex voto, but it bears many similarities to the form. ${ }^{64}$ It is small and painted on a metal plate, and while Kahlo is certainly not expressing gratitude for surviving the miscarriage, or for any other evident reason, she nevertheless seeks to share her experience as accurately as possible. Though we can and should draw inductive conclusions from her work about the trauma of miscarriage in general, she clearly wants the viewer to understand her very particular experience. She makes this evident with the inclusion of the incongruous industrial backdrop and the objects she paints tethered to her body. These objects will be more closely examined as elements of Kahlo's narrative, but here we must acknowledge the stylized image of an oversized male fetus, one that bears a resemblance to Kahlo's husband. This figure reminds the viewer that Kahlo is not grieving the loss of some unknown entity to which there was no deep attachment, but rather the loss of a child, already recognized with particular traits of form and character. This is, arguably, the deepest sort of grief.

As Walter Benjamin notes in his famous essay, The Work of Art in the Age of Mechanical Reproduction, "The manner in which human sense perception is organized, the medium in which it is accomplished, is determined not only by nature but by historical circumstances as well." 65 Here we must note that society at large no longer responds to visual art the way it did in the past. Freedberg puts this more specifically, "We may no longer have much leisure to contemplate the images before us, but people once did; and they turned contemplation into something useful, therapeutic, elevating, consoling, and terrifying. They did so in order to attain a state of empathy; and when we

\footnotetext{
${ }^{64} \mathrm{Andrea}$ Kettenmann has also observed the similarities between this painting and Mexican votive art. She notes that Kahlo "owned a large collection of ex-voto panels." Kettenmann, Frida Kahlo: Pain and Passion, 35.

${ }^{65}$ Walter Benjamin, Illuminations, ed. Hannah Arendt, trans. Harry Zohn (New York: Schocken Books, 1969), 222.
} 
examine how they did so, a brilliant light is cast not only on the function of images but on a potential that for many of us remains to be activated." 66 Freedberg is here referring to the medieval practice of using images to bring to mind the lives of saints and Biblical figures in order to inspire faith and righteous living in the worshiper. ${ }^{67}$ Although we seldom use images in this way today, their power to inspire and to engender strong affective responses has not been lost; it simply requires a specific type of attention. In this age of instant access to all manner of information and the attendant impulse to engage in multiple tasks simultaneously, the desire to devote undivided attention to a single image is perhaps uncommon, but this type of sustained, focused attention is a necessary component of empathetic engagement, whether with a work of art or a fellow human being. Classroom contemplation of Kahlo's painting provides an opportunity to encourage students in this process.

W. J. T. Mitchell has noted that, although true contemplation of images may be rare in today's society, we are still a visual culture. "The idea that images have a kind of social or psychological power of their own is, in fact, the reigning cliché of contemporary visual culture.... There is no difficulty, then, in demonstrating that the idea of the personhood of pictures is just as alive in the modern world as it was in traditional societies." ${ }^{68}$ Borrowing a term from post-colonial theorists, Mitchell proposes a "subaltern model" for examining the power of images and suggests "that we not confuse the desire of the picture with the desires of the artist, the beholder, or even the figures in the picture." ${ }^{69}$ What Mitchell seems to be suggesting is a personification of the picture

\footnotetext{
${ }^{66}$ Freedberg, The Power of Images: Studies in the History and Theory of Response, 161.

${ }^{67}$ Ibid., 162.

${ }^{68}$ W. J. T Mitchell, “What Do Pictures 'Really' Want?,” October, no. 77 (1996): 73.

${ }^{69}$ Ibid., 81.
} 
itself that would return certain rights that have been usurped in our tendency to consider only the desires of the artist and viewer. This type of esoteric theorizing is of limited value in the pedagogy of medical humanities, which seeks the immediate and practical benefits of study, but it nevertheless underscores the notion that it is possible to be moved by images even when we know nothing about the artist or the subjects in the painting. In the case of Henry Ford Hospital, the potential for empathetic engagement is strengthened because we have some familiarity with its context and therefore a more directed approach to the interpretation of its symbols.

When assisting students toward empathetic engagement with Kahlo's painting, it might be useful to explore Roland Barthes' notion of studium and punctum, conceived as he was attempting to understand the peculiar power of certain photographs, and recorded in Camera Lucida. Barthes describes the studium as a cultural or human quality of a photograph that allows the viewer to "participate" in, or at least feel a general connection with or interest in the picture. The viewer actively seeks this element in the photograph being considered. ${ }^{70}$ The punctum, on the other hand, is the "element which rises from the scene, shoots out of it like an arrow, and pierces me ... A photograph's punctum is that accident which pricks me (but also bruises me, is poignant to me)." ${ }^{71}$ What elements of the painting are easily "relatable," (to use a term often employed by students), and what elements are piercing, or more difficult to hold in our thoughts?

In Art as Therapy, Alain de Botton and John Armstrong attempt to address the question of what art should do for its viewers. They describe seven ways in which art "is a therapeutic medium that can help guide, exhort and console its viewers, enabling them

\footnotetext{
${ }^{70}$ Roland Barthes, Camera Lucida: Refelctions on Photography, trans. Richard Howard (New York: Hill and Wang, 1981), 26.

${ }^{71}$ Ibid., 27.
} 
to become better versions of themselves. ${ }^{72}$ In discussing the function of "Sorrow," the authors note that art may encourage "a profound engagement with sadness . . It tells us that sorrow is written into the contract of life."73 And yet, few people would seek a deliberate engagement with sadness. As Freedberg reminds us, the affective power of art is often rejected or repressed because of its power to disturb. ${ }^{74}$ In her 2003 study of war photography, Regarding the Pain of Others, Susan Sontag writes, "The photographs are a means of making 'real' (or 'more real') matters that the privileged and the merely safe might prefer to ignore."75

At some point, when considering Henry Ford Hospital, the viewer may be forced to decide whether to stay with the work and feel the sorrow expressed within it, or to disengage. Obviously, this is a choice made many times every day in the world of healthcare. Compassionate care requires empathetic engagement, and future chapters of this dissertation will discuss healthy ways of accomplishing this, but here, the goal is simply to encourage students to commit to a close encounter with Kahlo's work and to pay attention to the experience of emotional engagement.

Traditional medical wisdom prescribed an emotional detachment from patients, which was believed to foster rational decision-making. Recently however, practitioners and scholars have begun to argue that, "by allowing patients to move them, physicians gain access to a source of understanding illness and suffering that can make them more effective healers. Learning to skillfully empathize with patients is therefore not an ornamental aspect of medical training, but is as critical as learning to perform technical

\footnotetext{
72 Alain de Botton and John Armstrong, Art as Therapy (London: Phaidon, 2013), 5.

73 Ibid., 26.

${ }^{74}$ Freedberg, The Power of Images: Studies in the History and Theory of Response, 1.

${ }^{75}$ Susan Sontag, Regarding the Pain of Others (New York: Picador, 2003), 7.
} 
procedures." 76 In her discussion of trauma art, Jill Bennett differentiates between "crude empathy," which is grounded in affinity and involves "feeling for another insofar as we can imagine being that other" and empathy based upon "feeling for another ... that is characterized by a distinctive combination of affective and intellectual operations." 77 This type of empathy requires an engagement that is more intellectual than emotional. Even if there is nothing in Kahlo's work that stimulates an emotional response, for example, it is still possible to make a cognitive choice to consider the represented experience of being alone and vulnerable. This type of cultivated rather than spontaneous empathy is required of caregivers in cases where it is difficult or impossible to form an emotional connection with a patient; it allows the caregiver an alternative to emotional detachment or withdrawal. In addition, this type of empathy is nonjudgmental; it is not about becoming emotionally attached to a patient and thus perhaps making inappropriate decisions, it is rather a form of engagement that attempts to understand, respect, and take emotional part in the patient's journey through illness.

In his essay, "What is Empathy and Can it Be Taught?” Howard M. Spiro concludes, "If empathy depends on experience, then that is the area in which novels, fiction, stories, and paintings can enlarge empathy. Clinical tales, as Oliver Sacks calls them, are the most important; to look at a painting is, however, sometimes to be fooled."78 Henry Ford Hospital is both a clinical tale and a painting. As a clinical tale, the story of one patient's hospital experience, it offers the seasoned clinician an enlightening story of miscarriage, one that might never have been previously considered.

\footnotetext{
${ }^{76}$ Halpern, From Detached Concern to Empathy: Humanizing Medical Practice, xix.

77 Jill Bennett, Empathic Vision: Affect, Trauma, and Contemporary Art (Stanford: Stanford University Press, 2005), 10. Italics original.

${ }^{78}$ Howard M Spiro, "What Is Empathy and Can It Be Taught?," in Empathy and the Practice of Medicine, ed. Howard Spiro et al. (New Haven: Yale University Press, 1993), 11.
} 
As a painting, it offers the uninitiated a vicarious experience that could serve as a means of understanding suffering.

Eric Larson and Xin Yao have studied the concept of "emotional labor" as it was developed and explained by Arlie Russell Hochschild in The Managed Heart: The Commercialization of Human Feeling in 1983. The techniques presented in the book were designed to help people working in the service industry increase profits by behaving sympathetically and hospitably in all situations. ${ }^{79}$ In adapting the concepts for physicians, Larson and Yao define emotional labor as "the process of regulating experienced and displayed emotions to present a professionally desired image during interpersonal transactions ... For a physician, emotional labor uses psychological resources to engender personal cognitive and affective changes to project an empathic image for the patient." 80 Using the techniques of emotional labor to express empathy requires acting; "Individuals can either fake their emotional display by forging facial expressions, voice, or posture or they can try to alter their internal experience and act on emotions they actually experience. The former is called surface acting and the latter deep acting."81 Deep acting is similar to method acting in that it involves using memories and imagination to generate emotions that might be comparable to the emotions the patient is experiencing. ${ }^{82}$

Larson and Yao make it clear that their suggestions are not designed to enable unfeeling caregivers to dupe their patients, but instead are intended to be of assistance in times when a true emotional connection with a patient is difficult. They also point out

\footnotetext{
${ }^{79}$ Eric B. Larson and Xin Yao, "Clinical Empathy as Emotional Labor in the Patient-Physician Relationship," JAMA 293, no. 9 (March 2005): 1100.

80 Ibid., 1103.

81 Ibid., 1104.

82 Ibid., 1100.
} 
that with practice over time, empathetic engagement comes more naturally and requires less acting. ${ }^{83}$ Even so, there remains something distasteful about suggesting that caregivers use acting techniques to fake empathy. It seems manipulative and dishonest; a deliberate undermining of the trust patients must be able to place in their caregivers. Caregivers who are unable to feel a genuine, unmanufactured connection to their patients will not be able to provide compassionate care and must seek to understand the underlying reasons for this disconnect. Compassion fatigue is a serious concern in modern healthcare and is dealt with more fully in chapter four of this dissertation.

When using art and literature to explore the emotional nature of empathy, we are not asking students to manufacture emotion, but simply to pay attention to their own responses as they work to understand the experience being portrayed. Caregivers who seek to engage empathetically with their patients are doing so in an effort to practice the affective component of compassion. It is important for caregivers who have never experienced serious illness to have some means of understanding what their patients are going through and for seasoned caregivers to be reminded of the non-scientific side of caregiving. Using art and literature to practice empathetic engagement allows caregivers a means of responding with sincerity to patients whose experiences are completely unfamiliar.

Thus far this chapter has considered empathetic engagement between caregiver and patient as a crucial aspect of medicine practiced with narrative competence and has examined Henry Ford Hospital as a tool for investigating and practicing such engagement. I will now turn to the place of narrative in narrative medicine, and will

83 Ibid., 1105. 
consider the painting from the viewpoint of narrative theory and as an expression of Charon's narrative features of medicine.

The development of narrative competence requires practice in recognizing the elements of narrative and also an understanding that illness narratives are rarely straightforward. Some theorists emphasize the narrative element of plot, "a teleological sequence of events linked by some principle of causation: that is, the events are bound together in a trajectory that typically leads to some form of resolution or convergence," but this emphasis ignores the fact that, "many narratives resist, elude, or reject this model of plot and its explicit assumption of narrative unity, cohesion and teleology." 84 Illness narratives in particular are resistant to emplotment precisely because the elements that provide cohesion and purpose to daily living have been disrupted. "The universal desire, or need, for a story with temporality, causality, and some limited predictability for the future is thwarted by an impending illness, and part of the suffering that characterizes sickness is the result of living with a broken story."85 If, as Jerome Bruner argues, humans utilize narrative not only to represent reality but also to construct it, ${ }^{86}$ the patient's story of illness must be seen as an attempt to reconstruct a reality into which the experience of illness can be incorporated. Holmgren et al., see the ultimate goal of the medical caregiver as "helping the patient craft a new or amended narrative that can

\footnotetext{
${ }^{84}$ Brian Richardson, "Beyond the Poetics of Plot: Alternative Forms of Narrative Progression and the Multiple Trajectories of Ulysses," in A Companion to Narrative Theory, ed. James Phelan and Peter J. Rabinowitz (Malden, MA: Blackwell Publishing, 2005), 167.

85 Lindsay Holmgren et al., "Terminology and Praxis: Clarifying the Scope of Narrative in Medicine," Literature and Medicine 29, no. 2 (Fall 2011): 253.

${ }^{86}$ Jerome Bruner, "The Narrative Construction of Reality," Critical Inquiry 18, no. 1 (1991): 5. Italics mine.
} 
explicate the symptom or sign, provide a plausible causal chain, and begin to demystify the future." 87

It is a fair point to assert that Henry Ford Hospital is not a narrative painting. Unlike Masaccio’s Tribute Money, for example, which presents three distinct and progressive events in time, Kahlo gives us only one moment, so, conventionally speaking, there can be no plot. I would argue that Henry Ford Hospital does in fact tell a story, and does contain a plot with causal relationships, but that it follows a pattern common to illness narratives in that the plot is not readily apparent. It is, in the way of postmodern narration, fractured and disjointed, with elements that appear to be unrelated. If Kahlo were to describe the meaning of each of the symbols she has chosen to paint, the plot might become clear, but she is, of course, not available to share her insight with us. We can, however, take the information evident in the work itself and construct a provisional understanding of the narrative Kahlo created about her experience.

In explicating his theory of narrative construction of self, Paul Ricoeur uses Aristotle's concept of mimesis to describe the process of emplotment. Ricoeur divides mimesis into three phases: mimesis $_{1}$ is prefigured time, the period when the events of everyday life are experienced, but not yet been formed into narrative, mimesis ${ }_{2}$ is configured time, during which we structure the events of our life into a story with cause and effect, and mimesis ${ }_{3}$ is refigured time, during which we have assigned meaning to our story, which in turn, shapes the way we view and interpret the world around us. ${ }^{88}$ This concept of narrative construction is particularly useful when considering illness narratives, where mimesis ${ }_{1}$ might be thought of as the period before the illness or injury,

\footnotetext{
${ }^{87}$ Holmgren et al., "Terminology and Praxis: Clarifying the Scope of Narrative in Medicine," 254. 88 Paul Ricoeur, Time and Narrative, trans. Kathleen McLaughlin and David Pellauer, vol. 1 (Chicago: University of Chicago Press, 1983), 54-77.
} 
when daily life was perhaps comprehensible and predictable. The attempt to make sense of the situation in terms of causality and consequence occurs during Ricoeur's mimesis, and mimesis $_{3}$ is the period of time in which a patient seeks to find meaning in her altered state, perhaps reorders her priorities, and reconsiders her thoughts on the future. This is an extreme simplification of both Ricoeur's theories and the process of coming to grips with a life altering illness or injury. In reality, the different periods co-exist, overlap, and may not be linear, but like Elisabeth Kübler-Ross and her stages of grief, Ricoeur provides a useful frame of reference for deciphering a narrative that may initially appear incoherent.

In acknowledging both the potential benefits and the difficulties of practicing narrative medicine, Charon considers the issues that separate the sick and the well, caregiver and patient. She identifies four types of division: $\left.{ }^{89} 1\right)$ The relation to mortality 2) The contexts of illness 3) Beliefs about disease causality and 4) The emotions of shame, blame, and fear. ${ }^{90}$ Charon posits that these divisions often prevent the kind of trusting, transparent, nurturing relationships that would allow caregiving to function at its best and notes, "For the sick patient to accept the care of well strangers, those strangers have to form a link, a passage between the sick and the healthy who tender care. We need to see the chasms clearly if we want to bridge them."91

${ }^{89}$ Charon, Narrative Medicine: Honoring the Stories of Illness, 20-21. In her discussion Charon deals exclusively with the relationship between physician and patient, stating, "I believe that the relationships patients have with nurses, social workers, and therapists are less troubled than the relationships they have with doctors, due in part to issues of power, gender, class, clinical training, and patients' expectations of the different professions." I do not disagree with this statement, but because these divisions are present between sick people and well people in general, their implications are relevant to all types of caregivers.

90 Ibid., 22.

${ }^{91}$ Ibid., 21. 
Charon also identifies five narrative features of medicine that must be recognized and understood by caregivers hoping to engage meaningfully with their patients: 1) Temporality - having to do with time, and the passage of time as experienced by the patient 2) Singularity - the unique and un-reproducible nature of every narrative 3) Causality/contingency - the desire to find a causal relationship for illness or injury 4) Intersubjectivity - the self in relationship to others, and 5) Ethicality - the responsibilities that come to a caregiver as a result of hearing a patient's story. ${ }^{92}$

In Henry Ford Hospital, Kahlo has painted six objects surrounding her hospital bed. Each of the objects is tied to a red ribbon (many critics have noted the resemblance to blood vessels) that Kahlo holds against her abdomen. A closer examination of these objects reveals the ways in which they illuminate both the chasms that divide caregiver and patient, the elements of narrative medicine, and Ricoeur's ideas about the narrative construction of self.

Perhaps the most incongruous object of the six is the snail painted in the upper right corner of the work. It floats in the sky, as do the other objects, but appears to be moving toward Kahlo with its neck extended and its antennae raised. Although the snail can be seen in Christian art and has been variously identified with St. Jerome, Jesus, and the Virgin Mary,93 the meaning of Kahlo's snail is far less esoteric. "The snail, Frida once explained, refers to the slowness of the miscarriage, which, like a snail, was soft, covered and at the same time, open."'94 Kahlo's inclusion of the snail is the element that renders this painting narrative in nature

\footnotetext{
92 Ibid., 39-58.

${ }^{93}$ Hope B. Werness, The Continuum Encyclopedia of Animal Symbolism in Art (New York: Continuum International, n.d.), 376.

${ }^{94}$ Herrera, Frida: A Biography of Frida Kahlo, 144.
} 
rather than a series of symbolic associations. When she includes the element of temporality, Kahlo is recounting a story although, as is common with illness narratives, the story is fragmented and non-linear.

Narratologist Gérard Genette divides the element of temporality into three components, order, duration and frequency. Order refers to the chronological sequence of events that make up a story. Frequency refers to the fact that the events of a story may be repeated, or described in different ways by various characters. And duration compares the length of time it takes for an event to occur with the length of time it takes for a narrator to describe it. In other words, a narrator may take several minutes to describe a split-second occurrence, or may spend only a moment describing a decade of life. ${ }^{95}$ This mutability of time often comes to the forefront in a narrative of illness so it is not surprising that Kahlo chooses to represent temporality in her work. Margaret Edson makes a similar observation of temporality in $W$; $t$, when the character of Vivian Bearing, hospitalized near the end of her battle with ovarian cancer, remarks, "You cannot imagine how time... can be ... so still. It hangs. It weighs. And yet there is so little of it. It goes so slowly, and yet it is so scarce."96

Charon recognizes temporality as an element of narrative medicine, but I would argue that it is often also a cause of division between patient and caregiver that goes beyond the issue of mortality. Healthcare providers confront issues of temporality when struggling to answer the question, "How long have I got, Doc?" or when dealing with complaints about the length of time patients spend in waiting

${ }^{95}$ Lois Tyson, Critical Theory Today: A User Friendly Guide, 2nd ed. (New york: Routledge, 2006), 229. ${ }^{96}$ Margaret Edson, $W$; $t$ (New York: Farber and Farber, 1999), 35. Ellipses original. 
rooms, but they must also understand that any illness or injury may serve to alter the patient's experience of time passing. For Kahlo, time slowed to a snail's pace as the biological sequelae of her miscarriage unfolded and this altered sense of temporality was a significant feature of her dreadful experience.

At the foot of her bed Kahlo has painted an autoclave, a piece of equipment used for sterilizing medical instruments. According to Herrera, Kahlo explained to friends that the autoclave represented, "the mechanical part of the whole business,"97 and as such, we may connect it with Charon's narrative element of intersubjectivity. It is not possible to know with certainty what aspects of her experience Kahlo found "mechanical," but there is no shortage of evidence to suggest that many patients find their medical experiences indifferent and objectifying. When seen through the lens of intersubjectivity, the autoclave serves as a reminder that medical encounters are often seen as cold and impersonal. It is unlikely that students viewing the painting would recognize the device as an autoclave, especially since the type pictured is long obsolete, but if asked to describe it they might use terms such as dark, heavy, and perhaps frightening. Its somewhat ominous appearance reminds the viewer of the fear and dread that accompany disruptions of physical integrity.

Kahlo has also painted a plastic model of the female reproductive system and the bones of the female pelvic girdle. In healthy women, the reproductive organs and the pelvic girdle function in tandem to create a safe environment for the growth of a fetus. The depiction of these bones and organs outside her body, existing only as

\footnotetext{
${ }^{97}$ Hayden Herrera, Frida Kahlo: The Paintings (New York: Harper Collins, 1991), 71.
} 
plastic models connected to her with symbolic cords, underscores the acuity with which she felt their failure to function properly within her body and illustrates the narrative element of causality.

As Charon has noted, "The engine of narrative is its urge to make sense of why things happen, its longing to find or imagine connections among things, either through motive or cause."98 Kahlo has established a connection between the accident she suffered as a teenager and the failure of her pregnancy. In acknowledging this connection, she is also forced to accept that this miscarriage is not an isolated, randomly occurring incident, but that miscarriage will likely be the result of any pregnancy she experiences. The damage to her internal bones and organs is permanent and in spite of extensive medical intervention, their full functionality has not been restored. It is impossible, of course, to judge the veracity of Kahlo's interpretation of causality, but that is not the point. The point of developing narrative competence is learning to understand the ramifications of illness or injury from the patient's perspective.

These objects also serve to illustrate Kahlo's experience of mimesis, or the reconfiguration phase of her narrative construction. In seeking a cause for her miscarriage she acknowledges the injuries to her reproductive system and orders the events of her earlier life into a narrative that explains the situation in which she now finds herself.

The pink and purple orchid lying beneath Kahlo's bed is connected to her interpretation of causality, but also illustrates the singularity of her experience. In

\footnotetext{
${ }^{98}$ Charon, Narrative Medicine: Honoring the Stories of Illness, 48. Italics original.
} 
bloom, the orchid represents sexuality, beauty, and fecundity, but here the flower lies wilted and dying, cut off from its life source. For Kahlo, perhaps the belief that she would never be able to bear a child also brought about changes in her selfperception. It is possible that here she is showing the viewer her thoughts about what it means to be a woman, a wife, a lover. In the period of mimesis 3 , or refiguration, Kahlo perhaps abandons her idea of what the future might hold and questions the nature of her relationship with her husband.

In an effort to comprehend and recover from a severe and debilitating illness of his own, Shlomith Rimmon-Kenan studied autobiographical illness narratives in order to understand "continuity, its disruption, and the various ways of coping with the latter." 99 He notes, "Motivated by a conscious or unconscious desire to (re)establish continuity between present and past, these narrators tend to emphasize elements of their past history that they did not stress before the illness, to create new connections among events, to change the balance between foreground and background, etc."100 In Kahlo's visual narrative, she grapples with current and future complications that have been caused by past events. Rimmon-Kenan also explores the difficulty in crafting a story of illness that respects traditional narrative conventions of coherence and continuity. He believes the postmodern exploration of the fragmented nature of reality and identity offers a far better framework for the construction of illness narratives. ${ }^{101}$ His insights support the contention that Kahlo's work is narrative in nature even though it is not a continuous, linear construct.

\footnotetext{
${ }^{99}$ Shlomith Rimmon-Kenan, "The Story of 'I': Illness and Narrative Identity," Narrative 10, no. 1 (2002): 10 . 100 Ibid., 16.

101 Ibid., 20.
} 
In discussing the benefits of narrative competence and of being willing to enter into the world of another, Hilde Lindemann Nelson writes, "An inherent relationship exists between empathizing with others and grasping the complex truth of a situation, the multiple views from which a single event might be seen... We come to see that the truth of a moral experience lies in the aggregate of subjective realities, transformed by the reading mind through reflection, that reveals the sum of what matters in a specific human situation."102 Eric J. Cassell has attempted to describe the nature of suffering and notes, "Suffering occurs when an impending destruction of the person is perceived: it continues until the threat of disintegration has passed or until the integrity of the person can be restored in some other manner.... suffering extends beyond the physical."103 In reflecting upon the objects Kahlo has chosen to include in her painting, we come to understand that the source of her suffering goes even beyond the loss of a single child and includes the loss of a future in which bearing children is a possibility. Comprehending this aspect of the painting is not possible without a thorough exploration of each symbol Kahlo chooses to incorporate into her narrative.

Floating directly above the bed is the male fetus that Kahlo painted disproportionately large in relation to herself. There is tendency in the medical world, and in society at large, to treat miscarriage as a less devastating loss than the loss of a child that has already been born. Kahlo forbids this attitude when she depicts her fetus as a fully formed infant with recognizable features who floats away from the mother that

\footnotetext{
102 Hilde Lindemann Nelson, Stories and Their Limits: Narrative Approaches to Bioethics (New York: Routledge, 1997), 193.

${ }^{103}$ Eric J. Cassell, The Nature of Suffering and the Goals of Medicine, 2nd ed. (Oxford: Oxford University Press, 2004), 32.
} 
lies grieving for him. From the perspective of narrative medicine, Kahlo reminds her viewers of the ethical responsibilities incurred as a result of learning her story, of the imperative to remain open-minded and free of assumption.

In this painting Kahlo has rendered all the aspects of suffering that accompany the unwanted termination of a deeply desired pregnancy. She has given visual form to the emotional trauma of physical failings, to the fear and frustration engendered by an unfamiliar and often threatening medical environment, and most importantly, to the feelings of loneliness and isolation that almost always accompany unspeakable grief.

In her examination of the techniques authors of fiction use to create empathy in their readers, Suzanne Keen differentiates between empathy for particular characters and "situational empathy." "Situational empathy, which responds primarily to aspects of plot and circumstance, involves less self-extension in imaginative role taking and more recognition of prior (or current) experience." ${ }^{104}$ When asking students to attempt some type of empathetic engagement with Henry Ford Hospital, it is obvious that few of the women and none of the men will be able to access a personal experience of miscarriage. Even though Kahlo's work provides invaluable insight into that particular kind of grief, it is nevertheless important to remember that any experience of illness or injury has the potential to cause great sorrow. Keen suggests that fiction writers emphasize "common vulnerabilities and hopes through universalizing representations" in order to create empathy for characters with whom the reader has nothing in common. ${ }^{105}$ Kahlo's depiction of blood, indicating a physical wound, the tear, and her rendition of herself in a vulnerable and precarious physical state are all universalizing elements in the work.

${ }^{104}$ Suzanne Keen, "A Theory of Narrative Empathy," Narrative 14, no. 3 (October 2006): 215. 105 Ibid. 
It is important to remember that any attempt to interpret Frida Kahlo's thoughts or experience purely on the basis of her painting is entirely speculative. Any interpretation made by the viewer will not necessarily be an accurate interpretation of what Kahlo intended to express. The work is extraordinarily useful in the pedagogy of medical humanities, however, because of its ability to stimulate an empathetic reaction in the viewer and because it allows such a thorough exploration of the elements of narrative. When interacting with living patients, the caregiver must continually verify his or her interpretations with the patient. In discussing the narrative elements of Kahlo's work, it might be helpful to have students consider questions they would like to ask the artist if she were available and willing to discuss her experience.

Frida Kahlo's experience of miscarriage represents a traumatic life event in which the science of medicine had very little to offer. There was no way to fully repair her reproductive organs or the skeletal cradle that held them. There was no way to save her unborn child. In recounting a personal experience of feeling medically powerless, Rita Charon writes, "We had little clinically to offer this man. I did not know, then, that there is no limit to what one can give as a doctor. I did not know that I was allowed, as a doctor, to donate my presence, my attention, my regard." 106 This is the essence of compassion, and there is much that can be perceived and practiced using Henry Ford Hospital.

${ }^{106}$ Charon, Narrative Medicine: Honoring the Stories of Illness, 34. 


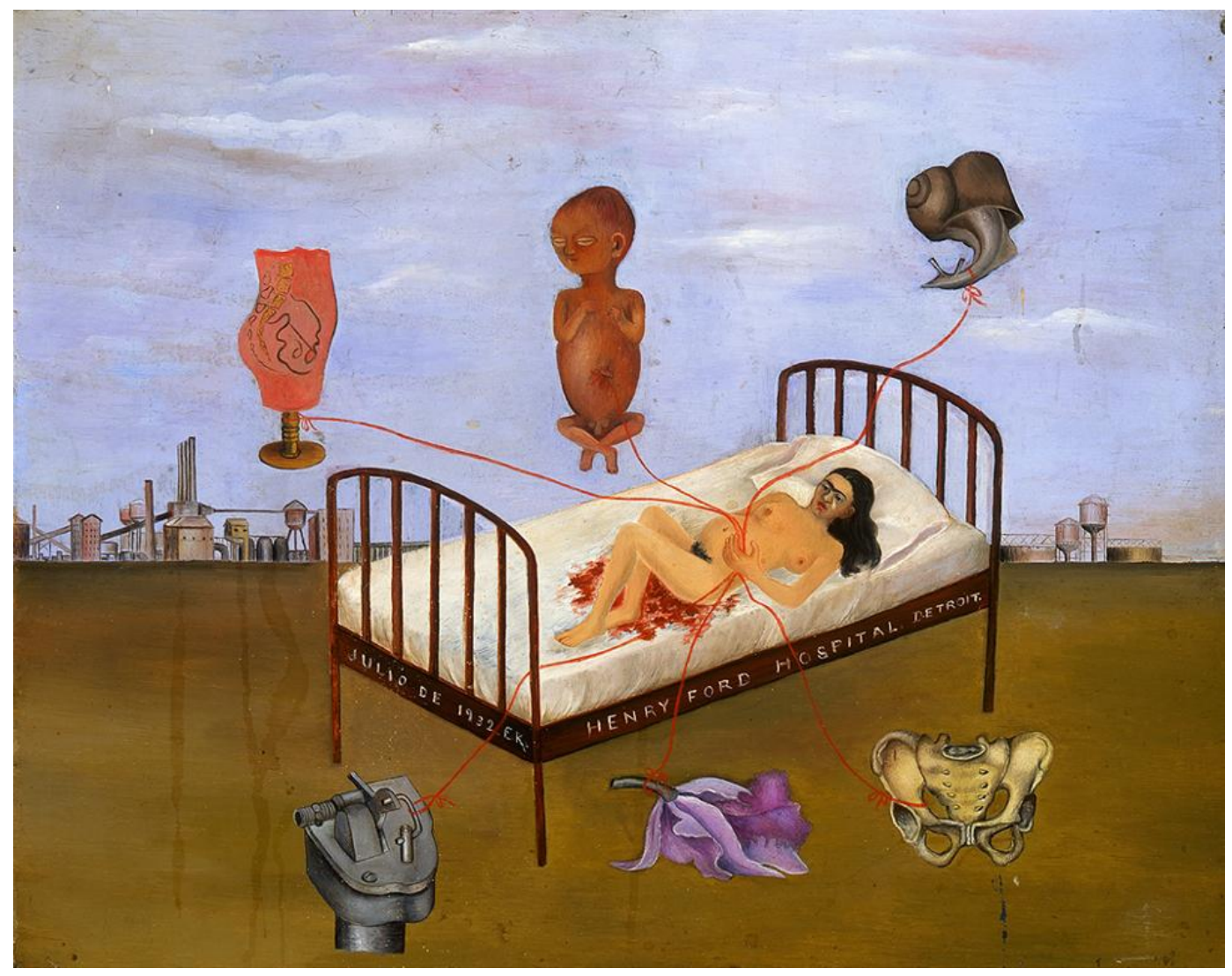

Figure 1

Frida Kahlo

Henry Ford Hospital

1932 


\section{CHAPTER TWO \\ THE PEDAGOGY OF SELF-AWARENESS: USING LITERATURE TO EXPLORE ALTERITY AND ADDRESS HEALTHCARE DISPARITIES}

"[M] ost of the variability in health status we find in the United States and other developed countries has little to do with health care and everything to do with one's position in the social hierarchy. "'107

Donald A. Barr, $M D, P h D$

In Health Disparities in the United States, Donald Barr presents evidence of inequalities in disease and death rates that exist along racial and socioeconomic lines in the United States. He cites extensive evidence documenting poorer health in people of lower socioeconomic categories, ${ }^{108}$ but also notes that even when income levels are the same, black people in the US continue to have much shorter life expectancies than whites. ${ }^{109}$ Barr references the work of Michael Marmot, who has described a "status syndrome" showing a correlation between social status and health regardless of income. ${ }^{110}$ Marmot writes, "Conventional explanations for noncommunicable disease -

\footnotetext{
107 Donald A. Barr, Health Disparities in the United States: Social Class, Race, Ethnicity, and Health (Baltimore: Johns Hopkins University Press, 2008), 1.

108 Ibid., 71.

109 Ibid., 52.

110 Marmot, "Status Syndrome," 1304.
} 
lack of access to medical care, unhealthy lifestyles - at best only partially explain the status syndrome. Rather, the lower individuals are in the social hierarchy, the less likely it is that the fundamental human needs for autonomy and to be integrated into society will be met. Failure to meet these needs leads to metabolic and endocrine changes that in turn lead to increased risk of disease."111 In other words, the psychological effects of one's social status are an important determinant of physical health regardless of lifestyle or access to healthcare. Although societal factors play a key, and often unrecognized, role in health and longevity, Barr also reports, "blacks and other minority racial/ethnic groups continue to receive less care and care that is of lower quality than whites."112 Barr cites the presence of unconscious individual racial biases as the primary reason for this disparity. ${ }^{113}$

Miller and Garran have noted that racism remains pervasive in the United States and often takes the form of unintentional aversion and racial microaggression. ${ }^{114}$ This aversion and microaggression "occurs when white people hold implicit attitudes about people of color - often at odds with a white person's conscious beliefs or intentions - that lead to negative interactions with people of color." 115 Barr points out that in more than twenty years of medical practice he has "never seen a case of conscious racism on the part of my physician colleagues." ${ }^{116}$

This chapter addresses three key findings noted in the previously mentioned research: (1) Persons living at the lower levels of societal hierarchies have a lower life

\footnotetext{
111 Ibid.

112 Barr, Health Disparities in the United States: Social Class, Race, Ethnicity, and Health, 200.

113 Ibid., 224.

114 Miller and Garran, Racism in the United States: Implications for the Helping Professions, Chapter 2. 115 Ibid., 96. Italics mine.

${ }^{116}$ Barr, Health Disparities in the United States: Social Class, Race, Ethnicity, and Health, xi.
} 
expectancy and increased risk of disease, (2) minority groups in the US receive lower quality healthcare than whites, and (3) the quality of healthcare is often affected by caregiver prejudice and biases that exist at an unconscious level even in persons with altruistic desires. How do we educate future caregivers so they are cognitively aware of hierarchical discrepancies in healthcare, and also affectively engaged in a manner that facilitates positive action to counteract these discrepancies? How do we help students acknowledge and mitigate their own unconscious prejudices and biases? This chapter suggests the study of literature offers an effective means of responding to these questions and presents a critical examination of two works of short fiction selected for their insight into the perils of status syndrome and their exploration of conscious and unconscious biases.

In their discussion of literature and the pedagogy of medical humanities, Shapiro et al., note the twenty-first century discourse in medical education revolving around virtue-based "professionalism" in medical caregivers. ${ }^{117}$ In this very recent article the authors note both the practical benefits of studying literature and the difficulties of quantitatively measuring the results of such study. They explain how close reading generates discussion and questions that subsequently inform the practice of caregiving: "Such an approach, translated into the clinical encounter, is likely to result in a critical professionalism through respect, engaged attention, and critical thinking within a very specific context." 118 These observations describe the ways in which close engagement with literature allows students to explore the world from an unfamiliar perspective by providing access to cultures and experiences that are not their own. In the words of

117 Shapiro et al., "Medical Professionalism," 2-3.

118 Ibid., 3. 
Arthur Frank, "stories work on people, affecting what people are able to see as real, as possible, and as worth doing or best avoided."119

Eudora Welty's “A Worn Path," first published in 1941, presents an unlikely and unassuming heroine who engenders deep respect and admiration from readers who come to know her narrative, and Richard Selzer's "Imelda," first published in 1982, introduces a young physician who discovers the humanity of his mentor, but fails to recognize his own hubris. Scholars of medical humanities have written about both stories, but the stories are useful in ways that have not yet been discussed. Welty's work has been praised for its power to elicit an empathetic response in the reader, ${ }^{120}$ but its importance as a metanarrative exemplifying the concept and quandary of alterity has not been explored. Selzer's work, perhaps because its themes are more specifically related to the practice of medicine, has not been subjected to the type of critical analysis that exposes its depiction of subtle and unconscious prejudices. In addition, while "A Worn Path" has been examined as an allegorical tale, ${ }^{121 ~ " I m e l d a " ~ h a s ~ n o t ~ b e e n ~ i n t e r p r e t e d ~ t h r o u g h ~ t h i s ~}$ hermeneutical lens even though Selzer's comments and the story itself give clues to the usefulness of such an approach. Each story has tremendous potential for enlightening students in ways that will enable them to address racial and societal disparities in healthcare and to become more aware of their own biases.

Phoenix Jackson, the protagonist of "A Worn Path," is an elderly black woman who must travel a great distance on foot to obtain "soothing medicine" for her grandson

\footnotetext{
${ }^{119}$ Arthur W. Frank, Letting Stories Breathe: A Socionarratology (Chicago: University of Chicago Press, 2012), 3.

${ }^{120}$ Regina Dilgen, "Addressing Ageism through Eudora Welty's 'A Worn Path,"' Radical Teacher, no. 98 (Winter 2014): 63, doi:10.5195/rt.2014.52.

${ }^{121}$ Elaine Orr, "Unsettling Every Definition of Otherness: Another Reading of Eudora Welty's 'A Worn Path,"' South Atlantic Modern Language Association 57, no. 2 (May 1992): 64-5.
} 
whose throat, Phoenix tells the nurse, "begin to close up again, and he not able to swallow. He not get his breath. He not able to help himself."122 Phoenix encounters many obstacles along her way, which anchors the story firmly within the genre of "road literature," a figurative exploration of the journey of life. ${ }^{123}$

Phoenix's journey begins in December, on "a bright frozen day in the early morning." 124 We are told that Phoenix is very old and small, and that her eyes are "blue with age." 125 Phoenix struggles to climb a hill, and then is caught in a thicket of briars on the way down. At one point, she must cross a creek by means of a fallen log. Phoenix walks the log and crosses the water with her eyes closed, relying on memory and intuition while dispelling fear and apprehension. She crawls through a barbed wire fence, and is knocked to the ground by a large black dog - "Over she went in the ditch, like a little puff of milkweed." 126 A hunter who laughs at her and presumes to know the nature of her journey helps her to her feet; “I know you old colored people! Wouldn’t miss going to town to see Santa Claus!"127 He later points his gun at Phoenix and then grudgingly admires her composure; “'Well Granny,' he said, 'you must be a hundred years old, and scared of nothing ... But you take my advice and stay home, and nothing will happen to you." "128 When she finally reaches Natchez, Phoenix must climb "a tower of steps, where she walked up and around and around until her feet knew to stop." ${ }^{129}$

\footnotetext{
122 Eudora Welty, "A Worn Path," in The Collected Stories of Eudora Welty (New York: Harcort, 1980), 148.

123 Neil D. Isaacs, “Life for Phoenix," in The Critical Response to Eudora Welty's Fiction, ed. Laurie Champion, Critical Responses in Arts and Letters 12 (Westport, CT: Greenwood Press, 1994), 38.

124 Welty, "A Worn Path," 142.

125 Ibid.

126 Ibid., 145.

127 Ibid.

128 Ibid., 146.

129 Ibid., 147.
} 
In addition to threats against her physical wellbeing, Phoenix must also contend with psychological obstacles. She experiences hallucinations brought on by fatigue and is fearful of large objects such as a scarecrow, which she initially believes to be a ghost, because her failing vision does not enable her to correctly identify them. The reader, who has made the journey along with Phoenix, comes to regard her as unfailingly courageous and intelligent. We admire her determination and find ourselves feeling deep respect for her dignity and fortitude in the face of difficult and often demeaning obstructions.

When Phoenix finally reaches the clinic, however, the attendant's first words are, "A charity case, I suppose,"130 a supposition based entirely upon Phoenix's appearance her age, skin color, and clothing - because Phoenix has not yet spoken a word. A nurse enters and informs the attendant, “Oh, that's just old Aunt Phoenix. She doesn't come for herself - she has a little grandson. She makes these trips just as regular as clockwork. She lives away back off the Old Natchez Trace."131 When questioned about her grandson, Phoenix, in a response that could be interpreted either as confusion or subtle defiance, remains silent for a few moments. The nurse responds, "You mustn't take up our time this way, Aunt Phoenix. Tell us quickly about your grandson, and get it over. He isn't dead, is he?"132 The nurse and the attendant have no time to consider the details of Phoenix's journey; they are uninterested in her narrative and therefore have no knowledge of her fortitude and no respect for her tremendous strength and wisdom.

“A Worn Path is a metanarrative in which Phoenix's personal narrative is available to the reader, but not to the other characters within the tale. The white people Phoenix encounters throughout the story draw immediate conclusions based upon her

\footnotetext{
130 Ibid.

131 Ibid.

132 Ibid., 148.
} 
appearance and refer to her as "granny," "grandma," and "old Aunt Phoenix," assuming a derogatory familiarity they believe is justified because Phoenix is aged, poor, and not white. The other characters assume Phoenix is simpleminded and incapable and they render her mute, both literally and figuratively. Readers, on the other hand, are aware of Phoenix's poetic intelligence, her strength, and her dignity. Phoenix requires assistance from both the hunter and the healthcare workers, and in both cases the response is first to infer, and then to insist upon, Phoenix's absolute powerlessness; the hunter achieves this with his gun and the caregivers with their words.

Literary scholars have variously interpreted "A Worn Path" as an allegorical representation of the Christian faith, ${ }^{133}$ a mythological tale of rebirth, ${ }^{134}$ an appeal for liberation theology, ${ }^{135}$ and an allegory of the African-American struggle for equality following the Civil War. ${ }^{136}$ As a source of enlightenment regarding persistent healthcare disparities in the United States, however, it becomes important to interpret the story less figuratively and to carefully consider the characters of Phoenix and her grandson.

In a 2005 interview for Sooner Magazine, published by the University of Oklahoma, Dr. Jerry Vannatta recalled a time when he had difficulty establishing an emotional connection with one of his patients. Vannatta is a white male and his patient, like Phoenix Jackson, was an elderly African American woman. As the patient described a situation from her life, Vannatta recalled a passage from the novel Beloved, by Toni Morrison; "the emotions I felt when I read that scene, came back to me in a flood and

133 Marilyn Keys, “'A Worn Path': The Way of Dispossession,” Studies in Short Fiction 16, no. 4 (Fall 1979): 354.

134 Dan Donlan, “'A Worn Path': Immortality of Stereotype,” The English Journal 62, no. 4 (1973): 54950; Jim Owen, "Phoenix Jackson, William Wallace, and King MacLain: Welty's Mythic Travelers," Southern Literary Journal 34, no. 1 (Fall 2001): 29.

135 Dean Bethea, "Phoenix Has No Coat: Historicity, Eschatology, and Sins of Omission in Eudora Welty's 'A Worn Path,'” International Fiction Review 28 (2001): 32-41.

136 Dennis J. Sykes, “Welty's The Worn Path.," Explicator 56, no. 3 (1998). 
were available to me so I could connect with my patient. She was telling me a story about her economic enslavement; the two stories joined. From that point on, we began to make a more meaningful bond and rapidly solved her problem about her ability to buy her medications." 137 So long as one remains cognizant of human singularity, recalling an empathic connection to a literary character in order to address a real life problem can become a useful means of bridging the chasm of alterity. Vannatta describes an emotional response to Morrison's work, and it is this affective engagement that makes literature so valuable to healthcare workers.

In his discussion of literary hermeneutics Hans-Georg Gadamer writes, "The important thing is to be aware of one's own bias, so that the text can present itself in all its otherness and thus assert its own truth against one's own fore-meanings ... Methodologically conscious understanding will be concerned not merely to form anticipatory ideas, but to make them conscious, so as to check them and thus acquire right understanding from the things themselves." ${ }^{138}$ If part of the reason we utilize literature in the pedagogy of medical humanities is to increase awareness of our own unconscious biases, we must first consider the biases we hold quite consciously. A typical student response (and reader response in general, I suspect) to "A Worn Path" is the formation of a strong sympathetic engagement with the character of Phoenix. Students express their desire to help Phoenix, to provide her transportation to the clinic or perhaps arrange home visits. These responses are altruistic and well-meaning, but they also exemplify the paternalism inherent in the practice of healthcare and help clarify the difference between sympathy and empathy. Engagement with the story and

137 Debra Levy Martinelli, “Medicine and Literature," Sooner Magazine, Fall 2005.

138 Hans-Georg Gadamer, Truth and Method, trans. Joel Weinsheimer and Donald G. Marshall, 2nd ed. (New York: Continuum, 1998), 269. 
conscientious attention to its effects on the reader sheds light the social exchanges that render Phoenix powerless.

One might argue that a story from 1941, a period in time when overt racism was routinely practiced and tolerated, has little relevance to modern healthcare, but today's more subtle forms of racism and ageism are no less harmful. As recently as 1992, in fact, one scholar wrote that the character of the hunter demonstrates genuine concern and admiration for Phoenix, that the white woman in Natchez ties Phoenix's shoes out of respect, and that the nurse shows Phoenix compassion!139 That a late twentieth century reader of this story could so completely misread the blatant condescension and disrespect these characters demonstrate is clear evidence that we often fail to acknowledge those parts of ourselves and our society that are most deeply troublesome. In healthcare there will always exist a power imbalance between the sick person and the caregiver simply because the ill person requires information and services that healthcare workers have the power to provide or withhold. In spite of corporatization of healthcare, the manner, timing, and efficiency with which these things are provided continues to lie primarily with individual caregivers. It is therefore imperative that caregivers recognize attitudes that disempower patients even when the caregiver means to be helpful.

In 1997 Anne Fadiman authored a groundbreaking non-fictional work titled The Spirit Catches You and You Fall Down: A Hmong Child, Her American Doctors, and the Collision of Two Cultures. A primary theme of the book is the existence of healthcare that is state of the art, but "culturally inaccessible" due to language barriers, fear, or

\footnotetext{
${ }^{139}$ James Robert Saunders, “'A Worn Path': The Eternal Quest of Welty's Phoenix Jackson," The Southern Literary Journal 25, no. 1 (1992): 71,72.
} 
simple ignorance on the part of both caregivers and their patients. ${ }^{140}$ This text changed the way healthcare is practiced at Mercy Medical Center in Merced, California and made a significant contribution to the discourse on cultural sensitivity in healthcare throughout the country. ${ }^{141}$ In the 2012 afterward to the second edition of the book, Fadiman notes that terms like "cultural humility" and "cultural responsiveness" are replacing the ubiquitous "cultural competence," and are being used to promote some sense of parity between caregivers and their patients as they seek mutual understanding. ${ }^{142}$

In “A Worn Path," it is Phoenix Jackson's place within the cultural and social hierarchy that influences the response of her caregivers. Her age and appearance determine her status and affect the treatment she receives. These facts must guide any interpretation of the story if it is to be meaningful to students of medical humanities. In discussing the effects of status syndrome, Marmot notes that ordinary life occurrences become detrimental to health and wellbeing "when there is low control and little predictability." 143 Caregivers hoping to benefit from reading "A Worn Path" must resist the urge to rescue Phoenix. We must avoid sympathetic observation and instead attempt to mitigate any alterity by allowing ourselves to imaginatively become the character of Phoenix. One of the most important, and overlooked, aspects of this story is the fact that caregivers never once ask Phoenix what she wants or needs.

This issue of alterity becomes important when asking students to attempt an empathetic rather than sympathetic engagement with the character of Phoenix because, as

\footnotetext{
140 Anne Fadiman, The Spirit Catches You and You Fall Down: A Hmong Child, Her American Doctors, and the Collision of Two Cultures (New York: Farrar, Straus and Giroux, 2012), 270. Italics mine. ${ }^{141}$ Patricia Leigh Brown, "A Doctor For Disease, A Shaman For the Soul: [National Desk]," New York Times, Late Edition (East Coast), September 20, 2009, sec. A.

142 Fadiman, The Spirit Catches You and You Fall Down: A Hmong Child, Her American Doctors, and the Collision of Two Cultures, 295.

143 Marmot, "Status Syndrome," 111.
} 
multiple studies have shown, humans are more likely to empathize with others whom they believe to be most like themselves. ${ }^{144}$ This effect can be mitigated, however, through the practice of "role taking": "A number of investigations have found that observers will experience parallel affective responses when they step outside their usual perspective on events and entertain the perspective of the target." 145 In other words, participants who are acting as observers in various psychological experiments, are more likely to experience emotions similar to those of the target participants when they consciously and deliberately imagine themselves as the target participant rather than the observer.

My observation in teaching "A Worn Path" is that students identify most readily with the caregivers at the clinic, and sometimes with the hunter. They then begin to describe ways in which their own behavior would be different from that of those characters if they were faced with a similar situation. This is quite a useful exercise, of course, but what becomes even more useful is to have the students imaginatively assume the character of Phoenix, and then closely read the portion of the story in which Phoenix becomes silent as the nurse is questioning her:

"Now, how is the boy?" asked the nurse.

Old Phoenix did not speak

"I said, how is the boy?"

But Phoenix only waited and stared straight ahead, her face very solemn and withdrawn into rigidity.

"Is his throat any better?" asked the nurse. "Aunt Phoenix, don't you hear me? Is your grandson's throat any better since last time you came for the medicine?"

With her hands on her knees, the old woman waited, silent, erect and motionless, just as if she were in armor.

\footnotetext{
144 Mark C. Davis, Empathy: A Social Psychological Approach, Social Psychology (Boulder, CO: Westview Press, 1996), 97.

145 Ibid., 114.
} 
"You mustn't take up our time this way, Aunt Phoenix," the nurse said. "Tell us quickly about your grandson, and get it over. He isn't dead, is he?"

At last there came a flicker and then a flame of comprehension across her face, and she spoke.

"My grandson. It was my memory had left me. There I sat and forgot why I made my long trip."

Phoenix's actions in this passage have been interpreted as the onset of senility, ${ }^{146}$ and even as an indication that Phoenix's grandson is, in fact, already dead, ${ }^{147}$ but the most plausible explanation comes from Elaine Orr, who notes, "Here [Phoenix] employs silence rather than narrative invention to rebel against white and male 'author-izations' of her journey as (m)other." ${ }^{148}$ In understanding Phoenix's silence as an act of quiet defiance against the caregivers' condescension, we can begin to understand the absence of autonomy that is such a crucial element of this story, and the ways in which reflexive responses often perpetuate rather than relieve that absence.

Near the end of "A Worn Path" it is revealed that Phoenix needs medicine for her grandson's throat because he had swallowed lye two or three years prior to Phoenix's most recent journey. ${ }^{149}$ In a revelatory article exploring the conditions of lye poisoning, Melissa Stang demonstrates how expertly Welty has indeed rendered the implications of status syndrome; "One 1939 study in the Southern Medical Journal, just a year before Welty wrote her story reported that although esophageal burns from lye were very common throughout the southern region, sixty percent of patients seen by doctors were black, and almost all of the remaining white patients were children of tenant farmers ...

\footnotetext{
146 Saunders, "A Worn Path," 64.

147 Roland Bartel, “Life and Death in Eudora Welty's 'a Worn Path,"' Studies in Short Fiction 14, no. 3 (Summer 1977): 289.

148 Orr, "Unsettling Every Definition of Otherness: Another Reading of Eudora Welty's 'A Worn Path,"' 67.

149 Welty, “A Worn Path,” 148.
} 
They surmised that these cases occurred as a result of poverty, a lack of both education and information on the dangers of lye poisoning." ${ }^{150}$ Including Stang's article as required reading for students studying "A Worn Path" provides important contextual information about the ways in which social hierarchies and isolation contribute to status syndrome. ${ }^{151}$ Phoenix tells the nurse, "My little grandson, he sit up there in the house all wrapped up, waiting by himself. We is the only two left in the world. He suffer and it don't seem to put him back at all. He got a sweet look. He going to last." ${ }^{52}$ The nurse responds to Phoenix with impatience, "trying to hush her now."153 Attention to Phoenix's dialog reveals that she is her grandson's only caregiver and that she is aware he will outlive her. The medical community's disregard for Phoenix's narrative is a brilliant example of the willful ignorance Peggy McIntosh describes in her seminal discussion of white privilege, "Unpacking the Invisible Knapsack." 154 The nurse hears Phoenix's words, but ignores their implications. The practice of narrative medicine demands attention to the ethical responsibilities that come with hearing a patient's story, ${ }^{155}$ and there are also ethical implications that come with knowing Phoenix Jackson's story even though it is fictional.

In 1965 Louise M. Rosenblatt, professor of comparative literature and literary theory at New York University, wrote Literature as Exploration, in which she developed a "transactional" theory of literature that advocates close reading and emphasizes "the essentiality of both reader and text, in contrast to other theories that make one or the other

\footnotetext{
150 Melissa Deakins Stang, "Parting the Curtain on Lye Poisoning in 'A Worn Path,"' Eudora Welty Review 1, no. 1 (2009): 16, doi:10.1353/ewr.2009.0001.

151 Marmot, "Status Syndrome," 111.

152 Welty, "A Worn Path," 148.

153 Ibid.

${ }^{154}$ McIntosh, "White Privilege."

155 Charon, Narrative Medicine: Honoring the Stories of Illness, 55.
} 
determinate."156 The book has been reprinted five times and Rosenblatt's ideas continue to influence literary scholars and theorists. ${ }^{157}$ Her theories on pedagogy have recently been criticized for placing more emphasis on exploring the emotional response of the reader than on teaching about literature, ${ }^{158}$ but this approach is precisely what makes Rosenblatt's ideas particularly useful to scholars of medical humanities. In our work, the primary objective of studying literature is not to perform a detailed analysis of the text itself, but to connect the text and reader in such a way that the reader's clinical practice is improved through engagement with the literature.

Rosenblatt breaks the experience of reading into efferent and aesthetic modes, where efferent reading involves the practical purpose of garnering information from the text, and aesthetic reading concerns the affective experience of "sensations, feelings, images, and ideas."159 She writes that these ways of reading are always in flux, and that the "shift of attention" from efferent to aesthetic is often ignored or taken for granted. 160 In the case of Welty's story, the efferent implication is the knowledge that we all carry inherent biases that affect the ways in which we respond to our patients. Recognizing our tendency to identify with literary characters that are most like us and instead attempting to identify with the "other" allows the reader a small understanding of an unfamiliar perspective. The reader thus becomes aware of a tendency to make assumptions and perhaps to patronize. Critical assessment of our affective response to

\footnotetext{
156 Louise M Rosenblatt, Literature as Exploration, 5th ed. (New York: MLA, 1999), xvi. 157 Wayne Booth, "Forward," in Literature as Exploration, 5th ed. (New York: MLA, 1999); Stewart Justman, "Bibliotherapy: Literature as Exploration Reconsidered," Academic Questions 23, no. 1 (February 18, 2010): 126, doi:10.1007/s12129-009-9147-1.

158 Justman, "Bibliotherapy," 133.

159 Rosenblatt, Literature as Exploration, 32-3.

160 Ibid., xviii.
} 
literature allows us to determine whether we are genuinely empathizing with a character or instead feeling a disempowering form of sympathy.

Similar techniques of close reading and transactional awareness can also be used to discern the deeper themes in Richard Selzer's "Imelda."161 Dr. Selzer was formerly a practicing surgeon and member of the faculty at Yale School of Medicine, and is the author of several works of fiction and non-fiction. In the preface to Letters to a Young Doctor, the collection in which "Imelda" appears, Selzer writes, "These pieces are not, strictly speaking, factual in the way that a medical textbook is factual. Nor are they journalism or reportage. They are literary renditions of medicine meant to strike resonating chords in the reader's mind."162

The unnamed narrator of "Imelda" is a young surgeon who writes about a medical mission trip he had been part of during his third year of medical school. The organizer of the mission and his former teacher is a brilliant plastic surgeon named Hugh Franciscus. At a remote village in Honduras the medical team encounters a young woman, Imelda, who has been brought in by her mother so the girl's complete cleft lip and palate can be repaired. Before the surgery begins, Imelda experiences malignant hyperthermia, a rare type of allergic reaction to anesthesia that causes uncontrollable increases in blood pressure and body temperature. With no ice available to lower her temperature, Imelda dies on the operating table. When Dr. Franciscus explains this outcome to the girl's mother, the mother believes that Franciscus has managed to repair the cleft palate prior to the girl's death; "she was happy now that the harelip had been fixed so that her daughter

${ }^{161}$ Richard Selzer, “Imelda," in Letters to a Young Doctor (San Diego: Harvest, 1996), 21-36.

162 Ibid. 
might go to Heaven without it."163 Franciscus does not correct the mother's mistaken assumption and instead steals into the morgue late at night to repair the cleft palate and lip.

As Daniel Burr has noted, students studying "Imelda" seem initially most interested in discussing the ethicality of performing surgery on a corpse, ${ }^{164}$ and this same dilemma seems paramount to the story's narrator, who at first sees the older surgeon's actions as those "of someone demented, or at least insanely arrogant."165 The medical student never speaks of the surgery and later even alters Franciscus's slide presentation of the trip in order to prevent anyone else from discovering what the surgeon has done. Years later, when the younger surgeon learns that Dr. Franciscus has died, he remembers Imelda and realizes the "unrealistic act was one of goodness."166

To the best of my knowledge, "Imelda" has been published only twice outside the realm of medical literature. The story appeared in the Touchstone Anthology of Contemporary Creative Nonfiction: Work from 1970 to the Present (2007) and in Themes (2005), a Prentice-Hall textbook designed to accompany freshman composition courses. Critical commentary on the story has thus been restricted primarily to writers within the disciplines of healthcare and medical humanities. Johanna Shapiro addresses the story in her discussion of the clinical gaze, ${ }^{167}$ and Ed Stieve suggests the story provides useful insights into ethics, the history of medicine, and cultural studies. ${ }^{168}$ In discussing the

\footnotetext{
163 Ibid., 31.

164 Daniel Burr, “Commentary,” Academic Medicine 84, no. 10 (October 2009): 1403.

165 Selzer, "Imelda," 32.

166 Ibid., 36.

167 Johanna Shapiro, “(Re)Examining the Clinical Gaze Through the Prism of Literature," Families, Systems, \& Health Summer 2002 20, no. 2 (2002): 166.

168 Ed Stieve, “The Medical Essay as an Invitation for Interdisciplinary Exploration," Quadrivium, no. 3 (November 2013).
} 
story as a means of engagement with literary studies, however, Stieve conflates the narrator and the author and appears to assume the literal truth of the story.

In the preface to the collection in which "Imelda" appears Selzer writes, "Each of these chapters is rooted in an event that I have experienced or witnessed. 'Imelda' took place while on a surgical expedition to the Third World," but he also notes, "I have roamed the imagination for metaphor, myth, and memory." 169 Much is lost, therefore, if "Imelda" is read as a literal first-person narrative, and much can be gained from understanding the mythological nature of the story, considering the young narrator and the elder Dr. Franciscus as archetypal characters.

In a paper discussing the usefulness of using myths as interpretive metaphors, Antonio Fernández-Cano et al., write, "Myths are used to tell a story or talk about a certain event or relevant person in the form of a metaphor. As such, they can be used to embody, examine and explain certain phenomena and characters. The myth is one of the enlightening phenomena with the greatest direct influence on the way in which humans think about their conscience, their history, and the exegesis and hermeneutics of their seminal texts."170 There is textual evidence to suggest Selzer has turned to mythology and metaphor in his rendition of the events in "Imelda."

In the opening paragraph Selzer writes, "Dr. Franciscus was the archetype of the professor of surgery," 171 and his use of the word archetype must be considered deliberate. Carl Jung postulated that the recurring motifs in myths and folklore proved the existence of biological archetypes present in the psyches of all humans throughout

\footnotetext{
169 Richard Selzer, “Preface," in Letters to a Young Doctor (San Diego: Harvest, 1996), np.

170 A. Fernandez-Cano et al., "A Narrative Review of Greek Myths as Interpretative Metaphors in Educational Research and Evaluation,” Educational Research Review 7, no. 3 (2012): 239. 171 Selzer, "Imelda," 21.
} 
time. ${ }^{172}$ Although the Jungian concept of archetypes as biological has been upended by genetic research, the notion of archetypes as "universal patterns producing meaning and guiding development" persists. ${ }^{173}$ That Dr. Franciscus is indeed a mythological archetype rather than a stereotypical professor of surgery or the epitome of such a man is evidenced by the descriptors Selzer's narrator employs. According to the nameless young surgeon, Franciscus interprets the human body so skillfully he has "the appearance of a prophet."174 To the medical students Franciscus was "someone heroic, someone made up of several gods ... if he had grown accustomed to his miracles, we had not." 175 The narrator also tells us Franciscus is an avid deer hunter, ${ }^{176}$ a piece of information that seems incongruous and unnecessary except that it aligns Franciscus even more closely with ancient warrior gods and heroes.

Tragic heroes of Greek mythology often possess a fatal flaw, usually hubris, which leads to their downfall. Franciscus tells the young narrator, "I'm taking a surgical team to Honduras next week to operate on the natives down there. I do it every year for three weeks, somewhere. This year, Honduras."177 Though Franciscus never explains why he makes these trips, the reader assumes some sort of humanitarian impulse. Yet Franciscus's words, "to operate on the natives," make his hubris clear. These are not people with whom Franciscus shares a common humanity; they are natives, a designation clearly demonstrating Said's theories of alterity as put forth in Orientalism; "they were seen through, analyzed not as citizens, or even people, but as problems to be solved ...

172 Erik Goodwyn, "Recurrent Motifs as Resonant Attractor States in the Narrative Field: A Testable Model of Archetype," Journal of Analytical Psychology 58, no. 3 (2013): 387.

173 Roesler C, "Are Archetypes Transmitted More by Culture than Biology? Questions Arising from Conceptualizations of the Archetype.," The Journal of Analytical Psychology 57, no. 2 (2012): 224.

174 Selzer, "Imelda," 21.

175 Ibid., 22.

176 Ibid.

177 Ibid., 23-4. 
The point is that the very designation of something as Oriental [or "native"] involved an already pronounced evaluative judgment."178 That Franciscus intends to "operate on" these "natives" confirms his objectification of the people. Their bodies are things he will invade, acting upon them as he sees fit.

Franciscus dictates the following plan of care for one of the "natives" suffering from a carcinoma of the eye and eye socket: "Operative plan: wide excision with enucleation of the eye. Later, bone and skin grafting." 179 To the nonmedical reader it might not be clear that enucleation means removal of the eyeball, causing a permanent and intractable disfigurement and loss of vision. If the nonmedical reader lacks important information about this plan, how much more oblivious would the patient have been? While the procedure may have been medically necessary, there is no indication the patient was informed, consulted, or asked for consent. The text simply notes, "The next morning we would be in the operating room where the procedure would be carried out." 180 Franciscus's hubris lies in his assumption that whatever action he chooses to take will be beneficial for the less fortunate "natives".

When Imelda appears at the clinic, she initially refuses to show her face to the doctors, but is quickly forced to submit to their examination. "Just then, Franciscus reached up and, taking the hand that held the rag, pulled it away with a hard jerk ... the defect was utterly hideous ... 'Take her picture,' he said ... Through the eye of the camera she seemed more pitiful than ever, her humiliation more complete ... There was the click of the camera. The girl winced. 'Take three more, just in case."'181 The

\footnotetext{
178 Edward W. Said, Orientalism (New York: Vintage Books, 1979), 207.

179 Selzer, "Imelda," 25.

180 Ibid.

181 Ibid., 27-8.
} 
narrator notices Franciscus seems "awed by the sight of this girl," and reasons, "Had she brought her mouth to him willingly, without shame, she would have been for him neither more nor less than any other patient." ${ }^{182}$ What are we to make of this passage? Close reading suggests a cruelty that has been unremarked by critics who tend to paint Franciscus as "a brilliant and dedicated physician so driven to achieve perfection he defies death," 183 or "at once highly competent and arrogant, and as we discover later, a compassionate practitioner."184 Yet Franciscus, noticing the girl's discomfort with being photographed, demands three more photos. As the narrator makes clear, the sense of "awe" Franciscus feels for the girl is not due to the unusual nature of her deformity, but to the fact that she is humiliated before him. In actuality, Franciscus is less a dedicated and compassionate surgeon than a capricious hero, before whom the less fortunate should bow. His hubris lies in his absolute certainty that he can improve Imelda's life by creating beauty out of chaos. When Imelda dies, Franciscus's veil of omnipotence is lifted and we are told he never again undertakes a medical mission trip. ${ }^{185}$

Franciscus's encounter with Imelda's mother after Imelda's death is genuinely moving. He accepts the mother's hand on his arm, and even appears to cry with her over the loss of her child. ${ }^{186}$ We come to believe that perhaps the post-mortem surgery is, in fact, an act of goodness, undertaken to provide Imelda's mother with the comfort she needs. And yet, it is also possible that Franciscus was merely preserving his own sense of importance. In repairing Imelda's face after her death he ensures that her mother will continue to be in awe of his power. In fact, one of the most important phrases within the

\footnotetext{
182 Ibid., 27.

183 Burr, "Commentary," 1403.

184 Stieve, "The Medical Essay as an Invitation for Interdisciplinary Exploration."

185 Selzer, "Imelda," 36.

186 Ibid., 31.
} 
description of Franciscus's encounter with Imelda's mother reads, "All that hope of love . . gone." ${ }^{187}$ This sentence makes it clear to the reader that at least part of what drives the surgeon's behavior is a desire to preserve his position as hero. There is a tendency to read "Imelda" sentimentally, as a tale of two physicians who find their humanity through failure and the realization that all humans suffer. Close reading prevents a superficial interpretation, however, and allows for more nuanced questioning of the moral of this story.

If we turn our attention to the young narrator, who tends to present himself as the innocent pupil, unjaded and still kind, in awe of his master and eager to soak up his knowledge, we can see that the student, although bilingual and altruistic, also demonstrates prejudice and biases that affect his ability to be a compassionate caregiver.

Burr notes, "Selzer never reveals the gender of his narrator, but I have found that male readers assume the narrator is a man, and female readers, a woman."188 I would argue that strong evidence of a male gaze makes a female narrator unlikely. Laura Mulvey first introduced the concept of a male gaze in her 1975 essay "Visual Pleasure and Narrative Cinema." The essay uses psychoanalytic theory to offer a critique of "the way the unconscious of patriarchal society has structured film form."189 While psychoanalytic theory and the idea of a patriarchal unconscious may not be tenable to modern healthcare practitioners, the universal presence of unconscious biases must be acknowledged if we are to overcome them. Mulvey writes, "In a world ordered by sexual imbalance, pleasure in looking has been split between active/male and passive/female.

\footnotetext{
187 Ibid., 30. Ellipses original.

188 Burr, “Commentary," 1403.

189 Laura Mulvey, "Visual Pleasure and Narrative Cinema," in The Norton Anthology of Theory and Criticism, 2nd ed. (New York: Norton, 2010), 2084.
} 
The determining male gaze projects its fantasy onto the female figure, which is styled accordingly."190 In "Imelda," Selzer creates this exact scenario. Franciscus seems drawn to Imelda because she is humiliated before him, and the narrator is drawn to her objective beauty. Both characters view Imelda as a potentially perfect sexual object and set about creating their fantasy, styling her accordingly.

Superficial assessment of the young narrator as an innocent apprentice who attempts to mitigate Franciscus's coldness overlooks the narrator's own tendency to objectify and sexualize the Honduran patients. In coming to see that even well-meaning caregivers fall victim to the shadow side of human nature enables students to become more conscious of their own potential frailties.

Early in the story we learn that the young narrator has been asked to join the medical mission team because he is fluent in Spanish. ${ }^{191}$ In spite of the fact that he is able to communicate with the Honduran people, the student accentuates the alterity between himself and the Hondurans by relying solely upon his visual assessment of them, and further complicates this approach by responding judgmentally to what he sees: "They had flat, broad, dumb museum feet. At first they seemed to me indistinguishable the one from the other, without animation. All the vitality, the hidden sexuality, was in their black hair. Soon I was to know them by the fissures with which each face was graven. But, even so, compared to us, they were masked, shut away."192

The tendency of medical caregivers to rely upon visual information for diagnosis was well discussed by Michel Foucault in The Birth of the Clinic, where Foucault traces an epistemological history of medicine. Foucault discusses the power of the gaze in

\footnotetext{
190 Ibid., 2088.

${ }^{191}$ Selzer, "Imelda," 23.

192 Ibid., 25.
} 
diagnosis, but also emphasizes the importance of non-judgment; "The gaze will be fulfilled in its own truth and will have access to the truth of things if it rests on them in silence, if everything keeps silent around what it sees." ${ }^{193}$ In describing the Honduran's feet as "dumb museum feet," the narrator appears to compare the living humans he encounters with museum displays of inanimate figures incapable of thought or speech. This could be seen as an initial reaction to being immersed in a wholly unfamiliar environment, perhaps for the first time in his life, but the narrator persists in his dehumanization of the Hondurans, remarking that when he did come to "know" them, it was only through the fissures of their individual faces. When the narrator compares the Hondurans to himself and declares them "masked, shut away," he places the failure of connection entirely with the Hondurans.

Repeated references to the sexuality and sensuality of the Honduran's black hair almost certainly indicates a heterosexual male narrator unaware of his objectification of the Hondurans and, in particular, of Imelda. The narrator makes use of poetic metaphor to describe Imelda, “A thin, dark Indian girl about fourteen years old. A figurine, orangebrown, terra-cotta, and still attached to the unshaped clay from which she had been carved," but reverts to decidedly un-poetic prose when describing Imelda's mother; "The mother was short and dumpy." 194 Later descriptions of Imelda follow the same pattern: "The girl had long, loose black hair. . Even with her in it, the dress was empty, something hanging on the back of a door. Her breasts made only the smallest imprint in the cloth, her hips none at all." 195 And, "She seemed to me then like an animal that looks

\footnotetext{
${ }^{193}$ Michel Foucault, The Birth of the Clinic, trans. A. M. Sheridan Smith (New York: Vintage Books, 1994), 108.

194 Selzer, "Imelda," 25.

195 Ibid., 26.
} 
outward at the infinite, at death, without fear, with recognition only."196 Also, "Above the thing [cleft lip and palate], clear almond eyes and long black hair reflected the light ... She was a beautiful bird with a crushed beak."197 Each description of Imelda is dehumanizing. She is either an object or an animal. Commentary on her breasts and hips is invasive and demeaning. Repeated references to her long dark hair draw the reader back to the narrator's initial observation that all "the hidden sexuality, was in their black hair,"198 and make it clear that Imelda is eroticized. Again, it is important to remember the narrator is capable of communicating with Imelda, but never does. Selzer, the author, seems aware of his construction of a dehumanizing male gaze when he writes these lines for his narrator, "Under our gaze the girl's eyes fell to her lap where her hands lay palms upward, half open."199

Both Eudora Welty and Richard Selzer present fictional accounts of healthcare workers' interactions with patients whose alterity presents an obstacle to compassionate care. In both stories, people in positions of power behave in ways that disempower and dehumanize the Other. In the case of Welty's caregivers, their assumption of superiority is obvious; Welty make plain her character's condescension, but Selzer's characters' dehumanization of their patient is far subtler because it lies below the conscious desires of seemingly altruistic characters.

In her seminal essay “Can the Subaltern Speak?” first published in 1985, Gayatri Chakravorty Spivak poses, "the possibility that the intellectual is complicit in the

\footnotetext{
196 Ibid.

197 Ibid., 27.

198 Ibid., 25.

199 Ibid., 27.
} 
persistent constitution of the Other as the Self's shadow." 200 Spivak critiques postcolonial attempts to construct a homogenous subaltern Other and also notes, "If, in the contest of colonial production, the subaltern has no history and cannot speak, the subaltern as female is even more deeply in shadow... we meditate upon an elusive female figure called into the service of colonialism."201 Spivak critiques not only the colonial muting of the subaltern female, but also anti-colonial revisionist attempts to provide the Other's voice. ${ }^{202}$ Imelda utters only one word in Selzer's story, her name, and the narrator's description of the sound adds an additional sensory element to the visual imagery of her appearance; "the syllables leaked through the hole with a slosh and a whistle," ${ }^{203}$ Imelda's voice is as grotesque as her wound. Imelda, as subaltern female, is called into the service of God-like surgeons who would "operate on" her, fix her, and thus provide her a voice. Spivak acknowledges the paradox that colonization often provided great benefits to the subaltern even in the face of subjugation. ${ }^{204}$ It is unrealistic to think that Imelda would not have welcomed the chance to have her defect repaired considering the embarrassment it seems to cause her or the difficulties she must have had with eating and speaking, but the fact remains; Imelda's voice is absent. Selzer's story gives the reader no indication of Imelda's response to Franciscus's assertion that, "Tomorrow, I will fix your lip. Mañana."205 Spivak notes that, when the voice of the

200 Gayatri Chakravorty Spivak, "Can the Subaltern Speak," in The Norton Anthology of Theory and Criticism, 2nd ed. (New York: Norton, 2010), 2114.

201 Ibid., 2120.

202 Ibid., 2124.

${ }^{203}$ Selzer, "Imelda," 27. Italics original.

${ }^{204}$ Spivak, "Can the Subaltern Speak," 2125.

205 Selzer, "Imelda," 27. 
Other is absent or negated, one explanation and narrative of reality [is] established as the normative one. ${ }^{206}$

From the perspective of the medical caregivers they encountered, both Phoenix Jackson and Imelda Valdez exist as voiceless alterities. How can consideration of the ways in which these characters were disempowered improve the practices of today's medical caregivers? Although they acknowledge, "psychological research on feeling and emotion has been far from decisive," David S. Miall and Don Kuiken nevertheless posit "aesthetic and narrative feelings evoked during reading interact to modify the reader."207 The researchers suggest:

In literary response, such feelings can roughly be sorted into four domains: (1) evaluative feelings toward the text, such as the overall enjoyment, pleasure, or satisfaction of reading a short story; (2) narrative feelings toward specific aspects of the fictional event sequence, such as empathy with a character or resonance with the mood of a setting; (3) aesthetic feelings in response to the formal (generic, narrative, or stylistic) components of a text, such as being struck by an apt metaphor; and (4) self-modifying feelings that restructure the reader's understanding of the textual narrative and, simultaneously, the reader's sense of self. ${ }^{208}$

The final two categories of feeling, aesthetic and self-modifying, become most important when literature is used to provide alternative perspectives or to increase selfawareness. The authors state that aesthetic feelings are stimulated when certain passages of text captivate the reader and cause him or her to read more slowly and to question the meaning of a text. ${ }^{209}$ The young medical student's descriptions of Imelda incorporate poetic metaphors that create exactly this type of response in the reader. Miall and Kuiken

\footnotetext{
206 Spivak, “Can the Subaltern Speak," 2115. Italics original.

207 David S. Miall and Don Kuiken, “A Feeling for Fiction: Becoming What We Behold,” Poetics 30, no. 4 (2002): 221-2. 208 Ibid., 223.

209 Ibid., 224-5.
} 
go on to say that aesthetic feelings, those that demand closer attention to the text and a reimagining of previously held ideas, encourage readers to evaluate and perhaps modify their traditional ways of seeing. ${ }^{210}$ What does it mean to view another person as a figurine made of clay? How would it feel to be thought of as a figurine? An animal? A bird with a crushed beak? As Miall and Kuiken have noted, not all readers respond aesthetically to any given work of literature, ${ }^{211}$ but even those who do not can be encouraged to think critically about the deeper implications of the figurative language used in this text.

If we set aside Selzer's comments regarding his work and view Franciscus and the narrator as actual people with human characteristics, we may see them in a more forgiving light and agree with traditional interpretations of Franciscus as a justifiably confident surgeon whose heart is opened when he grieves the death of a patient. His response to Imelda's shame can be seen as one of compassion; the wound itself did not move him, for he had seen many such wounds, but he was compelled to remove the embarrassment that caused Imelda's suffering. Franciscus repairs Imelda's face after her death because he shares the grief of Imelda's mother and wishes to provide her some comfort. We may view the narrator as a young man searching for a way to describe the haunting beauty of Imelda and her people, caught up in an experience he had no frame of reference for communicating. For the typical reader, the story is poignant and thought provoking.

Stanley Fish is generally considered a founder of reader-response theory, and his ideas regarding "interpretive communities" are especially useful in considering the lens

\footnotetext{
210 Ibid., 236.

211 Ibid., 238.
} 
through which scholars of medical humanities must view "Imelda." Even if we understand Franciscus and the narrator's sentiments as guileless, we must not accept them as moral or just, for to do so mutes the didactic power of the story. Fish contends that interpretive communities share interpretive strategies "that exist prior to the act of reading and therefore determine the shape of what is read." 212 The classroom of students considering careers in healthcare forms an interpretive community. If one goal of this community is to understand the form of unconscious biases and the prejudices they engender, we must recognize their presence even in otherwise admirable literary characters and thus become better able to recognize them in ourselves.

As previously mentioned, Shapiro et al., recently discussed the value of literature in the development of "professionalism" in medical caregivers. They describe this professionalism as "virtue-based attributes such as altruism, trust, honesty, patient empowerment, and commitment to social justice," ${ }^{213}$ and assert, "Close reading requires a wariness of superficial and facile interpretations, a clinical position that helps the clinician avoid bias, assumptions and judgmentalness." ${ }^{214}$ In an astute observation that beautifully illuminates the value of a more critical reading of "Imelda" the authors note, "Studying literature and reading stories reveal that even such enshrined professionalism values as compassion do not necessarily always serve moral ends; and point out ways in which such values need to be interrogated more critically to understand how they might go astray."215

\footnotetext{
${ }^{212}$ Stanley Fish, "Interpreting the Variorum," in The Norton Anthology of Theory and Criticism, 2nd ed. (New York: Norton, 2010), 1990.

213 Shapiro et al., "Medical Professionalism," 2.

214 Ibid., 3.

215 Ibid., 4-5.
} 
If we return to the original problems set forth in this chapter - healthcare disparities that result from social hierarchies that impair individual autonomy, and unconscious biases that lead to unintended acts of prejudice - we can see how close reading and discerning interpretations of "Imelda" and "A Worn Path" illuminate the mindsets and inclinations that perpetuate both the hierarchies and the biases. Students must, of course, be made aware of existing healthcare discrepancies, and the work of both Barr and Marmot are important sources of factual information. Literature is far more useful, however, in fostering the kind of self-exploration that allows individual caregivers to become aware of, and work to mitigate, their own constructions of alterity, subconscious and otherwise. Deep engagement with literature helps reveal our tendencies to judge, objectify, and patronize. We can only work to counteract these tendencies if we are aware of their existence. 


\section{CHAPTER THREE \\ THE PEDAGOGY OF BIOETHICS: USING DRAMATIC LITERATURE TO INTRODUCE VIRTUES AND PRINCIPLES}

"Great dramatic art addresses itself to our love of learning; it can overcome prejudices and preconceptions, and teach us to see the world and ourselves in a new way. "'216

Martha Nussbaum

The field of bioethics seeks to apply the principles and processes of philosophical inquiry to dilemmas brought about by extraordinary developments in modern medical treatment and research. This chapter briefly introduces the major theories of bioethics and asserts that, because most general undergraduate students have not yet been exposed to clinical dilemmas, bioethics, or perhaps even general philosophy, literature and the visual arts once again offer an important means of instilling key concepts. In addition, this chapter considers the question of what it means to be a virtuous person. Medical caregivers, because of their training and expertise, hold an inherent position of power in relation to their patients who are, because of illness or injury, often at their most

216 Martha Nussbaum, “Consequences and Character in Sophocles' Philoctetes,” Philosophy and Literature 1, no. 1 (1976): 26, doi:10.1353/phl.1976.0004. 
vulnerable. In this position of power, character matters. I believe the majority of students who choose careers in healthcare do so because they are genuinely altruistic and wish to be of service, however evidence demonstrates that the ability to feel and express compassion may be subverted by a for-profit healthcare industry and a medical culture that seems to value scientific knowledge over human kindness. ${ }^{217}$ It is therefore important for students to understand the concept of virtue and, through a process of selfexploration that can be guided by the study of literature and art, develop a frame of reference for maintaining their own virtue as they pursue a very demanding profession.

Two works of dramatic literature, one ancient and the other modern, will be used to immerse students in the questions and concerns of contemporary bioethics, thereby encouraging reflection, discussion, and the formation of individual interpretations of complex philosophical theories. As with other chapters in this dissertation, the literature is but one piece of a pedagogy that begins with the introduction of key vocabulary and concepts and continues with the exploration of these ideas through the study of literature and art.

Students who continue a course of study related to some aspect of healthcare will likely encounter an introductory bioethics course in which theories are presented and subsequently applied to case studies taken from actual clinical experience. For general undergraduates, most of whom are as yet unfamiliar with the world of clinical practice, exploring the important tenets of bioethics through literature rather than case studies has many advantages. Dramatic works of art from ancient and modern eras confirm the

\footnotetext{
217 Spiro, "What Is Empathy and Can It Be Taught?," 10; Halpern, From Detached Concern to Empathy: Humanizing Medical Practice, 17; Melanie Neumann et al., "Empathy Decline and Its Reasons: A Systematic Review of Studies With Medical Students and Residents.," Academic Medicine August 2011 86, no. 8 (2011): 996.
} 
universality and timelessness of ethical quandaries. In addition, fictional characters and situations demonstrate the importance of narrative in determining what each individual values most highly in times when difficult choices must be made. Readers are privy to the innermost desires and fears of literary characters in a way that does not often happen in real life but that can nevertheless provide insight into human nature and motivation. Finally, I would argue that discussion of the ethical dilemmas of fictional characters allows students greater freedom to explore their own reactions and responses than do case studies involving actual people. While it is important for readers to form an empathetic connection to fictional characters (most would say this what makes a work moving and meaningful) the absence of real life consequences and time constraints allows the exploration of multiple possibilities and the formation of alternate scenarios and outcomes.

Multiple theoretical constructs come into play within the larger discipline of bioethics, and although the developers and proponents of each seem to believe their own theory is completely sufficient for resolving ethical dilemmas, the fact is that each approach has attributes and shortcomings. Virtue ethics places premium importance on the moral character of medical practitioners, arguing that caregivers should possess specific virtues such as compassion, discernment, trustworthiness, integrity, and conscientiousness, in order to provide competent, ethical care. ${ }^{218}$ Principlism, arguably the theory most often taught and applied, ${ }^{219}$ proposes four principles - autonomy, nonmaleficence, beneficence, and justice - that should guide ethical decision making in

\footnotetext{
${ }^{218}$ Beauchamp and Childress, Principles of Biomedical Ethics, 40.

219 Gert, Culver, and Clouser, Bioethics: A Systematic Approach, 17.
} 
healthcare. ${ }^{220}$ Principlism is a deontological approach to ethics, arguing for the importance of rules of conduct and proper action over aspects of character. Casuistry rejects the idea that a single unified theory can be applied to all ethical dilemmas, and suggests a case-by-case approach that relies on precedents and previously established paradigms. ${ }^{221}$ Narrative Ethics argues that proficient use of any ethical theory requires narrative competence, ${ }^{222}$ i.e., the ability to "recognize, absorb, interpret, and be moved by the stories of illness," 223 and posits that such attention to narrative is not only beneficial, but ethically mandated.

Difficult and binding decisions must often be made in the practice of healthcare, and it is human nature to hope there will be one right answer to complex ethical dilemmas and that this answer can be found if one asks the right questions or knows the right theories. The fact is, however, some disagreements are not perfectly resolvable, and there are often cases where more than one solution is morally acceptable. ${ }^{224}$ It is better, then, to provide students with suitable guides for inquiry and examination than to portray bioethics as a means of finding certainty in the face of moral quandaries. Philoctetes, an ancient Greek drama and $W$; $t$, a Pulitzer Prize winning medical drama, each present ethical dilemmas with solutions that perhaps seem obvious, but upon closer evaluation, prove complex and confounding. Encouraging students to work through any initial certainty as they apply the precepts of bioethical theories to the quandaries presented in the dramas, allows expanded awareness, the practice of critical thinking, and the

\footnotetext{
220 Beauchamp and Childress, Principles of Biomedical Ethics, 12-3.

221 DeGrazia, Mappes, and Brand-Ballard, Biomedical Ethics, 33.

222 Brody, Stories of Sickness, 175, 179.

223 Rita Charon, "Narrative and Medicine," New England Journal of Medicine 350, no. 9 (February 26, 2004): vii.

${ }^{224}$ Gert, Culver, and Clouser, Bioethics: A Systematic Approach, 5.
} 
development of intellectual conscientiousness. But how does consideration of this literature aid in the development of virtuous character?

Examining the goals of ethics education, William Frey discusses the ways in which such education may be used not only to teach the characteristics of virtue, but also the "skills and competencies of moral expertise." 225 In other words, he suggests a pedagogy that goes beyond teaching what it means to be virtuous, and includes the expectation that such knowledge will be internalized, thereby fostering virtuous behavior. But perhaps a more salient question in the debate about whether or not virtue can be taught is; can we make students want to be virtuous? Practically speaking, students who care about developing and maintaining a virtuous character will make use of what this type of pedagogy has to offer while those whose interests lie elsewhere may not. As Ann Marie Begley notes, however, that should not keep us from making an effort to mold virtuous character in those who care for the sick. ${ }^{226}$

In discussing the "pedagogical implications of moral psychology," Frey lists four goals and objectives for teaching virtue:

1. Stimulate the moral imagination of students.

2. Help students recognize moral issues.

3. Help students analyze key moral concepts and principles.

4. Help students to accept the likelihood of ambiguity and disagreement on moral matters, while at the same time attempting to strive for clarity and agreement insofar as it is reasonably attainable. ${ }^{227}$

\footnotetext{
225 William J. Frey, "Teaching Virtue: Pedagogical Implications of Moral Psychology," Science and Engineering Ethics 16, no. 3 (September 1, 2009): 611, doi:10.1007/s11948-009-9164-z.

${ }^{226}$ Ann M. Begley, "Facilitating the Development of Moral Insight in Practice: Teaching Ethics and Teaching Virtue," Nursing Philosophy 7, no. 4 (2006): 260.

227 Frey, "Teaching Virtue," 621.
} 
This pedagogical model recognizes the importance of practicing virtue. It affirms that desiring a virtuous character, while important, is not enough to ensure its presence, especially in the face of conflicting interests and objectives. Developing and maintaining essential virtues requires deliberate attention and intention, skills that can be modeled in the classroom. According to Frey, "Moral skill sets can be taught successfully but require extensive practice accompanied by expert feedback." ${ }^{228}$ Frey describes moral imagination as, "the ability to project into the standpoint of others."229 This skill is not unlike empathy, and it, along with the other three objectives, can be practiced in the classroom using close reading of literature along with written and verbal reflection, as will be demonstrated in the remainder of this chapter.

Sophocles' Philoctetes was first performed in Athens in 409 BCE and won first prize at the festival of Dionysus. ${ }^{230}$ It tells the story of Philoctetes, a hero of the Trojan War made famous in Homer's Iliad. Philoctetes commanded seven ships for the Greeks, but before he ever reached Troy he was bitten by a snake at the temple of the goddess Chryse. His wound was so foul-smelling and his cries of pain so distracting, that Odysseus, commander of the Greek forces, abandoned Philoctetes on the deserted island of Lemnos. ${ }^{231}$

During the tenth year of the Trojan War Odysseus received a prophecy that the Greeks could not win without the invincible bow of Heracles, whose arrows never miss

\footnotetext{
228 Ibid., 618.

229 Ibid.

230 Carlevale, "Education, Phusis, and Freedom in Sophocles' Philoctetes," 28.

231 Judith Affleck, "Commentary," in Philoctetes, Cambridge Translations from Greek Drama (Cambridge: Cambridge University Press, 2001), v.
} 
their target. ${ }^{232}$ Upon his death and apotheosis, Heracles had bequeathed his bow to Philoctetes, the only person brave and compassionate enough to light Heracles' funeral pyre thus ending the suffering Heracles' endured after unknowingly donning a poisoned cloak. ${ }^{233}$ The bow remained with Philoctetes on the island of Lemnos for the ten years of his isolation. As the play opens, Odysseus has returned to Lemnos for the bow, but he knows Philoctetes now despises him, and has thus implored Neoptolemus, son of Achilles, to trick Philoctetes and seize the bow. ${ }^{234}$

Although Philoctetes is perhaps lesser known to general audiences than other Greek tragedies, it might be familiar to journal-reading physicians because of occasional attempts to diagnose the hero's wound. In 1989, Stefano suggested Philoctetes suffered from a venous ulcer. ${ }^{235}$ Grassi, Farina, and Cervini later argued for acute gouty arthritis, and suggested Sophocles was describing his own pain. ${ }^{236}$ In 2000, Bryceson, noted that Grassi et al., "ignore at least five essential points in the case history," and suggested a diagnosis of mycetoma, a fungal infection. ${ }^{237}$ Bryceson goes on to say, "Philoctetes' case illustrates nicely the need to take a careful travel history, and to pay attention to all the patient's complaints." 238 More recently, Horton Johnson diagnosed an infection with staph aureus, ${ }^{239}$ and Mark Powlson countered (perhaps tongue-in-cheek), "Dr. Horton Johnson, in his appraisal of Philoctetes' foot perhaps does not take sufficient account of

\footnotetext{
232 Sophocles, Philoctetes, trans. Judith Affleck, Cambridge Translations from Greek Drama (Cambridge: Cambridge University Press, 2001), line 113.

233 Ibid., l. 649; Affleck, "Commentary," 106.

${ }^{234}$ Sophocles, Philoctetes, 1. 63-75.

${ }^{235}$ C Stefano, "Philoctetes by Sophocles: A Case for Diagnosis," Journal of the Royal College of Physicians of London 23 (1989): 176.

236 Grassi W, Farina A, and Cervini C, "The Foot of Philoctetes.," Lancet (London, England) 354, no. 9196 (1999): 2156-7.

237 Bryceson A, “Philoctetes' Foot.," Lancet (London, England) 355, no. 9206 (2000): 850.

238 Ibid.

${ }^{239}$ Horton A. Johnson, "The Foot That Stalled a Thousand Ships: A Controversial Case from the 13th Century BCE," Journal of the Royal Society of Medicine 96, no. 10 (October 1, 2003): 508.
} 
the malevolence of centaurs ... the underlying cause of the condition was quite probably Burkholderia mallei," ${ }^{240}$ a bacterium that can cause infection in both horses and humans. Urso and Farella note, "Every myth contains an unalterable core, representing its point of contact with reality ... The core of Philoctetes's myth is a disease, which, in the Sophoclean tragedy, is presented in the foreground ... allowing the opportunity to analyze all available elements and to attempt a clinicopathologic investigation, in the hopes of identifying his affliction."241 In an effort to account for all Philoctetes' symptoms, Urso and Farella conclude that he suffered both fungal and bacterial infections as sequelae of the snakebite. ${ }^{242}$

These interpretations of Philoctetes as a case history exemplify a medical tendency to focus on corporeal phenomena at the expense of the many other insights offered by the drama. Approaching physical maladies as puzzles to be solved should not necessarily be discouraged since any sick person hopes for a physician skilled in diagnosis, but much is lost when physical diagnosis is stripped from its narrative context. It is important to remember, however, that these diagnostic approaches to Philoctetes also demonstrate the medical community's desire for practical benefits to the academic study of literature.

A review of the philosophical scholarship related to Philoctetes yields more theoretical observations and has important implications for learning to see beyond the mechanics of illness. Philosophers tend to focus on the moral characteristics of Odysseus and Neoptolemus, or on the wider implications for society as a whole. Two primary

\footnotetext{
${ }^{240}$ Mark Powlson, "Philoctetes," Journal of the Royal Society of Medicine 97, no. 2 (February 1, 2004): 100.

${ }^{241}$ Carmelo Urso and Vittoria Farella, "An Inquiry on Philoctetes's Disease," The AMerican Journal of Dermatopathology 18, no. 3 (1996): 327.

242 Ibid., 329.
} 
ethical dilemmas are presented in Philoctetes. A conflict exists because the Greek army will suffer defeat at the hands of the Trojans unless Philoctetes, with his invincible bow, can be persuaded to join the fight, ${ }^{243}$ but Philoctetes has refused to do so on the grounds that, because Odysseus abandoned him, he owes no debt of loyalty to the Greeks. ${ }^{244}$ The second conflict lies within the character of Neoptolemus, who must choose whether to honor his personal sense of integrity ${ }^{245}$ or his commitment to the Greek army. ${ }^{246}$

Martha Nussbaum has written extensively on the moral implications of Greek tragedy, and views Philoctetes as a man "undeserving of his misfortune, and who tells us explicitly that similar misfortunes might befall any human being." ${ }^{247}$ Nussbaum asserts that Odysseus seeks to use Philoctetes as a means to an end and considers this a consequence of living "in a world of moral blindness." ${ }^{248}$ She finds in Philoctetes a victim worthy of sympathy because he has retained his agency in the face of horrendous circumstances noting, "Philoctetes retains the capacity for friendship that eventually wins him his cure."249

In a closer examination of the character of Odysseus, Nussbaum writes,

I would like to argue that Sophocles portrays Odysseus as a man who accords ultimate value to states of affairs, and, specifically, to the state of affairs which seems to represent the greatest possible good of all citizens. He gives his approval to any action which he believes will best promote the general welfare, and resists the argument that there are certain actions which should not be done by an agent because of his character and principles, decrying this view as a form of squeamishness. ${ }^{250}$

\footnotetext{
243 Sophocles, Philoctetes, 66.

244 Ibid., 1245-50.

245 Ibid., 1048-9.

246 Ibid., 109-115.

247 Martha Craven Nussbaum, “Invisibility and Recognition: Sophocles' Philoctetes and Ellison's Invisible Man," Philosophy and Literature 23, no. 2 (1999): 259.

248 Ibid., 261.

249 Ibid., 262.

250 Nussbaum, "Consequences and Character in Sophocles' Philoctetes," 30.
} 
Although Nussbaum recognizes Odysseus' concern for the general welfare of others, she also notes, "The social system administered by an Odyssean is characterized by great emphasis on secrecy and plotting, together with a demand for blind obedience from the non-rulers. ${ }^{251}$ One could also make the case, however, that this is what we expect from a good leader - a strong grasp of the intricacies of human nature, and a willingness to stay focused on the larger picture, in this case, the welfare of the Greek army and consequently, of all the Greeks. G. J. Warnock explains the utilitarian philosophy of morality as follows; "An action is morally right if, and only if, it produces at least as great a balance of value over disvalue as any available alternative action." ${ }^{252}$ Seen in this light, Odysseus's concern for the welfare of the Greeks over that of Philoctetes is a morally right action.

In combing the play for insights into political justice, Aristide Tessitore notes the conflict between justice that seeks the common good and justice that provides retribution. ${ }^{253}$ Philoctetes' own sense of justice underlies his motivation for refusing to accompany Neoptolemus and seek treatment for his wound. 254 According to Tessitore, because Philoctetes sees the system of reward and punishment as the duty of the gods, his refusal to accompany Odysseus becomes a religious objection. ${ }^{255}$ Odysseus, on the other hand, expresses a more utilitarian and consequentialist view of justice in which victory

\footnotetext{
251 Ibid., 38.

252 G. J. Warnock, "The Object of Morality," in Philosophical Ethics: An Introduction to Moral Philosophy, 2nd ed. (New York: McGraw-Hill, 1991), 35.

${ }^{253}$ Aristide Tessitore, “Justice, Politics, and Piety in Sophocles' 'Philoctetes,'” The Review of Politics 65, no. 1 (2003): 61.

254 Sophocles, Philoctetes, 1. 1070-76.

255 Tessitore, “Justice, Politics, and Piety in Sophocles' ‘Philoctetes,"” 76.
} 
must be sought by any means possible. ${ }^{256}$ The character of Neoptolemus has yet another view of justice.

In his state of disability and disease we can, as the previously mentioned medical writers have done, consider Philoctetes a patient. Neoptolemus, the only character to acknowledge Philoctetes' needs in addition to those of the Greeks, becomes his potential caregiver. In addition, Neoptolemus pledges his assistance to Philoctetes when Philoctetes is at his most vulnerable, promising to stay with Philoctetes and guard his bow while Philoctetes is incapacitated by a spasm of pain:

PHILOCTETES: Oh, child! Take courage. Its attacks are sharp, but they are quickly over. Please, I beg you, don't leave me on my own. NEOPTOLEMUS: Don't worry, we'll wait. PHILOCTETES: You will? NEOPTOLEMUS: Be sure of it.

PHILOCTETES: I feel it's not right to place you under oath, child.

NEOPTOLEMUS: Just as it would be wrong for me to go without you.

PHILOCTETES: Give me your hand on it.

NEOPTOLEMUS: My hand says I will wait. ${ }^{257}$

This verbal contract signifies Neoptolemus' intention to care for Philoctetes and affirms that he considers his obligation binding. While the term 'justice' defies a singular definition, the principle of justice as outlined by proponents of principlism refers more specifically to distributive justice, defined by Beauchamp and Childress as, "fair, equitable, and appropriate distribution determined by justified norms that structure the terms of social cooperation."258 Yet, even if we confine our consideration of justice to the distributive realm, there are still multiple theories that "attempt to connect properties

\footnotetext{
256 Ibid., 66.

257 Sophocles, Philoctetes, 811-21.

258 Beauchamp and Childress, Principles of Biomedical Ethics, 241.
} 
of persons with morally justifiable distributions of benefits and burdens. ${ }^{259}$ Marooning Philoctetes on an uninhabited island reduces the burden of his illness to a single person, which may be considered a just action, but it also subverts the principle of autonomy, or Philoctetes' ability to act "freely in accordance with a self-chosen plan,"260

In addition, we must concede that what Philoctetes deems beneficent, to be returned to his homeland without ever again visiting Troy, ${ }^{261}$ Neoptolemus knows to be a most unhelpful course of action. ${ }^{262}$ Beauchamp and Childress define the principle of beneficence as "the moral obligation to act for the benefit of others," 263 and further state, “Promoting the welfare of patients - not merely avoiding harm - embodies medicine's goal, rationale, and justification."264 Recognizing his own frustration with Philoctetes' adamant refusal to accept the help being offered, Neoptolemus initially considers whether his agreement with Philoctetes remains binding, and tells Philoctetes, "People who cling to self-inflicted injuries, like you, have no right to anyone's sympathy or pity."265 Neoptolemus is not referring to the wound as self-inflicted, but to the unnecessary continuation of Philoctetes' suffering. Neoptolemus reminds Philoctetes that it is possible to maintain his autonomy and still provide help to the Greeks,

You will never find rest from this sickening affliction as long as the sun continues to rise and set where it does, unless you go of your own free will to the plain of Troy, meet with the sons of Asclepius who are with us there, and find relief from this disease; you, together with these

\footnotetext{
259 Ibid., 244.

260 Ibid., 99.

261 Sophocles, Philoctetes, 1. 1468-72.

262 Ibid., 1401-3, 1455-6.

263 Beauchamp and Childress, Principles of Biomedical Ethics, 197. Italics original.

264 Ibid., 205.

265 Sophocles, Philoctetes, 1. 1389-91.
} 
weapons and my help, will be known as the one who sacked the citadel. ${ }^{266}$

Philoctetes acknowledges Neoptolemus' good intentions, but continues to believe it would be wrong to fight on behalf of those who have shown him such tremendous dishonor. He entreats Neoptolemus, "When you took my right hand, you vowed you would take me home. Do that for me, child." 267 After being reminded of his duty, Neoptolemus agrees and in return Philoctetes promises to use his invincible bow to protect Neoptolemus and his homeland from the wrath of the Greeks. ${ }^{268}$ Although Neoptolemus has honored both his commitment to Philoctetes and Philoctetes' autonomy, his actions have placed the entire Greek army, as well as himself and the people of his homeland, in grave danger. Many would argue against the wisdom of this decision, and they would not be wrong. Neoptolemus' actions toward Philoctetes display beneficence and respect Philoctetes' autonomy, but they nevertheless place a great many others at risk, thereby subverting the principle of justice.

At first glance, a reader might agree completely with Neoptolemus' assertion that Philoctetes' behavior is utterly selfish and does not warrant the devotion of his potential caregiver. In fact, Philoctetes has been discussed as a non-compliant patient with an attachment to misery whose attitudes sabotage his own healing. ${ }^{269}$ But his unwavering refusal to accompany Neoptolemus to Troy does contain a small grain of altruism. As

\footnotetext{
266 Ibid., l. 1398-1404.

267 Ibid., l. 1468-70.

268 Ibid., l. 1476-83.

${ }^{269}$ Richard M. Gottlieb, "Refusing the Cure: Sophocles's Philoctetes and the Clinical Problems of SelfInjurious Spite, Shame and Forgiveness ${ }^{1}$," The International Journal of Psychoanalysis 85, no. 3 (2004): 669.
} 
Philoctetes makes clear, his animosity toward Odysseus goes beyond the personal, and includes a wish never to see such a man in charge of the wellbeing of others. ${ }^{270}$

Considering Philoctetes through the lens of principlism might lead us to side with Odysseus and deem as most worthy the actions that benefit the greatest number of people. We might conclude that the principle of justice overrides the principle of autonomy in this case, especially since it appears that Philoctetes' desires come, at least in part, from a place of prideful arrogance. The principle of autonomy is the driving force behind the rules of informed consent and is often considered a safeguard against medical paternalism, but it "is not excessively individualistic (thereby neglecting the social nature of individuals and the impact of individual choices and actions on others)"271

Encouraging students to consider Odysseus's actions through the lens of principlism allows them to reflect upon the concept of duty as it relates to ethical decision-making. Odysseus was bound by his duty to the Greek army and this influenced both his decision to abandon Philoctetes and his decision to retrieve the bow through subterfuge. Neoptolemus is unable to accept this course of action, however, because it conflicts with his perception of personal virtue. ${ }^{272}$

Describing the characteristics of virtue ethics, Pellegrino writes,

Virtue theories focus on the agent; on his or her intentions, dispositions, and motives; and on the kind of person the moral agent becomes, wishes to become, or ought to become as a result of his or her habitual disposition to act in certain ways. . . In a purely virtuebased ethic, the normative standard is the good person, the person

\footnotetext{
270 Sophocles, Philoctetes, 1. 1424-5.

271 Beauchamp and Childress, Principles of Biomedical Ethics, 99.

272 Mary Whitlock Blundell, "The Phusis of Neoptolemus in Sophocles' Philoctetes," Greece and Rome 35, no. 02 (1988): 138.
} 
upon whom one can rely habitually to be good and to do the good under all circumstances. ${ }^{273}$

Acknowledging the problem of what one defines as good in a general sense, Pellegrino nevertheless argues that it is possible to determine what is good within the discipline of healthcare, ${ }^{274}$ and also observes that the application of any kind of bioethical theory will continue to "depend on the kind of persons carrying out the moral acts and their analyses." 275 Pellegrino believes it is reasonable to expect healthcare providers to be virtuous because of the unique nature of the caregiver-patient relationship; "The promise made to the dependent patient directs the knowledge, techniques, and personal commitment of the physician or nurse to the telos of the relationship - helping and healing." ${ }^{276} \mathrm{He}$ lists seven essential virtues for healthcare providers: fidelity to trust and promise, benevolence, effacement of self-interest, compassion and caring, intellectual honesty, justice, (which he describes as a covenant between caregiver and patient rather than a commitment to distributive justice) and prudence. ${ }^{277}$ Pellegrino does not suggest virtuous character as the single determinant of ethical behavior, and points out that every "moral event" will involve "the agent, the act, the circumstance, and the consequence," but nevertheless argues for attention to and cultivation of virtue in healthcare providers. ${ }^{278}$

Returning to Philoctetes, we may consider the actions of Odysseus and Neoptolemus through the lens of virtue ethics as described by Pellegrino, and we may use

\footnotetext{
273 Edmund D. Pellegrino, "Toward a Virtue-Based Normative Ethics for the Health Professions," Kennedy Institute of Ethics Journal 5, no. 3 (1995): 254, doi:10.1353/ken.0.0044.

274 Ibid., 263-4.

275 Ibid., 266.

276 Ibid., 267.

277 Ibid., 268-70.

278 Ibid., 273.
} 
this relationship as a means of realizing Frey's pedagogical objectives. As commander of the army, Odysseus is not obligated to care for Philoctetes; his duty lies with his army. While his treatment of Philoctetes is not ideal, Odysseus sees it as necessary because Philoctetes' wound and cries of pain demoralized his soldiers and made it impossible for them to carry out the religious rituals that were required for victory. ${ }^{279}$ Neoptolemus, on the other hand, accepts a different form of duty when he agrees to care for Philoctetes during his incapacitating spasm.

Philoctetes entrusts his bow to Neoptolemus during this crisis in his illness, and Odysseus insists that Neoptolemus keep the bow and return to the Greek ships. This will be a death sentence for Philoctetes, who will now be unable to hunt for food. ${ }^{280}$ After numerous failed attempts to convince Philoctetes to rejoin the army, Neoptolemus reluctantly takes the bow and leaves with Odysseus. He turns back almost immediately, however:

ODYSSEUS: Tell me why you've turned back? Where are you going in such a rush?

NEOPTOLEMUS: I am going to undo a mistake I made earlier. ODYSSEUS: Your words alarm me. What mistake is this?

NEOPTOLEMUS: One I made in obedience to you and the whole army.

ODYSSEUS: What have you done that you shouldn't have?

NEOPTOLEMUS: I used shameful deception and trickery in catching him. ${ }^{281}$

Odysseus threatens to come after Neoptolemus with "every man in Greece," and proclaims Neoptolemus' words and actions most unwise, ${ }^{282}$ to which Neoptolemus

\footnotetext{
279 Sophocles, Philoctetes, l. 5-9.

280 Ibid., l. 1142.

281 Ibid., l. 1272-80.

282 Ibid., l. 1300, 1302.
} 
replies, "Perhaps not wise, but they are just - and that matters more than wisdom."283 This exchange perfectly exemplifies the concept of virtue according to Pellegrino. Neoptolemus considered his relationship with Philoctetes and the preservation of his own virtuous character of greater importance than his duty to Odysseus and the Greeks. In his actions, Neoptolemus displays each of the seven essential virtues outlined by Pellegrino, and thus can be said to have behaved virtuously within the context of his relationship, but this does not negate the negative consequences of his actions for everyone except Philoctetes. Our evaluation of Neoptolemus' decision will change depending upon whether we consider him a soldier of the Greek army or a friend to Philoctetes - in this case it seems he cannot behave virtuously in both roles simultaneously. Neoptolemus declares his intention in line 1472 and following when he agrees to return Philoctetes to his homeland even as he becomes fearful of the danger this will create for him and his countrymen.

Encouraging students to consider the contrast between Odysseus' duty-based approach to decision making and Neoptolemus' adherence to a more personal code of morality meets Frey’s pedagogical objectives of helping students recognize moral issues and analyze moral concepts and principles. The presence of ambiguity and disagreement also becomes clear, but the exercise of moral imagination allows students to contemplate their own construct of virtue. What aspects of character would they be unwilling to compromise even if duty required it?

Proponents of virtue ethics have considered the conduct of "moral exemplars," “individuals who reach and sustain outstanding moral conduct throughout their

283 Ibid., 1. 1303-4. 
professional or occupational careers, ${ }^{284}$ as a possible source of insight for the development of virtue. As Edmund L. Erde has noted, "Persons concerned with medical education sometimes argued that medical students need no formal education in ethics. They contended that if admissions were restricted to persons of good character and those students were exposed to good role models, the ethics of medicine would take care of itself." ${ }^{285}$ As with any profession, however, it is difficult to judge the character of every person seeking to enter and not all practitioners can be considered good role models. Students who consider virtuous character an important aspect of their practice may nevertheless hope to find a moral exemplar to consult and emulate. It is necessary, therefore, to consider the attributes of such a person. Discussion of the ways Neoptolemus displays (or does not display) Pellegrino's seven essential virtues allows students to reflect upon the qualities they consider essential in a role model. Students should be cautioned against hoping to find a moral exemplar that never makes mistakes, and should be encouraged instead to consider how an exemplar handles the inevitable human failings.

The moral dilemmas of Philoctetes are resolved with a deus-ex-machina; Heracles himself appears just as Neoptolemus and Philoctetes are preparing to leave the island and return to Philoctetes' homeland. Heracles promises to send Asclepius, Greek god of medicine and healing, to treat Philoctetes' wound and vows that only Philoctetes and Neoptolemus, working together, will bring about the downfall of Troy. He promises victory and glory to both of them so long as they look out for each other and show proper

\footnotetext{
284 Frey, “Teaching Virtue," 612.

${ }^{285}$ Edmund L. Erde, "The Inadequacy of Role Models for Educating Medical Students in Ethics with Some Reflections on Virtue Theory," Theoretical Medicine 18 (1997): 31.
} 
reverence to the gods. Neoptolemus and Philoctetes agree to this course of action and depart the island together. ${ }^{286}$

Gill interprets the appearance of Heracles as a reward for Neoptolemus' virtuous behavior, ${ }^{287}$ but Parham sees in Heracles a moral exemplar whose edicts both Philoctetes and Neoptolemus are willing to follow; "While Heracles has divine authority, he does not persuade by argument but by example. His fame, his divinity, come from his suffering. As the inheritor of his bow Philoctetes too must suffer and triumph."288 As a moral exemplar, Heracles requires three things of Philoctetes: that he humble himself enough to accept the healing of Asclepius, ${ }^{289}$ that he protect Neoptolemus as Neoptolemus has protected him, ${ }^{290}$ and that he show due reverence to the gods for his victory. ${ }^{291}$ This attention to self-effacement, to relationship, and to respect may be seen as traits to seek out and emulate in a moral exemplar.

However we interpret the deus ex machina, it remains true that no completely satisfactory solution was achievable without it and we must accept the fact that this is the case with virtually all bioethical dilemmas, otherwise they would not be dilemmas. Students should be encouraged to find some means of empathetic engagement with all three characters of Philoctetes and to carefully consider what each deems most important. My observation in teaching Philoctetes is that some students admire Neoptolemus' decision while others find it quite troubling. Many students admire Odysseus' devotion to those under his command, and some find Philoctetes' self absorption difficult to

\footnotetext{
286 Sophocles, Philoctetes, 1. 1485-1517.

287 Christopher Gill, “Bow, Oracle, and Epiphany in Sophocles' Philoctetes," Greece and Rome 27, no. 02 (1980): 144.

288 Parham SF, “Philoctetes' Wound.," Literature and Medicine 9 (1990): 18.

289 Sophocles, Philoctetes, 1. 1498-9.

290 Ibid., 1. 1511-2.

291 Ibid., l. 1514-6.
} 
tolerate. The objective in studying this drama is self-reflection, inquiry, and some level of comfort with uncertainty and imperfect outcomes as well as a basic understanding of virtue and principles.

Turning our attention to $W$; $t$, a more contemporary medical drama, we perhaps find the opposite of a moral exemplar, as the play includes several characters who clearly demonstrate how not to behave. $W$; $t$, reflects every single negative stereotype of healthcare in the United States: institutions in which no thought is given to human comfort, doctors who are callous and arrogant, and nurses who are kind but not terribly intelligent. Yet it won the Pulitzer Prize for drama in 1999, suggesting a resonance with the non-medical jury of theater critics who must have seen its "dealing with American life" as accurate. ${ }^{292}$ In 2002, HBO produced a film version directed by Mike Nichols that utilized a near word-for-word adaptation of the script and starred prestigious actors Emma Thompson, Christopher Lloyd, and Audra McDonald. ${ }^{293}$ Roger Ebert referred to it as one of the best films of 2002 and noted, "The movie is merciless in showing how hospital routine robs [Bearing] of her dignity."294 The play continues to be staged frequently and was part of the 2015 season at the Boston Center for American Performance. ${ }^{295}$

In spite of its obvious popularity with critics and the general public, the play's depiction of healthcare and healthcare providers is problematic for reasons that go beyond negative stereotypes. As noted by bioethicist Dr. Osborne Wiggins, any

292 “The 1999 Pulitzer Prize Winners: Drama,” The Pulitzer Prizes, accessed September 9, 2015, http://www.pulitzer.org/citation/1999-Drama.

293 Mike Nichols, Wit, DVD (Burbank: HBO Films, 2010).

294 Roger Ebert, “When a Movie Hurts Too Much | Roger Ebert's Journal | Roger Ebert," accessed November 1, 2015, http://www.rogerebert.com/rogers-journal/when-a-movie-hurts-too-much. 295 http://www.bu.edu/cfa/bcap/wit.html 
Institutional Review Board would have prohibited the research being conducted by the play's physicians, which renders the medical premise of the play erroneous. ${ }^{296}$ In addition, medical ethics (and common courtesy) would prohibit a physician from performing a pelvic exam on a woman with whom he was socially acquainted. Finally, the nurse, Susie, appears to work all shifts in all areas of the hospital, which is completely illogical.

Edson drew the inspiration for $W$; $t$ from her work as a unit clerk on an oncology floor of a large research and teaching hospital, ${ }^{297}$ and her depiction of physicians has come under scrutiny. Writing for The Annals of Internal Medicine, Faith McLellan, PhD (but not MD) notes, "Doctors come in for a deserved hit, as they treat their patient as an object, a research subject held at arm's length,"298 but, many physicians feel undeservedly singled out for ridicule. Writing for the New York Times, Abigail Zuger, MD, recalls feeling depressed after "watching yet another scathing indictment of modern medicine and the dubious habits by which some of us are either fortunate or unfortunate enough - take your pick - to earn our keep." ${ }^{299}$ In the article, Zuger offers quotations from other physicians. Sherwin B. Nuland, professor of surgery at Yale University states, "The doctor roles are stick figures, straw men, caricatures of the worst, completely unrealistic,"300 and Larry Norton, head of medical oncology at Sloan-Kettering insists, "People think clinical research is removed from the patient, but it's the absolute opposite.

\footnotetext{
296 Osborne Wiggins, October 13, 2015.

297 Charles McGrath, "Margaret Edson, Author of 'Wit,' Loves Teaching," The New York Times, February 16, 2012, http://www.nytimes.com/2012/02/19/theater/margaret-edson-author-of-witloves-teaching.html.

298 Faith McLellan, “W; T," Annals of Internal Medicine 131, no. 9 (November 2, 1999): 718, doi:10.7326/0003-4819-131-9-199911020-00030.

${ }^{299}$ Abigail Zuger, "When the Patient, Not the Doctor, Becomes the Hero.," New York Times 148, no. 51372 (December 15, 1998): F4. 300 Ibid.
} 
Our goal is to make sure that every patient in the study gets the best possible care... I'm saddened by the fact that the doctor is never well-represented. What we do and what we are and what we have to deal with has never been captured by art. It's a shame."301 As a member of the healthcare community myself, I am inclined to agree that the physician characters in $W ; t$ are not accurate representations. I feel it is important to tell students that, in all my years as a nurse, I never saw a physician behave with such complete disregard for patient well-being as those depicted in in this play. I believe Edson has created composite characters in Kelekian and Posner, and that they represent the worst possible combination of moral failures. I contend, however, that despite its inconsistencies and medical inaccuracies, this play has something to offer scholars and students of medical humanities.

Rita Charon acknowledges, "I hated the play the several times I saw it. I felt attacked by what I considered to be a crude and one-dimensional caricature of doctors and nurses. I felt defensive in the face of the wholesale blaming of medicine as a cruel enterprise." 302 But Charon could not ignore the overwhelmingly positive public response to the play and conceded, "Patients and their families seeing performances of Wit felt recognized or even vindicated by the play's savage portrayal of contemporary health care because, I suspect, such inhumane and therefore ineffective care is enacted every day in hospitals everywhere." 303 I disagree with Charon's generalization - acknowledging the appeal of the play does not mean we have to accept its portrayal of healthcare as accurate - but we must accept that Edson has captured the experience of being a patient in a way that resonates as authentic and we must consider what this should mean to healthcare

\footnotetext{
301 Ibid.

${ }^{302}$ Charon, Narrative Medicine: Honoring the Stories of Illness, 18.

${ }^{303}$ Ibid., 19.
} 
providers. If we become defensive and disregard the play because of its inaccuracies, we miss an opportunity for growth and enlightenment.

$W ; t$ is, at its core, about power and powerlessness. Vivian Bearing, the cancer stricken protagonist, is a brilliant woman, the foremost scholar in her field of study, yet her knowledge and expertise are useless in a world where her very life is at stake. This explains the appeal of the play to general audiences who have already felt, or fear a time when they will feel, at the mercy of a medical world in which their own knowledge and wisdom are useless, or worse, discounted. Roger Ebert writes of reviewing the movie positively prior to his own cancer diagnosis, but of being unable to watch it after, "I remembered it too clearly, perhaps, and dreaded re-living it ... I have had cancer, and had all too many hours, days and weeks of hospital routine robbing me of my dignity." 304 Ebert was not confirming the veracity of the conduct and situations depicted in the play, but rather the truth of the experience of powerlessness and loss of dignity experienced by patients. This is what caregivers must seek to understand and to prevent.

The protagonist of the script is Vivian Bearing, a university professor and preeminent scholar of the metaphysical poet John Donne. ${ }^{305}$ Vivian is diagnosed with stage four metastatic ovarian cancer and the primary setting of the play is "the University Hospital Comprehensive Cancer Center" where she receives treatment. ${ }^{306}$ The title, with semicolon, comes from an observation by Vivian's mentor, renowned Donne scholar E. M. Ashford, and references an "inauthentically punctuated translation" of Holy Sonnet Six in which the deeper meaning of the sonnet is lost when a semicolon replaces a

\footnotetext{
${ }^{304}$ Ebert, "When a Movie Hurts Too Much | Roger Ebert's Journal | Roger Ebert." ${ }^{305}$ Edson, $W ; t, 17$.

306 Ibid., 4.
} 
comma in the final stanza of the poem. ${ }^{307}$ According to Ashford, the semicolon represents an "insuperable barrier" between life and death, when in fact, "Nothing but a breath - a comma - separates life from life everlasting." ${ }^{308}$ In $W$; $t$, this semicolon may be seen as representing the insuperable barriers between the sick and the healthy, caregivers and their patients.

Vivian has devoted her entire life to the study of Donne's poetry and recalls herself as a cold and uncompromising professor who only now, at the end of her life, recognizes the importance of compassion and human connection. As the play begins Vivian discloses, "Now, I suppose we shall see, through a series of flashbacks, how the senior scholar ruthlessly denied her simpering students the touch of human kindness she now seeks." 309 Vivian draws parallels between her own interactions with students and the similarly impersonal relationships she has with her doctors, Harvey Kelekian, attending physician and chief of medical oncology, and Jason Posner, Vivian's former student, and the young medical resident working with Kelekian. ${ }^{310}$ Vivian's primary nurse is Susie Monahan, RN, BSN. ${ }^{311}$ Susie is the only caregiver that attempts to understand something of Vivian beyond her disease.

Late in Vivian's treatment cycle, when her digestive system has been virtually destroyed by chemotherapy, Susie brings Vivian a Popsicle and broaches the topic of Vivian's code status. After their conversation Vivian muses, "That certainly was a maudlin display. Popsicles? "Sweetheart"? I can't believe my life has become so ... corny. . we are discussing $m y$ life and $m y$ death, and my brain is dulling, and poor

\footnotetext{
307 Ibid., 13.

308 Ibid., 14.

309 Ibid., 59.

310 Ibid., 58, 21.

311 Ibid., 3.
} 
Susie's was never very sharp to begin with . .."312 As Vivian nears the end of her life she realizes that an uncompromising attention to scholarly detail has left her without the emotional resources to contemplate her own mortality. She muses,

(Quickly) Now is not the time for verbal swordplay, for unlikely flights of imagination and wildly shifting perspectives, for metaphysical conceit, for wit.

And nothing would be worse than a detailed scholarly analysis. Erudition. Interpretation.

Complication.

(Slowly) Now is a time for simplicity. Now is a time for, dare I say it, kindness. ${ }^{313}$

There are numerous moral lapses in the story, the most glaring of which is the fact that Vivian's physicians never tell her that her cancer is terminal. Instead, she is encouraged to consent to a horrific course of chemotherapy, ostensibly in the hope of a cure:

KELEKIAN: The important thing is for you to take the full dose of chemotherapy. There may be times when you'll wish for a lesser dose, due to the side effects. But we've got to go full-force. The experimental phase has got to have the maximum dose to be of any use. Dr. Bearing -

VIVIAN: Yes?

KELEKIAN: You must be very tough. Do you think you can be very tough?

VIVIAN: You needn't worry.

Only near the end of the play does Vivian realize she will not recover. ${ }^{314}$ Shortly before Vivian's death, Posner acknowledges the true purpose of her treatment was not to attempt a cure, but to document the physical effects of full dose chemotherapy; "Eight

\footnotetext{
312 Ibid., 69. Italics original. The phrase "my brain is dulling, and poor Susie's was never very sharp to begin with" is omitted in the film version of Wit. Also absent is the "giggling," a stage direction for Susie on p. 73 of the script. The effect of these omissions coupled with the masterful portrayal of Susie by Audra McDonald, is a depiction of an intelligent and skillful nurse rather than one who is kind but stupid. See: Nichols, Wit. ${ }^{313}$ Edson, $W ; t, 69$. Italics original. ${ }^{314}$ Ibid., 66.
} 
cycles of Hex and Vin at the full dose. Kelekian didn't think it was possible. I wish they could all get through it a full throttle. Then we could really have some data." 315

That Vivian was not fully informed of the nature of her illness or the purpose of her treatment denied her necessary information for consent and was a clear breach of the principle of autonomy. When considering the suffering induced by the course of treatment Vivian endures, Kelekian and Posner's actions may be seen not only as nonbeneficent, but also as maleficent in the extreme.

The physicians consistently fail to demonstrate any of Pellegrino's essential virtues for healthcare providers, and Susie, who has shown deep compassion and benevolence, fails to demonstrate intellectual honesty or fidelity to the trust Vivian has placed in her. Susie is aware of the deception perpetrated by the physicians, but does not share this information with Vivian until shortly before Vivian's death when she confesses, “There just isn't a good treatment for what you have yet, for advanced ovarian. I'm sorry. They should have explained this - "316 This scene presents an excellent opportunity to discuss situations in which a caregiver might be expected to behave in a way that violates her moral consciousness. Inviting the use of moral imagination, students can be asked to consider why an otherwise compassionate nurse might withhold information from her patient? Did she hope to protect Vivian somehow, or did she fear losing her job, as was the case when Jason performed the pelvic exam on Vivian in spite of his extreme discomfort? Where does Susie's duty lie, with her patient or with her employer? This is an ideal opportunity to request written reflections from students. They may be asked to reflect upon the obligations incurred when one accepts certain types of

\footnotetext{
315 Ibid., 75.

316 Ibid., 67.
} 
employment - for example, should pharmacists opposed to abortion be required to dispense Plan B? Or they might be asked to consider a time when they felt powerless in the face of authority.

According to the script, Vivian has no family and only one visitor throughout the eight-month course of her treatment. Like her physicians, Vivian is a researcher, devoted to the pursuit of knowledge and excellence in her field. ${ }^{317}$ Had anyone discussed the true nature of her illness and the need for medical research, there is a distinct possibility Vivian would still have agreed to participate. The physicians could not have known this, however, without knowing something of Vivian's narrative, specifically, her own lifelong quest for knowledge and information.

One of the most difficult tasks any caregiver faces is that of attempting to ascertain, often in only a matter of minutes, exactly what type and amount of information will be beneficial to the patient. Navajo Indians, for example, refuse to speak of death and believe that only someone who intends to bring it about would presume to discuss it, which means the subject of advance directives must be approached very carefully. ${ }^{318}$ Some patients prefer a "straight shooter" who provides factual results exactly as they are discovered, while others cope principally through some form of positive thinking and do not wish to hear of potentially negative outcomes. Many patients have strong familial or social support systems, while others must cope with healthcare issues alone. Often, patients will have some degree of medical knowledge gleaned from the internet or other sources, and may believe this information more accurate than what they hear from an unfamiliar caregiver. Maintaining patient autonomy dictates that all relevant information

317 Ibid., 18-20.

318 Ben Daitz, "On Navajo Reservation, Poem Helps Broach Topic of End-of-Life Care," The New York Times, January 24, 2011, sec. Health, http://www.nytimes.com/2011/01/25/health/25navajo.html. 
be provided to the patient, but decisions regarding the timing and manner in which this is done become the responsibility of the caregiver and are best undertaken with some knowledge of the patient's desires, support system, and knowledge base.

When speaking to Vivian about her options for end of life care, Susie offers the choices of "full code" and "Do Not Resuscitate," telling Vivian, "I wanted to present both choices before Kelekian and Jason talk to you." ${ }^{319}$ When Vivian asks whether Susie and the doctors disagree on the appropriate choice, Susie replies, "Well, they like to save lives. So anything's okay, as long as life continues ... they always want to know more things." 320 Vivian's response to this statement provides significant insight to her hopes and motivation: "I always want to know more things. I'm a scholar. Or I was when I had shoes, when I had eyebrows." 321 This leads the reader to wonder whether Vivian would have agreed to the chemo, perhaps even found meaningful purpose in the research, even if she had known there was no hope for a cure. The actions of both physicians throughout the play are utterly callous and inexcusable, but Vivian's words provide a subtle and poignant reminder of the ethical imperative of narrative practice. Beneficent care requires eliciting a patient's narrative and confirming some understanding of the patient's wishes. Narrative ethics mandates attention to the stories of patients' lives as the primary means of providing competent healthcare. ${ }^{322}$ In point of fact, no ethical decision can be made in the absence of narrative. Respect for the bioethical principles of autonomy and beneficence require knowledge of what the patient considers most

\footnotetext{
319 Edson, $W ; t, 67$.

320 Ibid., 68.

321 Ibid.

322 Rita Charon and Martha Montello, eds., Stories Matter: The Role of Narrative in Medical Ethics, Reflective Bioethics (New York: Routledge, 2002), ix.
} 
important in his or her care and such knowledge cannot be obtained without establishing a trusting relationship with the patient.

$W ; t$ opens with a presentational monologue in which Vivian addresses the audience and describes her interactions with her physicians:

VIVIAN: (In false familiarity, waving and nodding to the audience) Hi. How are you feeling today? Great. That's just great ... I have been asked "How are you feeling today?" while I was throwing up into a plastic washbasin. I have been asked as I was emerging from a four-hour operation with a tube in every orifice, "How are you feeling today?"

I am waiting for the moment when someone asks me this question and I am dead.

I'm a little sorry I' 11 miss that. ${ }^{323}$

This monologue exemplifies the impersonal treatment Vivian receives from her

physicians throughout the play beginning with her diagnosis:

VIVIAN: I'll never forget the time I found out I had cancer. (DR. HARVEY KELEKIAN enters at a big desk piled high with papers) KELEKIAN: You have cancer.

VIVIAN: (To audience) See? Unforgettable. It was something of a shock. I had to sit down. (She plops down.) KELEKIAN: Please sit down. ${ }^{324}$

At no time does either physician attempt more than a cursory interaction with Vivian, and Posner makes it clear that even this is simply a burdensome obligation:

JASON: Compromised kidney function is a highly complex reaction. I'm simplifying it for you.

VIVIAN: Thank you.

JASON: We're supposed to.

VIVIAN: Bedside manner.

JASON: Yeah, there's a whole course on it in med school. It's required. Colossal waste of time for researchers. (He turns to go. $)^{325}$

\footnotetext{
${ }^{323}$ Edson, $W ; t, 5$.

324 Ibid., 7.

325 Ibid., 55.
} 
When Jason conducts a pelvic exam on Vivian, his former professor, Vivian describes the experience as "degrading," and part of what she terms "learning to suffer." ${ }^{326}$ Healthcare workers familiar with common practice will no doubt find this scene implausible, but Edson is taking a bit of poetic license to highlight a point about the degradation patients may experience at the hands of unfeeling caregivers. Edson presents Kelekian and Posner as socially inept, caring only for the results of their research, and even this is not because of the good they might do, but simply because they are fascinated by the attributes of cancer on a cellular level. ${ }^{327}$ It is the absence of empathy that is so striking in both physicians. We are given the impression they've been taught "bedside manner" as an obligatory course without being taught any sense of why it actually matters to a patient. This illustrates the importance of encouraging students to practice empathetic engagement by imaginatively placing themselves in situations faced by fictional characters and attempting to understand their needs. Might Kelekian and Posner have behaved differently if their course on bedside manner had required them to reflect upon the experience of Ivan Illych, for example, or a similar figure from the literature and medicine canon? Many physicians report changes in their bedside manner after a personal experience of illness or injury, ${ }^{328}$ and the character of Vivian in $W$; certainly demonstrates the power of personal suffering to incite a previously undeveloped compassion for others, but making use of moral imagination in the empathetic engagement with literary characters allows a similar, if less profound, enlightenment. ${ }^{329}$

\footnotetext{
326 Ibid., 31-2.

327 Ibid., 56-7.

328 Oliver Sacks' A Leg to Stand On may be the best known example of physicians writing about this topic: Oliver Sacks, A Leg to Stand On, Touchstone (New York: Touchstone, 1998).

329 Rosenblatt, Literature as Exploration, 173.
} 
In her discussion of the possibilities for moral growth, Judith Andre notes, "The more sensitive one is to the effects of one's behavior on others, the more one is likely to help." ${ }^{330}$ She goes on to say that "becoming a sensitive observer is a "complex task" that requires "self-awareness and understanding." 331 Finally, and most salient for a medical humanities pedagogy, she suggests that the practice of moral reasoning be broadened to include the practice of moral reflection;

[Moral reflection] includes the consideration of myth and metaphor, attention to one's nagging doubts and suspect enthusiasms, and the use of moral imagination. Besides making real another person's point of view, moral imagination helps us think of creative alternatives that would allow us to avoid the horns of a dilemma. It makes us think about the conditions that led to the quandary, to do what is called "preventive ethics." 332

It is possible that Kelekian and Posner lack the milk of human kindness in part because they have never engaged in the self-reflection required to understand the needs of others. Vivian was similarly cold and insensitive until the loneliness and isolation of illness forced her to acknowledge her own desire for emotional connection and compassion. The reader discerns that if Vivian had lived, her interactions with students and others would have been vastly different than they were before her illness.

In the absence of such life altering personal experience, dramatic literature provides an excellent format for moral reflection. Because the entire literary work consists of dialog, students can be encouraged to engage the moral imagination by considering how specific conversations might be rewritten in a manner that provides the kindness Vivian seeks and prevents the indignities she is forced to suffer. This is an ideal

\footnotetext{
${ }^{330}$ Judith Andre, "The Medical Humanities as Contributing to Moral Growth and Development," in Practicing the Medical Humanities: Engaging Physicians and Patients, ed. Ronald A. Carson, Chester R. Burns, and Thomas R. Cole (Hagerstown, MD: University Publishing Group, 2003), 48.

${ }^{331}$ Ibid., 48-9. Italics original.

332 Ibid., 52-3.
} 
exercise for small group work and when complete, the rewritten scenes can be read for the class, engendering further discussion and the proposal of still more options. The four components of compassion (cognitive, affective, intentional, and motivational) may be considered individually as students are asked to show evidence of each in the rewritten scenes.

There is no doubt that the physicians in $W$; $t$ behave in a manner that is morally wrong. This fact holds true no matter which bioethical theory we are using to judge their behavior and serves to illuminate the presence of a common morality, "norms about right and wrong human conduct that are so widely shared that they form a stable (although incomplete) social agreement."333 The casuist theory of bioethics rejects the idea that, apart from this common morality, there are specific principles or guidelines that can be applied to every situation and instead looks to "paradigm cases" and precedents from which to draw judgments and make decisions. ${ }^{334}$ This underlying methodology, “thinking about new and perplexing cases by thinking about the perplexing case's similarities with clear, paradigmatic cases,"335 is something we do, consciously or subconsciously, any time we have a decision to make. When considering the case of Vivian Bearing, we cannot help but compare her situation with what it ought to have been, and this, ideally, influences our behavior in the future.

The only comfort Vivian receives during the entire course of her treatment comes during a visit from her former professor and mentor, E. M. Ashford, now eighty years old and in town for her great-grandson's fifth birthday. Ashford comforts Vivian by

\footnotetext{
333 Beauchamp and Childress, Principles of Biomedical Ethics, 2.

334 Ibid., 376-7.

335 Paul Cudney, "What Really Separates Casuistry from Principlism in Biomedical Ethics," Theoretical Medicine and Bioethics 35, no. 3 (2014): 209, doi:10.1007/s11017-014-9295-3.
} 
climbing into bed beside her and allowing Vivian to "nestle in" while Ashford reads to her. ${ }^{336}$ When Vivian declines a recitation of Donne, Ashford reads from a children's book, The Runaway Bunny, interpreting it as "A little allegory of the soul." 337 Vivian drifts peacefully off to sleep and does not wake. Ashford is able to provide Vivian with a few moments of serenity because she knows Vivian and does not turn away from her suffering. Ashford understands that Vivian finds solace in words and language and she offers these in addition to her own presence in a touching gesture of compassion.

Vivian's peace is short-lived, however, and her final indignity comes at the end of her life when, after requesting a do not resuscitate (DNR) order and having it entered into the chart by Dr. Kelekian in the presence of Jason, Jason nevertheless impulsively calls a full code for Vivian when he finds her unresponsive and without a pulse.

(SUSIE, hearing the announcement, runs into the room.)

SUSIE: WHAT ARE YOU DOING? JASON: A GODDAMN CODE. GET OVER HERE! SUSIE: She's DNR! (She grabs him.) JASON: (He pushes her away.) She's Research!338

The final moments of the play are a nightmarish scene in which Vivian's body is manhandled by the code team and subjected to electric shocks as Susie runs frantically between the code team members yelling STOP, while Jason reacts "(In agony) Oh, God." and finally “(Howling) I MADE A MISTAKE," before collapsing to the floor. ${ }^{339}$ After verifying the DNR, the code team members mutter, “- It's a doctor fuck-up. - What is he, a resident?"340 This scene may lead the reader to wonder whether Jason's howling

\footnotetext{
336 Edson, $W ; t, 79$.

337 Ibid., 80.

338 Ibid., 82.

339 Ibid., 82, 84.

340 Ibid., 82-85.
} 
collapse is because he finally understands the inhumanity of his actions or merely because he wonders if they have affected his future as Kelekian's fellow.

Either way, we have yet another moral lapse and ethical breach by one of Vivian's physicians. The doctor's actions and Vivian's suffering are not only the result of moral failures, but also of complete emotional detachment. $W ; t$ thus illuminates the importance of genuine human connection in the delivery of competent care. We can hope Jason's collapse marks some sort of epiphany in which he realizes the cost of his inhumanity.

In discussing the possibility for "epiphanic" knowledge that changes the way we live and practice, Anne Hunsaker Hawkins reminds us, "Narrative ethics often emphasizes the importance of attending to the patient's 'life-story.' But we should remember that every ethical decision marks the intersection of two stories, the patient's and the physician's, and epiphanic moments of imaginative insight or intuitive understanding occur in both." ${ }^{341}$ Studying the ethical breaches presented in $W ; t$ provides students with multiple opportunities for epiphanic insights as they come to understand the suffering caused by decidedly unethical behavior rendered by caregivers with no regard for their patient apart from the statistics her case provides.

The insights gained from studying great literature and art come about as the result of a process of self-exploration induced by the works themselves and encouraged through discussion and written reflection. Grappling with ethical dilemmas and demonstrating virtue in the presence of suffering often involves a process ethicists refer to as reflective equilibrium. Beauchamp and Childress write, "The goal of reflective equilibrium is to

341 Anne Hunsaker Hawkins, "Medical Ethics and the Epiphanic Dimension of Narrative," in Stories and Their Limits: Narrative Approaches to Bioethics, ed. Hilde Lindemann Nelson (New York: Routledge, 1997), 168. 
match, prune, and adjust considered judgments and their specifications to render them coherent with the premises of our most general moral commitments." 342 In their view, making ethical decisions that we can live with first requires an awareness of our own moral convictions. Vivian Bearing's narrative is presented in the form of a dramatic script that lays bare the consequences of unethical conduct, and encourages students to form their own ideas of morally acceptable and unacceptable behavior.

In discussing the possibility of teaching virtue to nursing students, Ann Marie Begley observes, "We can teach 'the four principles' approach and students can learn these and apply them just as well as they can the 'signs and symptoms' of diseases." 343 Begley does not believe this is enough, however, and affirms that educators also bear some responsibility for shaping virtuous character. She notes, "We many not achieve a satisfactory result with all students, but we must try, and the pessimism involved in considering all students to be beyond our influence is unwarranted." 344 The methods Begley advocates for teaching virtue involve enhancing a student's capacity for emotional response and sensitivity, ${ }^{345}$ and this is precisely where dramatic literature offers such a wealth of possibilities. According to Begley, "While the situations to which we respond are imaginary, the felt emotions are real." 346 The fictional character of Vivian Bearing, a scholar of words and wit, offers a narrative of illness that is challenging but ultimately enlightening.

In Stories of Sickness, Howard Brody writes, "There is, unfortunately, little evidence to support the notion that the teaching of ethics, as is currently done in most

\footnotetext{
342 Beauchamp and Childress, Principles of Biomedical Ethics, 382.

343 Begley, "Original Article," 260.

344 Ibid.

345 Ibid.

${ }^{346}$ Ibid., 262. Italics original.
} 
medical schools, produces a more humane or compassionate professional. The narratives reviewed in this book might persuade us that the better way to produce more compassionate physicians is to abolish all courses in medical ethics and replace them with courses in medicine and literature.”347

If we return to Frey's suggestions for teaching virtue it becomes clear why literature is so effective - it stimulates the moral imagination as students become empathetically engaged with complex characters, it allows the consideration of multiple courses of action and removes real-life time constraints so all moral issues can be considered and key concepts and principles can be analyzed, and it encourages students to become more comfortable with ambiguity even as they work to construct their own ideas of what it means to be a virtuous human being.

${ }^{347}$ Brody, Stories of Sickness, 270. 


\title{
CHAPTER FOUR \\ THE ART OF MINDFULNESS: HELPING CAREGIVERS CARE FOR THEMSELVES
}

\author{
"Creativity is the work of healthcare." 348 \\ $\sim$ Rita Charon
}

While most practitioners agree that compassionate caregiving based upon narrative practice and an empathetic emotional relationship with patients is ideal, they also fear that time constraints and threats to their own emotional well-being make this style of practice untenable. ${ }^{349}$ This chapter addresses these obstacles and suggests that cultivation of intentional, nonjudgmental, present moment awareness, or "mindfulness," 350 helps make even the briefest clinical encounters more therapeutic and also helps prevent the burnout and compassion fatigue associated with caregiving. In addition, understanding the therapeutic mental state of "flow,"351 and cultivating activities that encourage this state helps future caregivers realize the importance of habits

\footnotetext{
${ }^{348}$ Rita Charon, "Narrative Medicine" (Classroom visit, Bellarmine University, Louisville, KY, September 22, 2015).

${ }^{349}$ Halpern, From Detached Concern to Empathy: Humanizing Medical Practice, 15-7.

350 Jon Kabat-Zinn, Mindfulness for Beginners: Reclaiming the Present Moment and Your Life (Boulder, CO: Sounds True, 2012), 1.

${ }^{351}$ Csikszentmihalyi, Flow: The Psychology of Optimal Experience.
} 
that are mentally and emotionally restorative. Because compassionate caregiving often involves deep emotional investment, self-care requires more than warm baths or other activities designed to reduce stress; it requires special attention to cognitive processes that influence thought and emotion.

Drawing upon Jon Kabat-Zinn's concept of mindfulness, Mihaly Csikszentmihalyi's theory of flow, and Wassily Kandinsky's interpretations of form and color, this chapter asserts that viewing and creating nonrepresentational art as a means of contemplative practice allows students to become aware of the ever-present stream of thought and to develop some mastery over its content. The cultivation of sustained attention and present moment awareness fosters therapeutic clinical encounters in which patients feel heard and cared for even when the encounters are brief. These skills also enable caregivers to be empathetically present with their patients without carrying those emotions into other areas of their lives.

In developing the classroom exercises proposed in this chapter I have made extensive use of Dr. Ronald Epstein's techniques for cultivating healthy habits of mind. ${ }^{352}$ While non-objective art provides an excellent medium for bringing Epstein's ideas into the classroom, it is important to note this is not an effort to teach art appreciation or art history, but rather a means of promoting a particular form of metacognition. Before beginning a discussion of pedagogy, we must understand the importance of teaching caregivers to care for themselves.

Researchers studying dissatisfaction in healthcare workers often use the terms burnout and compassion fatigue interchangeably, but there are subtle differences between the two. Carla Joinson first used the phrase "compassion fatigue" in 1992 to denote a

352 Epstein, "Mindful Practice in Action (II)." 
specific type of burnout that occurs in healthcare workers, especially nurses. ${ }^{353}$ Smart et al., note, "Burnout can result from any situation of being overworked and is not unique to caring professions ... combatting burnout will require attention to organizational variables such as workload and patient volume . . Compassion fatigue, however, may require personalized interventions." 354 In 2010 nurse researchers in South Africa constructed a comprehensive definition of compassion fatigue and noted that it develops in phases and ultimately results in "a state where the compassionate energy that is expended by nurses has surpassed their restorative processes, with recovery power being lost."355 In describing the all-inclusive effects of compassion fatigue they write:

[T] he indicative signs of compassion fatigue are the physical effects of burnout, absence of energy, and accident proneness, the emotional effects of breakdown, apathy and a desire to quit, the social effects of unresponsiveness, callousness, and indifference towards patients, the spiritual effects of poor judgment and disinterest in introspection, and the intellectual effect of disorderliness. ${ }^{356}$

Under "risk factors" the authors list "contact with patients," highlighting the fact that all types of caregivers are at risk for compassion fatigue as well as burnout. ${ }^{357}$

Research consistently shows that as many as sixty percent of physicians report symptoms of compassion fatigue including "emotional exhaustion, depersonalization (treating patients as objects), and low sense of accomplishment." 358 The prevalence of

\footnotetext{
353 Carla Joinson, "Coping with Compassion Fatigue," Nursing 22, no. 4 (April 1992): 116.

${ }^{354}$ Denise Smart et al., "Compassion Fatigue and Satisfaction: A Cross-Sectional Survey Among US Healthcare Workers," Nursing and Health Sciences 16, no. 1 (March 2014): 4, doi:10.1111/nhs.12068. 355 Siedine Knobloch Coetzee and Hester C. Klopper, "Compassion Fatigue Within Nursing Practice: A Concept Analysis.," Compassion Fatigue within Nursing Practice: A Concept Analysis. 12, no. 2 (June 2010): 237, doi:10.1111/j.1442-2018.2010.00526.x.

356 Ibid., 239. Italics mine.

357 Ibid., 240.

358 Michael S. Krasner et al., "Association of an Educational Program in Mindful Communication with Burnout, Empathy, and Attitudes Among Primary Care Physicians," Journal of the American Medical Association 302, no. 12 (September 2009): 1284.
} 
burnout and/or compassion fatigue is higher among physicians than for other occupations in the general population. ${ }^{359}$ For nurses, the rate of burnout and compassion fatigue may be even higher than for physicians, with research showing that more than eighty percent of emergency room nurses demonstrate "moderate to high" levels of burnout and compassion fatigue. 360

Wariness of compassion fatigue is part of the reason physicians have traditionally been encouraged to maintain a sense of emotional detachment from their patients, yet, as Halpern points out, such emotional detachment does not help physicians avoid the symptoms of compassion fatigue. ${ }^{361}$ On the contrary, physicians who report the highest levels of job satisfaction are those who develop caring, empathetic relationships with their patients. ${ }^{362}$ Caregivers must have confidence in their ability to maintain their own emotional well-being before they will be able or willing to engage empathetically with their patients, however. If they do not have such confidence, both the affective and motivational components of compassion become impossible. Teaching students the principles of mindfulness as a practice of self-care may alleviate this fear since it is well documented that the practice of mindfulness is beneficial in reducing the symptoms of compassion fatigue and that it improves relationships between caregivers and their patients. ${ }^{363}$ Medical schools are increasingly offering courses in mindfulness, but there is

359 Tait D. Shanafelt et al., "Burnout and Satisfaction With Work-Life Balance Among US Physicians Relative to the General US Population," Archives of Internal Medicine 172, no. 18 (October 8, 2012): 1377.

${ }^{360}$ Crystal Hooper et al., "Compassion Satisfaction, Burnout, and Compassion Fatigue Among Emergency Nurses Compared With Nurses in Other Selected Inpatient Specialties," Journal of Emergency Nursing 36, no. 5 (September 2010): 420.

${ }^{361}$ Halpern, From Detached Concern to Empathy: Humanizing Medical Practice, 15.

362 Howard M. Spiro, "Empathy: An Introduction," in Empathy and the Practice of Medicine, ed. Howard Spiro et al. (New Haven: Yale University Press, 1993), 2.

363 Ronald M. Epstein, "Mindful Practice," Journal of the American Medical Association 282, no. 9 (September 1, 1999): 833-39; Lacie White, "Mindfulness in Nursing: An Evolutionary Concept 
no consistency of format, and courses are generally only offered as electives. ${ }^{364}$ Given the empirically proven benefits of mindfulness education, I believe its precepts should be introduced to general undergraduate students considering careers in healthcare, thus allowing the students to assess the value of such habits in creating compassionate relationships and developing healthy practices of self-care before they embark on supremely challenging careers. This suggestion is not without caveats, however, and these will be discussed in detail.

A consistent state of mindfulness, or nonjudgmental, present moment awareness, is developed through meditation and other contemplative practices designed to encourage mental stillness and somatic awareness. ${ }^{365}$ While the concept of mindfulness and the meditation practices associated with it have their roots in Theravada Buddhism, the practices of Mindfulness Based Stress Reduction (MBSR) and Mindfulness Based Cognitive Therapy (MBCT) are two examples of the secular application of mindfulness principles. ${ }^{366}$ The contemplative practices developed for MBSR have been shown to reduce anxiety and depression, improve memory, strengthen the immune system, reduce

\footnotetext{
Analysis," Journal of Advanced Nursing 70, no. 2 (February 2014): 282-94, doi:10.1111/jan.12182; Peter Morgan, "Health Care Workers' Experiences of Mindfulness Training: A Qualitative Review," Health Care Workers' Experiences of Mindfulness Training: A Qualitative Review 6, no. 4 (201508): 744-58, doi:10.1007/s12671-014-0313-3; Howard B. Beckman et al., "The Impact of a Program in Mindful Communication on Primary Care Physicians:," Academic Medicine 87, no. 6 (June 2012): 81519.

364 Patricia L. Dobkin and Tom A. Hutchinson, "Teaching Mindfulness in Medical School: Where Are We Now and Where Are We Going?," Medical Education 47 (2013): 768-79, doi:0.1111/medu.12200. 365 Kabat-Zinn, Mindfulness for Beginners: Reclaiming the Present Moment and Your Life, 54-7. ${ }^{366}$ James Carmody, "Eastern and Western Approaches to Mindfulness: Similarities, Differences, and Clinical Implications," in The Wiley Blackwell Handbook of Mindfulness, ed. Amanda Ie, Christelle T. Ngnoumen, and Ellen J. Langer, 1st ed. (Hoboken, NJ: John Wiley \& Sons, 2014), 48.
} 
hypertension, and improve an overall sense of well-being, among other positive physical and emotional effects. 367

Although the benefits of mindfulness have been subjectively reported and documented, the exact neurophysiological mechanisms at play in achieving those benefits are still poorly understood. ${ }^{368}$ One theory proposes that meditation interrupts a pattern of rumination; a maladaptive thought process that involves constant repetitive thinking. ${ }^{369}$ Rumination has become an important topic for researchers studying emotion because of its association with anxiety and depression. ${ }^{370}$ López-Pérez and Ambrona have studied emotional responses to perceiving a person in need and have attempted to identify the causative factors that differentiate empathetic concern from personal distress. ${ }^{371}$ They write that personal distress occurs in observers who experience a strong vicarious emotional response to the suffering of others, but lack the ability to regulate those emotions. This may cause the observer to turn away from the person in need or to attempt the suppression of his or her own emotional response. ${ }^{372}$ (Recall the emotional symptoms of compassion fatigue are apathy and a desire to quit.) The researchers studied two types of emotional regulation, rumination and reappraisal. Reappraisal is a positive emotional response that "involves thinking about what happens in a different way, by changing the mindset and by making a different interpretation of the event." ${ }^{373}$ Their

\footnotetext{
367 For a comprehensive list of the benefits of meditation as well as the studies in which they were documented, see: Mark Williams and Danny Penman, Mindfulness: An Eight-Week Plan for Finding Peace in a Frantic World (New York: Rodale, 2011), 6 and 50-52. 368 White, "Mindfulness in Nursing," 283.

369 B. López-Pérez and T. Ambrona, "The Role of Cognitive Emotion Regulation on the Vicarious Emotional Response," Motivation and Emotion 39, no. 2 (2014): 302, doi:10.1007/s11031-014-9452- 
studies demonstrated "reappraisal led to a higher empathic concern, [and] rumination led to higher personal distress. ${ }^{374}$ In the parlance of mindfulness, this is called responding to a situation rather than reacting to it, and the capacity for healthy response is developed through an awareness that thoughts are only thoughts and do not always reflect reality. ${ }^{375}$

David Vago suggests mindfulness is a type of "meta-awareness" that enables one to "shift from identifying personally with thoughts and feelings to relating one's experience in a wider field of awareness, and in which one can engage with an object of attention without avoiding it or becoming entangled (as in rumination)." 376 For caregivers, rumination might include constant thoughts and emotions related to the suffering of others, or self-recrimination for being unable to eliminate that suffering. A reappraisal of the same situation might allow a caregiver to reflect upon the ways in which he or she provided a comforting presence even if nothing more could be offered.

The wealth of positive results coming from research on mindfulness-based interventions (MBI's) in healthcare and psychology has lead to a proliferation of programs and teachers. This suggests a need for careful critical examination and awareness that mindfulness practices are not for everyone. At this point in time, however, I am aware of only one critical voice in the scholarly journals. In 2014 Daniel David observed,

In psychotherapy, mindfulness was initially conceptualized as a tool that should be used when standard evidence-based treatments - like cognitive-behavioral therapy - fail or do not achieve optimal, longterm outcomes. .. mindfulness has more recently come to be viewed as a first line intervention, be it independent and/or part of

\footnotetext{
374 Ibid., 305.

375 Williams and Penman, Mindfulness: An Eight-Week Plan for Finding Peace in a Frantic World, 41.

376 David R. Vago, "Mapping Modalities of Self-Awareness in Mindfulness Practice: A Potential Mechanism for Clarifying Habits of Mind," Annals of the New York Academy of Sciences 1307, no. 1 (January 1, 2014): 30, doi:10.1111/nyas.12270.
} 
multimodal treatments, for many psychological disorders and conditions, rather then [sic] circumscribed to some clinical context . . . My contention, which will no doubt stir academic controversy, is that the indiscriminate practice of mindfulness in psychotherapy, particularly if such practices are viewed as a panacea, may well unintentionally create an unhealthy detachment from the very feelings that make us human. ${ }^{377}$

In responding to David's concern, Gardner, Moore, and Marks insist that David is misunderstanding the intent of mindfulness-based interventions (MBI) in psychotherapy;

The purpose of mindfulness use in MBCT [Mindfulness Based Cognitive Therapy] is to allow for increased perspective-taking (greater awareness of possibilities), so that one can make effective choices in response to emotional experience. It is not meant to neutralize the emotional experience, but to recognize patterns of the mind that contribute to withdrawal, inaction, ineffective decisionmaking, etc., in the service of avoiding emotional experience. ${ }^{378}$

Several things are worth noting about David's criticism and the subsequent rebuttal. First, the reason MBI's have become first line treatments is because they have proven effective for so many people, but David is right to urge caution in seeing such successes as a universal panacea. I do concur, however, with Gardener, et al., who view his concerns about detachment as misguided. David is referring to a particular tenet of mindfulness called non-attachment that addresses the fact that many of our thoughts and emotions are the result of our own perceptions, which may or may not be valid. David suggests that a student who has no anxiety about whether he will pass or fail an exam is less likely to put forth the effort to excel, and that a healthy level of "motivational

377 Daniel David, "Some Concerns About the Psychological Implications of Mindfulness: A Critical Analysis," Journal of Rational-Emotive \& Cognitive-Behavior Therapy 32, no. 4 (October 15, 2014): 319, doi:10.1007/s10942-014-0198-z.

378 Frank L. Gardner, Zella E. Moore, and Donald R. Marks, "Rectifying Misconceptions: A Comprehensive Response to 'Some Concerns About the Psychological Implications of Mindfulness: A Critical Analysis,'” Journal of Rational-Emotive \& Cognitive-Behavior Therapy 32, no. 4 (October 1, 2014): 337, doi:10.1007/s10942-014-0196-1. 
relevance" is important to success. ${ }^{379} \mathrm{He}$ is correct, of course, but he has misinterpreted non-attachment, which never discourages putting forth one's best effort, but simply suggests that clinging to expected outcomes is not a healthy state of mind. Preparing for a test with an attitude that all is lost if I do not do well, will not allow optimal preparation. Likewise, if I have done my best to prepare, but still fail the exam, nonattachment would suggest it is not the end of the world, but rather an opportunity for reassessment. Detachment does not seek to eliminate thoughts or emotions, but suggests an awareness that we often cling to expectations and fears in a way that prevents peace of mind. 380

David's criticisms are related to MBI's used in psychotherapy, but mindfulness training is becoming increasingly prevalent in mainstream culture and Gardner et al., rightfully acknowledge the possibility of misinformation being espoused by therapists or teachers who are not properly trained. ${ }^{381}$ This is likely to be a growing concern as interest in mindfulness increases and instructor training programs proliferate.

While I could find no reports of adverse reactions to meditation in scholarly journals, a recent opinion piece in The New York Times ${ }^{382}$ references an article in The Atlantic that highlights the fact that meditation is not suitable for everyone. Thomas Rocha quotes psychiatrist and Brown University Medical School professor Willoughby Britton, who is leading "an effort to document, analyze, and publicize accounts of the

\footnotetext{
379 David, "Some Concerns About the Psychological Implications of Mindfulness," 315-6.

380 Jon Kabat-Zinn, Coming to Our Senses (New York: Hyperion, 2005), 53.

381 Gardner, Moore, and Marks, "Rectifying Misconceptions," 335-6.

382 Adam Grant, "Can We End the Meditation Madness?," The New York Times, October 9, 2015, http://www.nytimes.com/2015/10/10/opinion/can-we-end-the-meditation-madness.html.
} 
adverse effects of contemplative practices."383 The article notes that Britton and her team have collected data from "nearly 40" subjects who were "fairly out of commission, fairly impaired for between six months [and] more than 20 years." 384 While forty is a miniscule number considering the millions of people now engaged in some form of contemplative practice, it does indicate the possibility of severe adverse responses in people who might be emotionally or psychologically fragile.

While the benefits of mindfulness make it an important tool for many healthcare providers, introducing it in the classroom must be done with caution. The classroom is an ideal place for practicing sustained attention and present moment awareness, for encouraging non-judgment, and for helping students become aware of their own patterns of thought, but it is not the place for lengthy meditations. In addition, it is important to stress that even brief periods of meditation are optional. When introducing meditation practices in the classroom, I keep the exercises very short (2-3 minutes) and I make a promise to my students that I will not be watching them. Those who choose to follow the meditation are free to do so, while others may opt to read or put their heads down for a couple of minutes. I do require that all electronic devices be put away.

A typical introduction to mindfulness meditation involves cultivating present moment awareness and slowing the constant stream of thoughts by paying attention to the physical sensations of breathing. ${ }^{385}$ As Kabat-Zinn and others have noted, human beings are constantly thinking, most often either remembering the past or considering the future, and these thoughts have a profound effect on our emotions and our lives; "Out of the

\footnotetext{
383 Tomas Rocha, "The Dark Knight of the Soul," The Atlantic, June 25, 2014, n.p., http://www.theatlantic.com/health/archive/2014/06/the-dark-knight-of-the-souls/372766/. ${ }^{384}$ Rocha, "The Dark Knight of the Soul."

385 Williams and Penman, Mindfulness: An Eight-Week Plan for Finding Peace in a Frantic World, 4-5.
} 
vortex of our thoughts, first emotions arise, and then moods and behaviors, and finally habits and traits of character." 386 The object of mindfulness meditation is to "calm the turbulent mind" and return it to the present moment. ${ }^{387}$ As thoughts arise in the mind, the meditator acknowledges them and then gently returns attention to the physical sensations of the breath entering and leaving the body. Williams and Penman explain,

Focusing on each breath in this way allows you to observe your thoughts as they arise in your mind and, little by little, to let go of struggling with them ... You come to the profound understanding that thoughts and feelings (including negative ones) are transient ... mindfulness allows you to catch negative thought patterns before they tip you into a downward spiral. It begins the process of putting you back in control of your life. ${ }^{388}$

When introducing students to the practice of mindfulness meditation using the breath, it is important to emphasize nonjudgmental awareness. Students who find it difficult to maintain attention on the breath may become frustrated or feel that they are doing it wrong or are unable to meditate, but the initial objective is simply to become aware of the constant stream of thoughts that dominate our everyday lives. ${ }^{389}$ There is no attempt to eliminate these thoughts or to judge their validity, the goal is to acknowledge their presence and gently return attention to the breath. Students who find these short meditations useful can be directed to texts that offer expanded instruction or to campus or community based meditation programs like MBSR, or Koru Mindfulness, a shorter program of instruction designed especially for college students and faculty. 390

\footnotetext{
386 Matthieu Ricard, Why Meditate: Working With Thoughts and Emotions, trans. Sherab Chödzin Kohn (Carlsbad, CA: Hay House, 2010), 23.

387 Ibid.

388 Williams and Penman, Mindfulness: An Eight-Week Plan for Finding Peace in a Frantic World, 5. 389 Jon Kabat-Zinn, Wherever You Go, There You Are: Mindfulness Meditation in Everyday Life (New York: Hyperion, 2005), 21.

390 "Koru Mindfulness - Meditation for College Aged Students," Koru Mindfulness, accessed October 1, 2015, http://korumindfulness.org/.
} 
Because not all students will be interested in exploring the practice of meditation, other forms of quieting the mind and developing present moment awareness should be introduced. Viewing and engaging with fully abstract or nonrepresentational art offers outstanding opportunities for practicing sustained attention and nonjudgmental awareness. Because nonrepresentational art lacks the familiar objects and images that guide the mind and evoke emotional responses, it presents an opportunity to observe the process of thinking itself. In addition, many students come to class already convinced they do not like nonrepresentational art because they believe they do not understand it or because they fail to see artistic skill evidenced in its creation. This provides an excellent opportunity for examining the judgmental quality of our thoughts and practicing the task of suspending that judgment.

Doctor Ronald Epstein, from the Department of Family Medicine and Psychiatry at the University of Rochester, has written extensively about the mindful practice of medicine. Epstein suggests "an 8-fold teaching method to improve the capabilities of health professionals by fostering four key habits of mind: attentive observation, critical curiosity, informed flexibility, and presence." ${ }^{391}$ Although Epstein teaches medical students, interns, and residents, ${ }^{392}$ his methodology and objectives are equally useful in other situations where one hopes to introduce the key habits of mindfulness. Epstein's "8-fold method" incorporates the following techniques: priming, availability, asking reflective questions, active engagement, modeling while 'thinking out loud', practice, praxis, and assessment and confirmation. ${ }^{393}$ Here I discuss the ways in which Epstein's

\footnotetext{
391 Epstein, "Mindful Practice in Action (II)," 11.

392 Ibid., 12.

393 Ibid.
} 
techniques may be used in conjunction with Wassily Kandinsky's 1924 Blue Painting

[Figure 2] $]^{394}$ in guiding students toward healthy habits of mind.

Kandinsky was one of the first artists to paint fully abstract works, ${ }^{395}$ and his theories regarding the power of color remain intriguing, if not empirically provable. ${ }^{396}$ While Kandinsky's association of colors with spiritual properties ${ }^{397}$ was likely the result of synesthesia and his interest in Theosophy, ${ }^{398}$ people often do have emotional and/or cognitive reactions to color, and these are worth exploring.

As of October 5, four of Amazon.com's top twenty bestselling books for 2015 were coloring books for adults. ${ }^{399}$ These books feature intricate, complex designs, often in the form of nature scenes or mandalas that are meant to be colored with pencils, markers, or paints. In a recent article for The New Yorker, Adrienne Raphel situates the coloring book trend as part of a "Peter Pan Market" in which adults are reading young adult literature, going to summer camps, and attending "preschool" in an effort to reduce stress and bring play back into their lives. ${ }^{400}$ However, I am not convinced the coloring books necessarily belong in the same odd category as summer camps and preschools for adults. Working with color in a way that does not demand artistic training or talent speaks to a universal human fascination with color that has been explored by

394 Wassily Kandinsky, “Collection Online | Vasily Kandinsky. Blue Painting (Blaues Bild). January 1924 - Guggenheim Museum,” accessed October 12, 2015, http://www.guggenheim.org/newyork/collections/collection-online/artwork/1943.

395 Will Grohmann, Wassily Kandinsky: Life and Work, ed. Milton S. Fox, trans. Norman Guterman (New York: Harry N. Abrams, 1958), 81.

${ }^{396}$ Anatoliy V. Kharkhurin, "Is Triangle Really Yellow? An Empirical Investigation of Kandinsky's Correspondence Theory," Empirical Studies of the Arts 30, no. 2 (July 2012): 168, doi:10.2190/EM.30.2.d.

397 Wassily Kandinsky, Concerning the Spiritual in Art, trans. M. T. H. Sadler (New York: Dover, 1977), 36.

398 Kharkhurin, “Is Triangle Really Yellow?,” 172.

399 http://www.amazon.com/gp/bestsellers/2015/books/ref=zg_bsar_cal_ye

400 Adrienne Raphel, "Adult Coloring Books and the Rise of the 'Peter Pan' Market," The New Yorker, accessed September 24, 2015, http://www.newyorker.com/business/currency/why-adults-arebuying-coloring-books-for-themselves. 
philosophers, scientists, and artists for millennia. Color theorists disagree about whether color is a physical property of objects (physicalism) or simply a mental property in which the viewer projects his or her sensory experience of color onto a colorless object (eliminativism) ${ }^{401}$ but all agree color has aesthetic characteristics to which humans respond. ${ }^{402}$

Research has shown that emotional responses to color are both innate and culturally mediated. ${ }^{403}$ In 2006 Clarke and Costall noted that while previous research demonstrated a general finding that, “'cool' colors are soothing, and 'warm' colors stimulate," a more qualitative study was needed to understand "the more subtle connotations of colors, the multiple meanings of a single color, and also the participants reasons for these connotations." ${ }^{404}$ Their results were consistent with previous research, but they also found individual responses to color were "emotionally multifaceted," and were influenced by experience and cultural associations. ${ }^{405}$

Art historian John Gage has written extensively about the history and meaning of color and suggests, "A unifying framework for the study of colour in all its aspects might indeed be provided by the history of art, precisely that subject where it has hitherto been so meagerly treated." ${ }^{406}$ In Color and Meaning: Art, Science, and Symbolism, Gage traces the artistic use of color through various time periods and locales and notes that by

401 Laura Gow, “Colour," Philosophy Compass 9, no. 11 (November 2014): 803-4, doi:10.1111/phc3.12173.

402 T. W. Allan Whitfield and Jianne Whelton, "The Arcane Roots of Colour Psychology, Chromotherapy, and Colour Forecasting," Color Research and Application 40, no. 1 (February 2015): 99, doi:10.1002/col.21862.

403 R. D'Andrade and M. Egan, "The Colors of Emotion," American Ethnologist 1, no. 1 (February 1974): 49, doi:10.1525/ae.1974.1.1.02a00030.

404 Tom Clarke and Alan Costall, "The Emotional Connotations of Color: A Qualitative Investigation," Color Research and Application 33, no. 5 (October 2008): 406, doi:10.1002/col.20435. 405 Ibid., 409.

406 John Gage, Color and Meaning: Art, Science, and Symbolism (Berkeley: University of California Press, 1999), 12. 
the time twentieth century artists had become intrigued with the idea of nonobjective work, they possessed "a number of well-articulated colour-systems which allowed them to consider colour as in the nature of a language." ${ }^{407}$ Kandinsky, in particular, devoted tremendous energy to explaining the affective power of color.

Kandinsky experienced some level of synesthesia, a condition Gage describes as "the simultaneous response of two or more senses to a single stimulus," 408 and was also influenced by the Theosophical Society, ${ }^{409}$ whose texts considered colors "as they are experienced by the adept in auras, or 'thought-forms." 410 Kandinsky's ideas about color, particularly his "correspondence theory," in which he suggested, "keen colours are well suited by sharp forms (e.g., a yellow triangle), and soft, deep colours by round forms (e.g., a blue circle), ${ }^{\prime 11}$ were not universally supported by other artists, ${ }^{412}$ and have been disproven by recent empirical testing, ${ }^{413}$ but his attempt to render a subjective sensory experience into words nevertheless provides insight for the contemplation of nonobjective paintings.

According to Kandinsky, paintings are composed of form and color, "Form alone, even though totally abstract and geometrical, has a power of inner suggestion," ${ }^{414}$ but if an artist wishes to understand the spirit, "The starting point is the study of colour and its effects on men." ${ }^{415}$ The following is a sampling of Kandinsky's writing on the universal qualities of color:

\footnotetext{
407 Ibid., 248.

408 Ibid., 252.

${ }^{409}$ Kandinsky, Concerning the Spiritual in Art, 13-14.

410 Gage, Color and Meaning: Art, Science, and Symbolism, 242.

${ }^{411}$ Kandinsky, Concerning the Spiritual in Art, 29.

412 Gage, Color and Meaning: Art, Science, and Symbolism, 241.

413 Kharkhurin, "Is Triangle Really Yellow?"

${ }^{414}$ Kandinsky, Concerning the Spiritual in Art, 28.

415 Ibid., 36.
} 
Yellow is the typically earthly colour. It can never have profound meaning ... The power of profound meaning is found in blue... Green is the most restful colour that exists. . . Not without reason is white taken as symbolizing joy and spotless purity, and black grief and death. A blend of black and white produces gray ... which is silent and motionless ... The varied powers of red are very striking . . . brown, unemotional, disinclined for movement . . . Just as orange is red brought nearer to humanity by yellow, so violet is red withdrawn from humanity by blue. ${ }^{416}$

Clearly, not everyone will agree with Kandinsky's color associations, but most people acknowledge being soothed by some colors and stimulated by others, or at least having an affinity for some colors over others, and this fact lends itself well to contemplation. Epstein's method for instilling attentive observation, critical curiosity, presence, and informed flexibility provides an ideal framework for contemplating Kandinsky's Blue Painting in a classroom setting.

The first component of Epstein's method for teaching mindfulness in medicine is priming, which "involves setting the expectation that students will report on their own mental processes." ${ }^{417}$ When using this method in clinical practice Epstein requires students to discuss the ways in which they prepare for seeing a patient and also to examine their own thoughts and feelings during the clinical encounter. In this way, Epstein asks students to go beyond clinical findings and the methodical ways in which patient information is usually collected. ${ }^{418}$ When using Epstein's method in the classroom, we begin by asking students to discuss ideas they already hold about nonobjective art. Marc Rothko's "multiform" paintings and Jackson Pollock's "splatter" paintings are useful aids in this discussion because students often dismiss them as lacking skill or creative intention. In fact, a very frequent comment is, "I could do that myself."

\footnotetext{
416 Ibid., 38-41.

${ }^{417}$ Epstein, "Mindful Practice in Action (II)," 12.

418 Ibid.
} 
Students might then be asked to recognize the judgments they hold and, insofar as possible, to release them and attempt to view Kandinsky's work with a "beginner's mind." Beginner's mind refers to an attitude that allows, "open and unencumbered inquiry ... 'In the beginner's mind there are many possibilities, but in the expert's mind there are few. $"{ }^{419}$

The second stage of Epstein's method is being available, which he describes as "creating quiet, uninterrupted spaces on a regular basis for rehearsal (such as a seminar, reflection group, or retreat) as well as moments of contact during chaotic real-life contexts. ${ }^{\prime} 420$ When he speaks of rehearsal, Epstein is referring to the moments in which we practice deliberate, non-judgmental attention. Quiet moments provide the best opportunity for this, and the hope is that making use of quiet moments may develop a habit that is also useful in the midst of chaos and struggle. As part of this step Epstein suggests keeping a journal, and written reflections also work well when asking students to consider Kandinsky's work in a thoughtful, intentional way. Students may be asked to write a one-page reflection on the painting, specifically discussing their observations about color and line. This may be done in the classroom or as homework, but it is important that students not seek any outside sources of information about the work and rely instead on their own observations. At this point it is not necessary to discuss any sort of emotional response to the work, although some may wish to do so. The purpose of this assignment is to encourage focused, sustained attention. Having thoughts on paper exponentially increases the potential of step three, asking reflective questions.

\footnotetext{
${ }^{419}$ Kabat-Zinn, Coming to Our Senses, 85, footnote.

${ }^{420}$ Epstein, "Mindful Practice in Action (II)," 12.
} 
"Reflective questions are designed not to edify, but rather to invite doubt and ambiguity so that students can discover their own answers." 421 When using this method in a healthcare setting Epstein points out, "clinical data gathering is commonly conditioned by the expected diagnosis." ${ }^{22}$ In other words, we see what we expect to see. Engaging with Blue Painting, long enough and deeply enough to write a full page of observations requires students to move past superficial examination. Reflective questions begin simply enough with "What did you notice about this painting?" Responses consistently reveal a fascinating variety of perceptions. Many students simply write exactly what they see, yellow triangle, red square, green circle, etc., while others form associations; "that looks like ..." or "that reminds me of ..." Epstein suggests the following questions, "What did you observe?" "In what ways were you surprised?" "How did you respond to that feeling of surprise?" "What interfered with your observations?" The goal, he says, "is to help students internalize a habit of selfquestioning."

The discussion engendered by these questions as they relate to student observations of Kandinsky's work stands in testament to the efficacy of Epstein's method. Students are fascinated by the many ways of seeing expressed by their classmates and appear to become more open-minded as a result of hearing them. There is a natural connection, or cause and effect, between asking reflective questions and active engagement, the fourth step in Epstein's method. Students find ways of engaging with the work they had not previously considered. At this point it is interesting to provide students with some context for the painting by discussing Kandinsky's color theories and

421 Ibid.

422 Ibid.

${ }^{423}$ Ibid., 13. 
his contention that a primary purpose of art is to express the innermost needs of the $\operatorname{artist.}^{424}$

The fifth component of Epstein's method is “Modeling. Thinking out loud and encouraging the student to do the same... Thinking out loud makes it apparent that good medical practice requires the constant effort of recognizing and correcting for errors, rather than merely the linear pursuit of protocol.”425 Introducing Kandinsky's ideas, along with those of other color theorists, will give students some idea of the intentionality with which artists make their decisions. By this point in the process, most students should feel comfortable with ambiguity and multiple viewpoints and they should also be willing to share their own thoughts, even if they find themselves disagreeing with others. Modeling could take the form of statements such as, "Kandinsky believed yellow could never have any sort of profound meaning, but I am not entirely sure what he meant by 'meaning'." This may seem a pointless esoteric statement, but it reflects a desire to understand what is being expressed and an acceptance that thoughtful consideration is being asked of the viewer.

Epstein's next step for encouraging a habit of mindfulness is practice, which he defines as, "disciplined repetition in controlled settings." ${ }^{\text {"26 }}$ Here he is referring to the active and intentional process of being aware of our own thoughts and reactions, which sounds quite simple. It is deceptively difficult, however, to break habitual patterns of thinking. As with the mindfulness breathing meditation, the objective when engaging with Kandinsky's work is to notice the patterns of our thoughts. An aesthetic response to color is a near universal human tendency, but one that varies between individuals. At this

${ }^{424}$ Kandinsky, Concerning the Spiritual in Art, 34-5.

425 Epstein, "Mindful Practice in Action (II)," 13-14.

426 Ibid., 14. 
point students should be asked to specifically consider the vibrant colors in Blue Painting, thinking carefully about the associations and emotions that arise. This type of deliberate metacognition is useful practice for future caregivers who will at times feel overwhelmed and who may experience strong reactions to specific patients or situations. Developing a practice of nonjudgmental awareness of our thoughts and emotions allows us to understand and respond to them in ways that are helpful rather than impulsive.

Epstein suggests practicing curiosity. ${ }^{427}$ If we consider Kandinsky's thoughts about yellow and blue, we may feel we understand his color choice in this particular painting where blue predominates and yellow appears in small, constrained forms. But approaching the work with curiosity, or beginner's mind, requires us to consider our own responses to the painting. Are we, in fact, soothed by the green? What stands out and draws our attention? What does it mean for a particular element in a painting to be powerful? It is worth noting here that even Kandinsky sensed some ambiguity in describing the power of color. He wrote, "Yellow, if steadily gazed at in any geometrical form, has a disturbing influence, and reveals in the colour an insistent, aggressive character," 228 but also, "Yellow is the typically earthly colour. It can never have profound meaning." ${ }^{29}$

Epstein's seventh step, praxis, involves taking the habits of mind practiced in the classroom and transferring them to lived experience. 430 Our objectives in studying Kandinsky's work were to practice attentive observation, critical curiosity, informed

\footnotetext{
427 Ibid.

${ }^{428}$ Kandinsky, Concerning the Spiritual in Art, 37.

429 Ibid., 38.

${ }^{430}$ Epstein, "Mindful Practice in Action (II)," 15.
} 
flexibility, and engaged presence. ${ }^{431}$ Reviewing these habits of mind with students suggests an alternate way of approaching both the familiar and the unfamiliar. Students should be asked to reflect upon and discuss the ways in which these habits might be brought to bear in relationships, schoolwork, leisure activities, and other aspects of their lives. Nurturing these habits of mind is a lifelong process, but one that carries the potential for improving both emotional well-being and the capacity for empathetic engagement.

The final step in Epstein's method is assessment and confirmation. In this step he is referring primarily to mock clinical encounters in which medical students are observed by their peers and mentors with everyone, including the student, subsequently completing questionnaires designed to assess evidence of reflective questions, curiosity, and presence. ${ }^{432}$ For students in an undergraduate classroom setting, the best method of assessment is to have them complete an out of class experiment in which they are asked to consider each of the objectives separately, make a conscious effort to apply at least one of them in a real life setting, and note the results. For example, students might be asked to devote their undivided attention to one particular task or conversation - no television or music in the background, no cell phone, no internet. This can be surprisingly difficult and enlightening for students accustomed to multitasking. Another possibility is to have students write a short reflective essay on something about which they are passionately curious. They are not to seek answers or attempt to satisfy their curiosity, but instead should simply reflect on the nature of that curiosity. Where did it come from? What

\footnotetext{
431 Ibid., 11-12.

432 Ibid., 16.
} 
does it motivate them to ask, read, or think about? How has it, or will it, influence their choices and behavior?

Encouraging students to examine their own patterns of thought and providing exercises that allow them to do so, teaches a type of self-awareness that has proven useful in combatting compassion fatigue, and it seems likely that such practices would be equally useful in preventing it. Mihaly Csikszentmihalyi's concept of flow includes many of the same mental practices as mindfulness. Csikszentmihalyi notes that the desire for happiness has always been a chief concern of mankind, and that this pursuit "is a circuitous path that begins with achieving control over the contents of our consciousness." "433 Csikszentmihalyi writes, "Flow' is the way people describe their state of mind when consciousness is harmoniously ordered, and they want to pursue whatever they are doing for its own sake." ${ }^{34}$ He goes on to say, "Everything we experience - joy or pain, interest or boredom - is represented in the mind as information. If we are able to control this information, we can decide what our lives will be like. The optimal state of inner experience is one in which there is order in consciousness." ${ }^{335}$

Csikszentmihalyi lists eight universal components of the state of flow:

First, the experience usually occurs when we confront tasks we have a chance of completing. Second, we must be able to concentrate on what we are doing. Third and fourth, the concentration is usually possible because the task undertaken has clear goals and provides immediate feedback. Fifth, one acts with a deep but effortless involvement that removes from awareness the worries and frustrations of everyday life. Sixth, enjoyable experiences allow people to exercise a sense of control over their actions. Seventh, concern for the self disappears, yet paradoxically the sense of self emerges stronger after the flow experience is over. Finally, the sense of the duration of time is altered; hours pass by

${ }^{433}$ Csikszentmihalyi, Flow: The Psychology of Optimal Experience, 2.

434 Ibid., 6.

435 Ibid. Italics original. 
in minutes, and minutes can stretch out to seem like hours. The combination of all these elements causes a sense of deep enjoyment that is so rewarding people feel that expending a great deal of energy is worthwhile simply to be able to feel it. ${ }^{436}$

According to Csikszentmihalyi, the activities and situations leading to this state of flow are different for every individual, but "optimal experience," and the psychological conditions that make it possible, seem to be universal. ${ }^{437}$ Understanding the flow experience, and working to find ways to bring such experiences into our lives creates a beneficial state in which thoughts are well ordered and attention flows effortlessly. As with the exercises that promote mindfulness, familiarity with the experience of flow allows one to transfer the same constructive states of mind to other life experiences.

Encouraging students to create nonrepresentational works of art fulfills the most important requirements for achieving a state of flow and will be described in the following paragraphs. Prior to the creative assignment, students should be familiar with the components and benefits of flow and should understand the purpose of the assignment as an intentional attempt to create and experience this state.

For small groups, the instructor may provide materials. Tempera paints are nontoxic and inexpensive. Providing the three primary colors as well as black and white allows for the creation of multiple hues, tints, and shades. Basic white printer paper or paper plates work well as supports, and inexpensive paint brushes in a variety of sizes can be reused multiple times. For larger classes, a set of watercolor paints (Crayola 16 count watercolor paint sets include black and white and are available for under five dollars in many locations) may be included in the list of required materials.

\footnotetext{
436 Ibid., 49.

437 Ibid.
} 
For this in-class assignment students are asked to create a fully abstract painting, one that contains no recognizable objects. Possible prompts for the assignment are to create a nonrepresentational painting of a favorite holiday, to create a painting that expresses a particular theme or concept, or to try and paint a specific emotion such as fear, boredom, or happiness. The idea behind the assignment is to have students work with color and line only. Students should have a clear goal in mind before they start to paint, and should thoughtfully consider the colors and forms that most closely represent the ideas they are hoping to express. Students should be given thirty minutes to work on their paintings, and they should be told that during this time nothing else is expected of them; their work is theirs alone, there are no expectations other than their attention to the project, and they will not be graded on their efforts.

Csikszentmihalyi notes that an optimal flow experience depends upon a "golden ratio between challenges and skills" - if the challenge of an activity exceeds one's skills, the activity is likely to be frustrating rather than fulfilling. Conversely, if the skill level is much higher than the activity demands, the activity will likely be boring and will not command one's full attention. ${ }^{438}$ A second impediment to flow is self-consciousness or self-criticism. ${ }^{439}$ Asking students to create a fully abstract work helps remove the idea that one must be "talented" or skilled at representational drawing.

Interestingly, I have had very few students who did not find this exercise enjoyable, or at least relaxing. Most students report experiencing some level of flow, particularly an altered sense of time passing and of being completely absorbed in their work. It is important to allow for a period of discussion and reflection once the exercise

\footnotetext{
438 Ibid., 50-3.

${ }^{439}$ Ibid., 64-5.
} 
is complete. Why were particular colors chosen? Were the colors appealing because of their association with memories, cultural artifacts, or the natural world? What types of line were used to express emotions or themes? What specifically enhanced or hampered a student's ability to experience the state of flow? Was there an impulse to compare one's work with others nearby? Was the inner critic present or absent?

Not all students will wish to make a habit of painting, of course, but what is important is helping them become aware of the benefits of the state of flow and the conditions that encourage such a state. This knowledge allows students to consciously bring more of these experiences into their lives. As with mindfulness, the objective is to recognize and practice a therapeutic state of mind. As Csikszentmihalyi notes, "Contrary to what we tend to assume, the normal state of the mind is chaos. Without training, and without an object in the external world that demands attention, people are unable to focus their thoughts for more than a few minutes at a time." ${ }^{440}$

It is possible that as a result of these practices of mindfulness and flow, some students will develop a greater appreciation for visual art, or will find a kind of art that captures their attention and awakens their curiosity. Some might even find the creation of nonobjective art allows them to experience a state of flow that helps maintain optimal habits of mind. But these are not the goals of the exercises. There is no expectation that students will come to appreciate art or its creation. The goal is to help students understand the importance of a particular state of mind in which they are present, engaged, curious, and open minded. Becoming familiar with this state of mind will then allow students to seek ways of maintaining it.

440 Ibid., 119. 
Previous chapters of this dissertation have made clear the importance of compassionate caregiver-patient relationships. Such compassion requires the consistent expenditure of emotional energy, a giving of self that if not replenished, can intensify the effects of burnout and lead to compassion fatigue. Caring for the body is important exercise, proper nutrition, and healthy sleep habits all contribute to emotional well-being, but specific practices that maintain a healthy state of mind are also crucial for caregivers. Mindfulness and flow are beneficial and restorative practices that equip future caregivers for lifelong compassion.

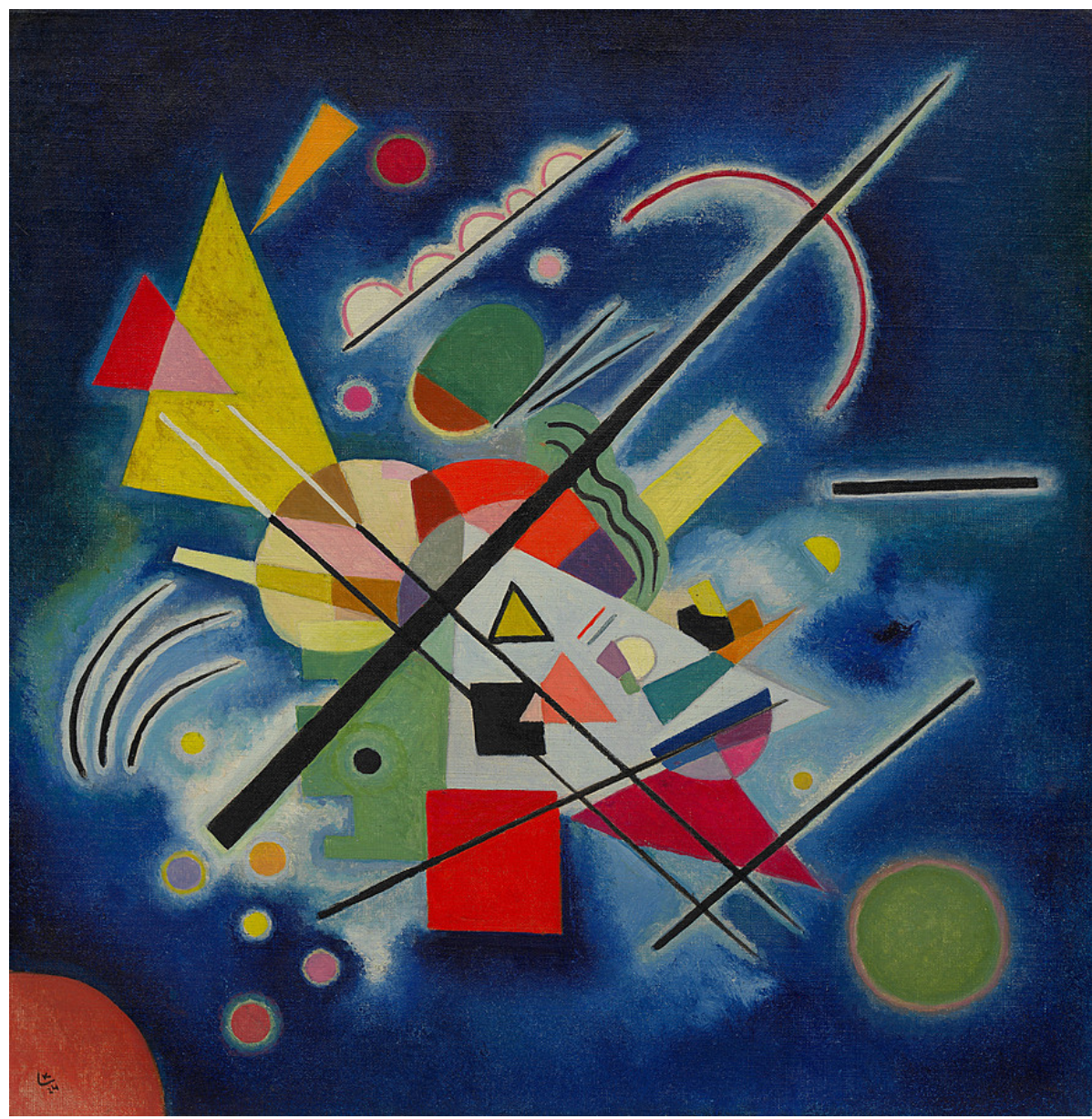

Figure 2: Blue Painting Wassily Kandinsky 1924 http://www.guggenheim.org/new-york/collections/collection-online/artwork/1943 


\section{CHAPTER FIVE - THE IMPORTANCE OF MEDICAL HUMANITIES PEDAGOGY: A CASE STUDY}

"Might not the powers of medicine and nursing and therapy improve by virtue of our education in hearing others tell of pain?" 441

\section{Rita Charon and Maura Spiegel}

The ways in which we allow our patients to tell of pain and the quality of our listening to their story has everything to do with whether or not we are able to mitigate their suffering. As caregivers we must learn what it means to be compassionate, to offer our undivided attention in a nonjudgmental way, and to protect our own mental and emotional well-being in the process. As teachers, our job is to provide future caregivers with the tools they will need to accomplish these tasks.

This dissertation suggests the primary objectives of medical humanities pedagogy should be twofold: (1) To help future caregivers form compassionate, therapeutic relationships with their patients, and (2) to help them care for themselves in ways that prevent compassion fatigue. To that end, providing students with the tools to develop and maintain a sense of compassion for patients and themselves is one of the most

${ }^{441}$ Rita Charon and Maura Spiegel, "On Conveying Pain/On Conferring Form," Literature and Medicine 24, no. 1 (Spring 2005): vi, doi:10.1353/lm.2005.0019. 
important goals for undergraduate medical humanities education. I have utilized the following definition of compassion as put forth by researchers at Stanford University:

A complex multidimensional construct that is comprised of four key components: (1) an awareness of suffering (cognitive component), (2) sympathetic concern related to being emotionally moved by suffering (affective component), (3) a wish to see the relief of that suffering (intentional component), and (4) a responsiveness or readiness to help relieve that suffering (motivational component). ${ }^{442}$

But, I have argued that the second component of compassion should reflect empathetic concern, defined as feeling with another person and reflecting an interactive relationship, rather than sympathetic concern, which alludes to feeling for another person and therefore preferences the role of the observer or caregiver. ${ }^{443}$ I have proposed that, in order to develop the skills necessary for practicing this type of compassion for their patients and themselves, students must be taught the essentials of narrative medicine, bioethics, and mindful self-care. Previous chapters have argued that literature and the visual arts offer the best means of introducing and instilling these concepts and have suggested specific pedagogical strategies for doing so. In this final chapter I present a case study, a particular type of medical literature in which details of a specific case are presented as a means of sharing knowledge, insights, or questions with other caregivers. ${ }^{444}$ Andrew Marsh's narrative and his art offer future caregivers a means of understanding why their attention to narrative, ethics, and their own well-being is vital to the compassionate practice of healthcare.

\footnotetext{
${ }^{442}$ Jazaieri et al., “A Randomized Controlled Trial of Compassion Cultivation Training," 23. Italics original.

${ }^{443}$ Stein-Parbury, Patient \& Person: Interpersonal Skills in Nursing, 141.

${ }^{444}$ Michael R Kidd and Deborah C Saltman, "Case Reports at the Vanguard of 21st Century Medicine," Journal of Medical Case Reports 6, no. 156 (January 2012): 1, doi:doi:10.1186/1752-1947-6-156.
} 
Marsh is a gifted artist who suffers chronic pain as a result of damaged discs in the cervical, thoracic, and lumbar regions of his spine. His experience with the healthcare community demonstrates the profound necessity for medicine practiced with narrative competence and compassion, particularly in the case of chronic pain and other conditions for which traditional medicine still has surprisingly little to offer. Marsh's case also represents a situation in which caregivers are confronted with the dual challenges of having few effective treatment options and attempting to create a mutually therapeutic relationship with the infamous "noncompliant patient." (More about this designation later.) This is precisely the scenario in which many caregivers would feel the need to become emotionally detached from the patient and/or to suppress their own emotions, both of which are precursors to compassion fatigue. ${ }^{445}$ Marsh's story thus brilliantly exemplifies the importance of a medical humanities pedagogy that provides tools for compassionate relationships and mindful self-care. In addition, his artwork offers the viewer a brilliant visual representation of physical pain, thereby providing some means of understanding an experience that "does not simply resist language, but actively destroys it." 446

Each of Marsh's wood and metal sculptures represents a creative confluence of penetrating intellect and sheer brute force. They are magnificent in their power and organic beauty, but in that beauty a sense of torment is evident: they bulge and twist with sharp angles and broken lines. Marsh preserves the essence of his medium - the strength and grandeur of a sycamore tree, for example - while simultaneously contorting the form, suggesting the presence of some internal

\footnotetext{
${ }_{445}$ Coetzee and Klopper, "Compassion Fatigue within Nursing Practice."

${ }^{446}$ Scarry, The Body in Pain: The Making and Unmaking of the World, 4.
} 
paroxysm. The effect is disconcerting, and it is meant to be so. For students of medical humanities, it is worthwhile to explore the issues raised by Marsh's work, perhaps even to feel something of his anger, so as to avoid complacency in the face of healthcare's ongoing challenges. ${ }^{447}$

Marsh's passion lies in creating large scale welded, cast metal, and wood sculptures. A classically trained artist, Marsh earned an MFA from Southern Illinois University in 2001, and hoped to enjoy a lifelong career in the arts. In December 2002 while working as the principle metal fabricator for the City Museum in St. Louis, Missouri, Marsh was bending a large, flat, steel bar by hand. The bar was fifteen feet long, four inches wide, and half an inch thick. One end of the bar was welded down and Marsh was bending the other end into a complex twist that arched back on itself. $\mathrm{He}$ worked section by section while an assistant welded each segment into place. At the hardest part of the bend, Marsh's feet slipped from under him and the bar recoiled, throwing him into the air and hyperextending his back. Even though he was in pain, Marsh continued working and later sought help from a chiropractor. ${ }^{448}$

In February 2003, after progressively worsening back pain, Marsh sought traditional medical treatment. At that time an MRI revealed bulging discs in the lumbar, thoracic, and cervical regions of his spine. Marsh was given narcotics, muscle relaxers, anti-epileptics (used to treat nerve pain), and non-steroidal anti-inflammatory drugs (NSAIDs). He was limited to "light duty" at work, which, for Marsh, continued to involve "strong man fabrication" - bending, twisting, lifting, climbing, crawling, and being physically compressed into tight spaces as he designed and carried out construction

${ }^{447}$ Lisa Shugoll, adapted from the curator's statement for 1000 Cuts, an exhibit of Andrew Marsh's work. University of Louisville, September 2013 - February 2014.

${ }^{448}$ Andrew Marsh, Personal Interview, November 25, 2012. 
of MonstroCity, an enormous interactive sculpture and playground at the City Museum. Marsh was also treated with physical therapy, but was released from the program in August 2003, having reached "maximal medical improvement" according to his physician and physical therapist. Marsh continued working in spite of "constant pain and a litany of re-injuries." ${ }^{449}$

On March $4^{\text {th }}, 2004$ while working on MonstroCity, Marsh lost movement and sensation in both legs. He was taken to an urgent care facility and then transferred to a hospital where an MRI showed no significant change in his injury. Physical therapy was resumed but Marsh remained confined to a wheelchair until the following June. During that time he was referred to a psychiatrist for "management of his medications." He was treated with opiate (narcotic) analgesics, anti-epileptics, anti-inflammatories, antipsychotics, and anti-depressants in addition to physical therapy and trigger point injections with anesthetics and steroids. He reacquired the use of his legs in September 2004, but remained partially wheelchair bound. The pain worsened and his narcotic medication was changed from fentanyl to the more powerful morphine. He was also treated with epidural steroid injections and continued trigger point injections. In February 2005 Marsh quit all medications "cold turkey." He asserts,

I was mad at everything. Mad at the doctors. Mad at myself. Tired of being controlled by meds that didn't have the effects they were supposed to and that complicated everything. I felt lost. I saw a general practitioner every two months, a physical therapist three times a week, a psychiatrist once a week, and the pain management doctor three times a week. And I finally just told everyone I wasn't coming back. The meds were getting more extreme and I didn't feel like it was going anywhere. They offered no alternatives; this was their program. The objective was to get me out of pain and

${ }^{449}$ Ibid. 
they just kept increasing the pain meds. I was comatose for three months. ${ }^{450}$

Never able to work more than a few hours at a time and often unable to work at all, Marsh was fired from his job at City Museum in May 2005. He moved to Louisville, Kentucky in December, and was referred to the pain management clinic at Norton Hospital. He requested no narcotics or anti-depressants and was able to cope with his pain without such medications until March 2006. At that time he began receiving epidural steroid injections every six months at the site of the lumbar protrusion. The injections provided moderate pain relief for two to four months, but he continued to experience radiating pain from the other damaged areas. By late 2012 his medication regimen included Relafen, an NSAID, twice a day, Tramadol, a non-narcotic pain reliever twice a day, and a muscle relaxer he took about every two weeks. In 2012 Marsh's strategy for pain control revolved around fortitude and stamina:

I have these long periods of endurance, to see how long I can go without taking anything. My whole treatment now is based on plateau pain medication, not an escalating schedule. I'm not gonna do that again. So when the meds don't work, they don't work. To help when they don't work I usually drink bourbon. On a basic pain scale I maintain about a seven. When I take a muscle relaxer that drops to about a six and that's how I exist. ${ }^{451}$

By medical standards, Marsh was considered a very high functioning chronic pain patient, holding a full-time job as assistant director of the Conn Center for Renewable Energy at the University of Louisville, frequently riding arduous trails on his bike, and creating massive sculptures of wood and metal. When asked how he achieved this level of functionality in spite of his pain, Marsh replied,

\footnotetext{
450 Ibid.

451 Andrew Marsh, Personal Interview, December 2, 2012.
} 
I walk two miles every night. I also ride about five thousand miles a year. It keeps me physically fit and helps my state of mind. I pour metal. I make sculpture. I use my chainsaw. It's an expressive medium for trying to give form to how I feel. It's an outlet. I feel great while I'm doing it and I feel horrible afterward. The subject matter is all body pain and injury. I work as much as I can, then completely withdraw from it. 452

Within the healthcare community, Marsh was considered a success story, but he was also a "non-compliant patient," a patient who refuses to follow medical advice. The trail riding, the heavy lifting, and working with a chainsaw were all likely to worsen his injury or create additional injuries, and thus were contraindicated, yet Marsh preferred to take those risks rather than give up the things he most enjoyed doing. In 2012, Marsh's relationship with most of his healthcare providers was contentious, to say the least.

While acknowledging that medical treatment allows him to function in spite of his pain, Marsh is resentful that it took years of suffering before he was able to achieve an acceptable quality of life. Arriving at this point required repeated requests for an altered treatment plan and finally a decision to discontinue all therapy and medications - an extremely dangerous move considering the drugs he was taking at the time. When asked via email what doctors could have done differently that might have prevented this risky decision and provided help more quickly, Marsh replied,

I don't know what they could have done. I'm not a doctor. I was just tired of being drugged and semi-conscious, but still in pain. My friends didn't recognize me, my wife and son avoided me, and I was totally miserable. The side effects of that much medication really worried me, especially the morphine. I asked the pain doc and the shrink about their choice of regimen, and both of them told me I was going to be a long-term management case, and to prepare for taking all these meds for a while. I found that unacceptable, so I fired both of them, quit the meds, and reclaimed my life. If I was

452 Ibid. 
not going to be out of pain, I felt there was no reason for being drugged. I still feel that way. ${ }^{453}$

Careful consideration of Andrew's narrative is revealing. He intensely disliked the sedation associated with his medication regimen. He felt isolated from his friends and family. He was worried about the long-term effects of the medicine. He was lost and miserable, suffering physically, yes, but also suffering emotionally. He felt disabled by both the pain and the treatment regimen. His physicians conceded that Marsh's pain was intractable and likely to be chronic, (an unfortunate fact for many patients, and one that will be discussed more fully later in this chapter). In spite of Marsh's assertion that a portion of his misery stemmed from the effects of the medication, which was doing very little to relieve his pain or his emotional distress, his physician suggested he just get used to being on the meds. Marsh makes it very clear he discussed all aspects of his misery with his physicians, even sharing his personal journal with them at one point, but no one heard his whole story.

In the world of healthcare there is perhaps no more vexing problem for caregivers and their patients than that of chronic pain. In 2011 the Institute of Medicine (IOM) published Relieving Pain in America: A Blueprint for Transforming Prevention, Care, Education, and Research. According to this document, "Common chronic pain conditions affect approximately 100 million U.S. adults . . . Many shortfalls in pain assessment and treatment persist despite humanity's intimate familiarity with pain throughout history ... In general, these shortfalls arise through gaps in policy, treatment, attitudes, education and research." 454

${ }^{453}$ Andrew Marsh, "Paper," December 5, 2012.

${ }^{454}$ Institute of Medicine (IOM), Relieving Pain in America (Washington, DC: National Academies Press, n.d.), 2. 
Patients in pain seek help from medical caregivers who, by virtue of their training and experience, hopefully possess the knowledge and expertise necessary to provide relief of suffering. The situation is complicated, however, because a person in pain often has no readily available language with which to express the nature of his or her suffering. In addition, the medical community generally relies on the presence of empirical evidence, such as abnormalities in laboratory values, physical exam, or diagnostic imaging to make a diagnosis and suggest a treatment plan, but for the patient in pain, such evidence is often absent. Acute pain occurs when there is some form of injury to the body that results in tissue damage. As a result of physiological processes that remain very poorly understood, acute pain often becomes chronic, meaning it persists even after the initial injury has healed. ${ }^{455}$ In addition, certain conditions such as fibromyalgia cause pain and tenderness even though no initiating tissue damage has ever been present. ${ }^{456}$ Functional MRI scans show changes in the forebrains of patients experiencing pain even in the absence of other physical indicators and can be a reliable clue to the presence of pain and the efficacy of treatment, ${ }^{457}$ but such scans are unnecessary for most patients, leaving them with no empirical means of proving they are in pain.

In the third edition of Essentials of Pain Management, Robert R. Edwards and Charles B. Berde acknowledge, "By its very definition, pain is an internal, subjective experience that cannot be directly observed by others or measured by the use of

\footnotetext{
455 C. Voscopoulos and M. Lema, "When Does Acute Pain Become Chronic?," British Journal of Anaesthesia 105, no. 51 (December 2010): i72, doi:10.1093/bja/aeq323.

${ }^{456}$ Adam R. Burkey, "Neuroanatomy and Neurophysiology of Pain," in Treatment of Chronic Pain by Interventional Approaches: The American Academy of Pain Medicine Textbook on Patient Management, ed. Timothy R. Deer et al. (New York: Springer, 2014), 3.

457 Ibid., 8.
} 
physiologic markers or bioassays." 458 And yet for the patient in pain, communicating the nature of suffering is all too often relegated to forms from which data can be standardized. The most commonly used pain assessment tools include the numeric pain scale (NPS), the visual analog scale (VAS), and the McGill Pain Questionnaire (MPQ), each of which is designed to allow patients in pain a way of conveying their experience. ${ }^{459}$

The NPS is a verbal assessment tool in which the patient is asked to rate his or her pain on a scale from zero to ten, with zero being no pain and ten being the worst possible pain. ${ }^{460}$ The NPS has become the ubiquitous standard by which patients communicate the intensity of their pain because it is quick, easy, can be used with non-literate patients, requires no materials, and has proven a reliable indicator of the efficacy of treatment. ${ }^{461}$ It offers no means of describing the quality of pain and is generally only used to convey severity, improvement, or worsening of pain.

The VAS is simply a line, usually ten centimeters in length, with pain qualifiers at either end [Figure 3]. The line may be placed vertically or horizontally, and the qualifiers are phrases such as "No pain" at one end and "Worst possible pain" at the other. The patient is asked to place a mark on the line indicating his or her current level of pain. The line may be segmented and numbered, and visual representations of simple facial

\footnotetext{
458 Robert R. Edwards and Charles B. Berde, "Pain Assessment," in Essentials of Pain Medicine, ed. Honorio Benzon et al., 3rd ed. (Philadelphia: Saunders, 2011), 28.

${ }^{459}$ Gillian A. Hawker et al., "Measures of Adult Pain: Visual Analog Scale for Pain (VAS Pain), Numeric Rating Scale for Pain (NRS Pain), McGill Pain Questionnaire (MPQ), Short-Form McGill Pain Questionnaire (SF-MPQ), Chronic Pain Grade Scale (CPGS), Short Form-36 Bodily Pain Scale (SF-36 BPS), and Measure of Intermittent and Constant Osteoarthritis Pain (ICOAP).," Arthritis Care and Research 63, no. S11 (November 2011): S240-52, doi:10.1002/acr.20543.

460 John D. Childs, Sara R. Piva, and Julie M. Fritz, "Responsiveness of the Numeric Pain Rating Scale in Patients with Low Back Pain," Spine 30, no. 11 (June 2005): 1331, doi:10.1097/01.brs.0000164099.92112.29.

${ }^{461}$ Hawker et al., "Measures of Adult Pain," 242.
} 
expressions are often included for patients unable to read English. Like the NPS, this scale is used to convey intensity of pain and changes in that intensity.

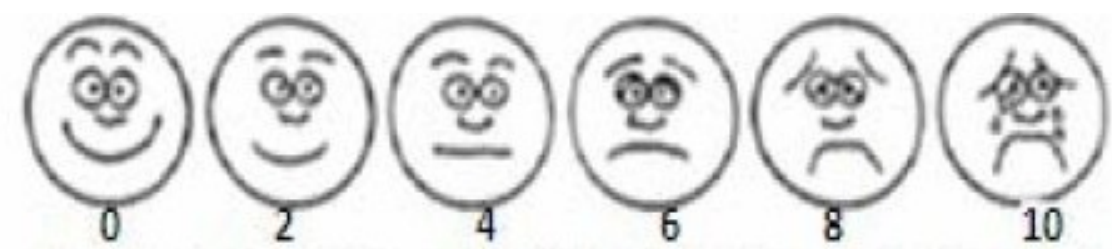

No Hurt Hurts little Hurts littleHurts little Hurts little Hurts worst bit more more more

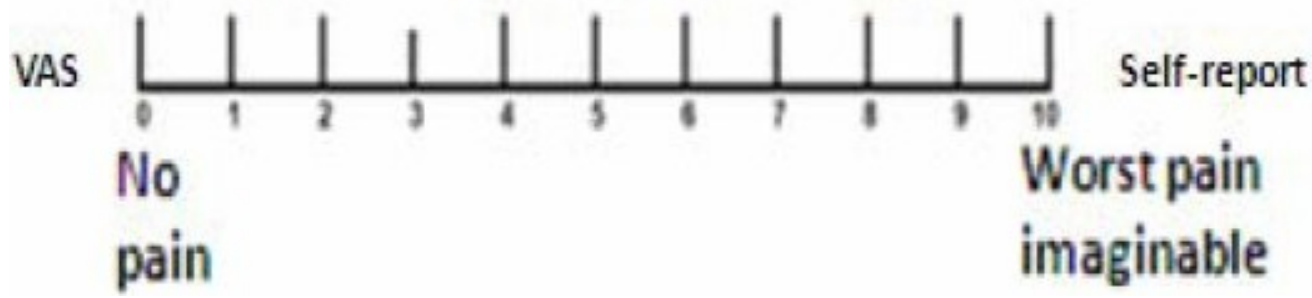

Figure 3 Visual Analog Pain Scale 462

The most comprehensive of these three assessment tools is the McGill Pain Questionnaire [Figure 4], which is designed to convey both intensity and quality of pain. Ronald Melzack developed the MPQ in 1975 after conducting extensive research into the words patients used to describe their pain. Melzack concluded, "the pain descriptors (at least a large number of them) could be classified into three major groups: sensory, affective, and evaluative." ${ }^{\prime 63}$ In order to complete the questionnaire, patients are asked to circle one word in each section that best describes their pain. The test administrator scores the responses based upon a predetermined numerical ranking for each word and the sum of these values gives the pain rating index, or PRI. In addition, the patient is

462 Anuj Gupta et al., “Clinical Aspects of Acute Post-Operative Pain Management \& Its Assessment.," Journal of Advanced Pharmaceutical Technology and Research 1, no. 2 (April 2010): 102.

${ }^{463}$ Ronald Melzack, “The McGill Pain Questionnaire,” Anesthesiology 103 (2005): 201. 
asked to describe the present pain intensity (PPI) by rating it on a scale of 0 - no pain, to 5 - excruciating pain. ${ }^{464}$

Marsh is familiar with all of these assessment tools and reports that he has been asked to complete each of them on multiple occasions. He finds them all equally useless in elucidating his experience, although it is notable that he, like most patients, continues to rely on the numeric pain scale when attempting to describe the intensity of his pain. He began filling out the MPQ during one of our interviews in 2012, but quickly became frustrated [Figure 5].

I mean, how am I supposed to do this when every single one of these words is applicable at any given time? It changes as I move, how do I show that? There's no way to represent the continuum of time! If I had ten of these that I could fill out moment to moment with different movements - it changes when I stand up, it changes when I twist, it changes if I bend over. What is this supposed to tell someone? They compare it with scans, which are based on me holding completely still, in a fixed position; they don't show what it looks like when I bend over; no one's ever seen that. What I experience is far beyond this tool. [Referring to the human form on which the patient is supposed to mark the location of his or her pain] How do I show that it starts here, but it radiates through my arms and down my legs and out my head? There's nothing on here that says 'It feels like I'm being dipped in acid!'465

While standardized assessment forms are indispensible for research studies attempting quantitative measurement of pain levels and pain control, they become counterproductive when used as a primary means of gathering information from individual patients. The principles of narrative medicine provide a much more useful context through which the patient's experience can be shared with a caregiver. The MPQ may provide useful words for a patient attempting to convey an inexpressible sensory experience, but it must be used to begin a conversation and not as an endpoint. Narrative

464 Edwards and Berde, "Pain Assessment," 29.

465 Marsh, Personal Interview, December 2, 2012. 
practice requires a willingness to engage in a qualitative rather than quantitative approach to diagnosis and treatment, and because it is the only means of understanding the patient's suffering, it is ethically mandated.

In his discussions of medical morality, Edmund Pellegrino observed, "To act in the patient's interests implies the promise that the physician will act in such a way that the patient's interpretation of the good life will be protected and that he will have an opportunity to make the value choices that so often underlie the decisions about what should be done. ${ }^{466}$ Allowing a patient to make his or her own value choices requires an attitude of nonjudgment on the part of the caregiver. For patients with chronic pain this is complicated by treatment practices that have traditionally relied on opioid medications.

According to Marsh, the fact that he was physically strong enough to continue working for a time after his injury coupled with his "punk rocker" appearance (spiked hair and piercings) often led doctors to conclude that he was seeking drugs he did not physically need. "C'mon!!” he writes in an email discussing this experience, "I had ridiculously free access to any number of illicit drugs, but instead chose to spend hours of my life WAITING to be seen by a doctor, then being spoken to with utter disdain and disbelief once seen." 467 Marsh's perception is corroborated by the IOM report, which notes a troublesome attitude within the healthcare community; "when pain could be ascribed to an underlying disease, such as cancer, it was accepted as real and treated with concern. [When] underlying disease was less well defined, the cultural perception of and response to the pain by the health care community was dramatically different." ${ }^{\prime 468}$

\footnotetext{
466 Edmund Pellegrino, "Toward a Reconstruction of Medical Morality," The American Journal of Bioethics 6, no. 2 (2006): 67.

${ }^{467}$ Marsh, "Paper." Emphasis original.

468 Institute of Medicine (IOM), Relieving Pain in America, x.
} 
The sheer number of patients in pain coupled with a shortage of caregivers trained to manage chronic pain means that most patients are treated by primary care physicians who attempt to alleviate the pain as best they can, often turning to narcotic medications. ${ }^{469}$ Opioids have become a first line approach to pain management for reasons including expediency, pressure from the patient for immediate pain relief, and marketing by pharmaceutical companies. ${ }^{470}$ This rise in treatment with opioid medications is associated with an increase in overdose and overdose related deaths. ${ }^{471}$ Writing in March 2015, Franklin et al., declare, "An epidemic of morbidity and mortality has swept across the United States related to the use of prescription opioids for chronic noncancer pain. More than 100000 people have died from unintentional overdose, making this one of the worst manmade epidemics in history." 472 Adding to this tragedy is the fact that research has shown that although opioid analgesics are useful in the treatment of acute pain, they are ineffective in treating chronic pain, and sometimes even make it worse. ${ }^{473}$ According to Michael Schatman, Executive Director of the Foundation for Ethics in Pain Care, the lack of education related to pain management and the risks of opioids illuminates an enormous breach of medical ethics. ${ }^{474}$

Dr. Jerome Schofferman of the San Francisco Spine Institute notes that the pharmaceutical industry currently funds forty to sixty percent of all continuing medical

\footnotetext{
469 John F. Peppin et al., "The Complexity Model: A Novel Approach to Improve Chronic Pain Care," Pain Medicine 16, no. 4 (April 2015): 654-5, doi:10.1111/pme.12621. 470 Ibid., 655.

${ }^{471}$ Joseph W. Frank et al., "Update in Pain Medicine for Primary Care Providers: A Narrative Review, 2010-2012," Pain Medicine 15, no. 3 (March 2014): 427, doi:10.1111/pme.12337.

472 Gary Franklin et al., "A Comprehensive Approach to Address the Prescription Opioid Epidemic in Washington State: Milestones and Lessons Learned.," American Journal of Public Health 105, no. 3 (March 2015): 463, doi:10.2105/AJPH.2014.302367.

473 Wilson M. Compton, Maureen Boyle, and Eric Wargo, "Prescription Opioid Abuse: Problems and Responses," Preventive Medicine 80 (November 2015): 5, doi:10.1016/j.ypmed.2015.04.003. ${ }^{474}$ Michael E. Schatman, "The Medical-Industrial Complex and Conflict of Interest in Pain Education," Pain Medicine 12 (December 2011): 1710-12, doi:10.1111/j.1526-4637.2011.01284.x.
} 
education offered to physicians. ${ }^{475}$ Schofferman acknowledges a mutually beneficial relationship between pharmaceutical companies and physicians when it comes to "the development and evaluation of new medications," but also points out the inherent conflict of interest when the biomedical industry actively markets drugs and devices at physician education conferences. ${ }^{476}$ "Physicians attending a CME [continuing medical education] conference supported by industry are more likely to use the sponsoring company's product ... industry marketing strategies rely heavily on physician education in a variety of formats to boost drug sales." ${ }^{477}$ Schofferman recommends complete divestment between physician medical associations and the pharmaceutical industry, but acknowledges, "it may be difficult to accomplish and even to convince some educators and leaders of its necessity, importance, and eventual value." ${ }^{478} \mathrm{He}$ also notes, "bias and influence created by COI [conflict of interest] are not intentional, but are an unconscious neuropsychosocial response to which everyone is susceptible." ${ }^{479}$ It is beyond the scope of this dissertation to address the myriad implications of Schofferman's observations, but they do illuminate the importance of diligent attention to both patient narrative and the presence of outside influence. Marsh makes it clear that opioid medications did little to relieve his pain and significantly worsened his quality of life, yet his physician continued to prescribe them, perhaps because other options required more difficult and time consuming conversations.

\footnotetext{
475 Jerome Schofferman, "The Medical-Industrial Complex, Professional Medical Associations, and Continuing Medical Education," Pain Medicine 12, no. 12 (December 1, 2011): 1713, doi:10.1111/j.1526-4637.2011.01282.x.

476 Ibid.

477 Ibid., 1716.

478 Ibid.

${ }^{479}$ Ibid., 1714.
} 
A recent article in Clinical Psychology and Psychotherapy notes, "The experience and report of pain is a subjective and private one, which is composed of one's perception not only of the pain severity but also of the suffering related to the pain. Empirical findings suggest that perceived disability, or one's perception of his or her ability, impacts medical and functional outcomes in those with CP [chronic pain]. In fact, perceived disability is found to affect these outcomes regardless of the primary cause or nociceptive origin, duration and severity of pain." ${ }^{480}$ The importance of this finding in mitigating the suffering of patients in pain cannot be overstated. Patients have better outcomes, which is to say a better quality of life, if they do not feel disabled by their pain. The article also notes, "high NA [negative affect] (particularly anger, anxiety, boredom and sadness) was the most important predictor of higher current and subsequent pain levels, followed by depressive mood." 481 In cases where physical pain cannot be eliminated, it is imperative that physicians understand what brings enjoyment and empowerment to their patient. To label Marsh "non-compliant," or to insist on a treatment regimen that would eliminate the activities he most enjoys is not compassionate healthcare.

The process of restoring Marsh's well-being might have started much earlier had any of his physicians taken the time to determine what his pain actually meant to him and what had been lost as a result of his accident. Marsh writes,

Perhaps the worst part of all is what has happened to my expectations of medically supported health. I was assured my entire life up to this point that if and when I became ill or injured, a doctor could be trusted to sort

\footnotetext{
480 Jessica C. Payne-Murphy and Abbie O. Beacham, "Revisiting Chronic Pain Patient Profiling: An Acceptance-Based Approach in an Online Sample," Clinical Psychology and Psychotherapy 22, no. 3 (June 2015): 240, doi:10.1002/cpp.1886.

481 Ibid., 241.
} 
me out. It came as a shock to find the callous disregard for my quality of life or even for the fact that I had been injured at all! ${ }^{482}$

Marsh's healing began when he insisted on a treatment plan that maintained a quality of life he found acceptable. His refusal to be disabled or to take medications that made him feel worse were healthy responses, the efficacy of which are born out by current research, yet none of which were recommended by his clinicians. His arduous path to recovery is filled with valuable insight for caregivers.

Marsh's current large-scale sculptures and performance art had much smaller, but equally provocative precursors. By 2007, Marsh was working full time as a grant writer at the J. G. Brown Cancer Center, but was still physically unable to resume his previous metalwork, and remained frustrated by the loss of this creative outlet. He began extracting small bits and pieces of cardboard, plastic, and metal from his household garbage and fabricating these into sculptures he called Pain Trophies [Figure 6]. As his physical strength and emotional outlook improved, he created sand molds for the patterns and with the help of friends, cast the sculptures in metal [Figure 7]. These twisted, tortured sculptures are extraordinary visible expressions of pain, and their creation marked a major milestone in his healing process.

From 2006-2015 Marsh continued a pain management regimen of Tramadol, Relafen, and lumbar spinal steroid injections. His pain level was cyclical, temporarily improving for a month or two after the steroid injection, but generally staying around a six. The steroid injections triggered periods of internal rage that, while "hugely productive for chainsaw wood carving," created tension in his relationships. He continued to work with a chainsaw, creating sculptures from very large felled trees, often

482 Marsh, "Paper.” 
in remote locations [Figure 8] and coped with the pain by creating a flat bench where he could lie down, stretch, and readjust his spine [Figure 9]. ${ }^{483}$

In January 2015, Marsh was working alone at a remote site, lifting heavy wood and carving in snow. Although his pain was no greater than usual at the time, he later noticed worsening pain in his left leg. He continued working although his sciatic route pain increased to an eight or nine level, and assumed the steroid injection he had received in December was wearing off early. His plan was simply to cope with the pain until his next injection in June, a technique he had been using for years, and to discontinue large scale carving until the pain subsided. In March 2015, he created Walking Wounded [Figure 10], a site-specific installation and performance piece consisting of twenty-one wood molds for iron casting, and three telephone pole sized torches used in the casting performance.

When molten iron, heated to greater than three thousand degrees Fahrenheit, is poured into molds carved in recently felled trees, the water content in the unseasoned wood creates enormous steam explosions that expel the molten metal forty to fifty feet high. The explosions may repeat two or three times from every mold [Figure 11]. For Marsh, the molds represent vertebral discs, and the explosions give visual form to "the constantly occurring set of sensations when living with the presence of chronic back pain. They are visual representations of pain, inflammation, spasms." Such variations on his theme of pain-related artwork reflect his own ongoing misery and also create a connection to the suffering of others. His work remains installed on the grounds of Sloss Historical Furnaces in Birmingham, Alabama. ${ }^{484}$

\footnotetext{
${ }^{483}$ Andrew Marsh, Personal interview, October 24, 2015. ${ }^{484}$ Ibid.
} 
In December 2013, I helped curate an exhibit of Marsh's sculptures in Ekstrom Library on the University of Louisville campus. My goal was to expose my own students and the university community to the expressive power of Marsh's work and to help them understand the artist's drive to create even in the face of physical pain. Marsh's artist's statement for the exhibit reveals both his inspiration and his hope for the work:

A product of boundless enthusiasm tempered with chronic pain, each sculpture rises from a series of decisions based on imperfect information and questionable motives in a moving spectrum of experience. My abstract carving with a chainsaw starts with a battle plan full of contingencies and unknowns. Chaos and disorder of the unimaginable are balanced with desire and skill to generate expressions that resonate, rendering that which is unseen, but felt, experienced, and endured ... I am unwilling to succumb to laziness, indifference, or misanthropy, and am determined to live well. As much as the twisting pain urges otherwise, I am compelled to instill a balance between its brutal exorcism, eruptions of maniacal happiness, and the glow of sanity retained. ${ }^{485}$

Marsh continued to find emotional comfort in creating large-scale sculptures, but notes, "At the time of creating and pouring Walking Wounded, the sciatic pain was the worst it had ever been and I was having trouble walking. My left leg was dragging." 486 After the show, Marsh visited his physical therapist for a massage, but the therapist recognized a potentially serious situation and instructed him to call his physician, who scheduled an MRI for the next morning. After viewing the results of the MRI, which showed a herniated lumbar disc, Marsh's pain management physician scheduled an appointment for Marsh with a neurosurgeon. Ten days later Marsh had a surgical repair

${ }^{485}$ Andrew Marsh, "Artist's Statement," 1000 Cuts, University of Louisville. September 2013-February 2014.

486 Marsh, Personal interview. 
of the herniated disc and now, for the first time in years, his pain level is usually about a three. ${ }^{487}$

Marsh and his neurosurgeon are currently working to wean him off both the Tramadol and the NSAID, and Marsh is restricted to "normal" activity - riding his bike on the road, but not trails, walking up to five miles per day, and light weight lifting in the gym at the physical therapy complex. Emotionally, Marsh is working to regain some sense of equilibrium in his life. Although his pain levels decrease with daily activity, he still wakes with a level of five or six, which can trigger depression. His relationships remain strained after years of dealing with the consequences of constant pain and pain medications.

Marsh relates that his neurosurgeon predicts re-injuries in the future, given the fragility of Marsh's spine and the type of activities he enjoys; yet the surgeon respects Marsh's decisions. Marsh considers this relationship the best he has ever had with a caregiver because he does not feel judged or ridiculed for the choices he makes and because his own goals and desires are given consideration and respect. Marsh favorably refers to the anesthesiologist who managed his pain medications and steroid injections prior to surgery as a "pill pushing and needles kind of guy."488 Ironically, caregivers whose focus is entirely upon the relief of physical pain are often ineffective as healers.

The IOM considers effective pain management "a moral imperative, a professional responsibility, and the duty of people in the healing profession," but also acknowledges the complexity of chronic pain and the need for an interdisciplinary

\footnotetext{
487 Ibid.

488 Ibid.
} 
approach to its treatment. ${ }^{489}$ Since 2004, psychological treatment for patients with chronic pain has focused on cognitive behavioral therapy (CBT) designed to encourage acceptance and commitment, "living with pain without reaction, disapproval or attempts to avoid it ... a disengagement from struggling with pain, a realistic approach to pain and pain-related circumstances, and an engagement in positive everyday activities." ${ }^{\prime 40}$ For some patients, the very things that give their lives joy and meaning are the things that put their physical bodies in jeopardy. Being unable, or fearing that one will become unable to participate in these activities often causes more suffering than physical pain. The affective and motivational components of compassion come from an attitude of nonjudgment in which the caregiver respects the patient's self-knowledge. Unfortunately, multimodal treatment and narrative based medical care are not available for many patients suffering chronic pain.

In a position paper published in 2009, Pain Medicine attempted to address the myriad problems associated with chronic pain treatment in the US and noted, "no single physician trained in pain medicine possesses the full scope of medical training an knowledge that has become necessary in the modern treatment of pain conditions." ${ }^{491}$ The authors recommend development of a two-year residency program following graduation from medical school that would "train physicians to treat the most complex pain conditions, assuring competence in the biopsychosocial 'whole person' perspective and the development of the interdisciplinary approach to pain care that is so lacking in

\footnotetext{
${ }^{489}$ Institute of Medicine (IOM), Relieving Pain in America, 3.

${ }^{490}$ Payne-Murphy and Beacham, "Revisiting Chronic Pain Patient Profiling," 241.

491 Michel Y. Dubios, Rollin M. Gallagher, and Philipp M. Lippe, eds., "Pain Medicine Position Paper.," Pain Medicine 10, no. 6 (2009): 989, doi:10.1111/j.1526-4637.2009.00696.x.
} 
today's treatment environment." 492 To the best of my knowledge, no such programs have yet been implemented. Interdisciplinary care is still possible, of course, and is imperative in the management of chronic pain. Peppin et al., note the difference between interdisciplinary and multidisciplinary care; "Multidisciplinary care consists of care provided by several disciplines and typically is not coordinated nor having [sic] shared treatment goals. Interdisciplinary pain care relies upon a team of health care providers that possess unique skills and knowledge that compliment each other."493 Marsh received care from a variety of specialists over the course of his treatment, but it was multidisciplinary, rather than interdisciplinary in approach, and left him as the primary manager of his own condition.

The twenty-first century development of specialty journals such as Pain Medicine and the recent publication of the position papers and other documents referenced in this chapter as well as the multitude of research studies dedicated to understanding the complex causes of chronic pain are encouraging, but the necessary "cultural transformation in the way pain is understood, assessed, and treated" 494 remains a hope for the future rather than an present day reality. For this reason, cases like Andrew Marsh's represent one of the most difficult challenges for both caregiver and patient.

Marsh experienced near constant moderate to severe pain for over a decade and continues to experience pain at a lower degree of intensity. Treatment of such pain continues to rely heavily on opioid medications that destroy quality of life and carry enormous risks for dependency and death, creating an ethical dilemma that pits the risks of such medications against the "moral outrage" of persistent pain. A larger scale ethical

\footnotetext{
492 Ibid., 991.

493 Peppin et al., "The Complexity Model," 654.

494 Institute of Medicine (IOM), Relieving Pain in America, 1.
} 
dilemma is created by the conflict of interest in allowing pharmaceutical companies to fund a great deal of education and research related to chronic pain.

The best hope for restoring quality of life to patients with chronic pain is therapy that focuses on accepting pain while reducing disability, a very difficult thing for many patients and caregivers to concede. Compassionate care in such difficult circumstances mandates narrative practice so all causes of suffering can be identified and addressed. In order to prevent compassion fatigue, caregivers must be skilled in habits of mind that allow sustained attention and nonjudgment. Marsh's case highlights the necessity of a medical humanities pedagogy that trains caregivers to understand the virtue of compassion and to safeguard their ability to provide compassionate care to their patients and themselves. 
MCGILL PAIN QUESTIONNAIRE

RONALD MELZACK

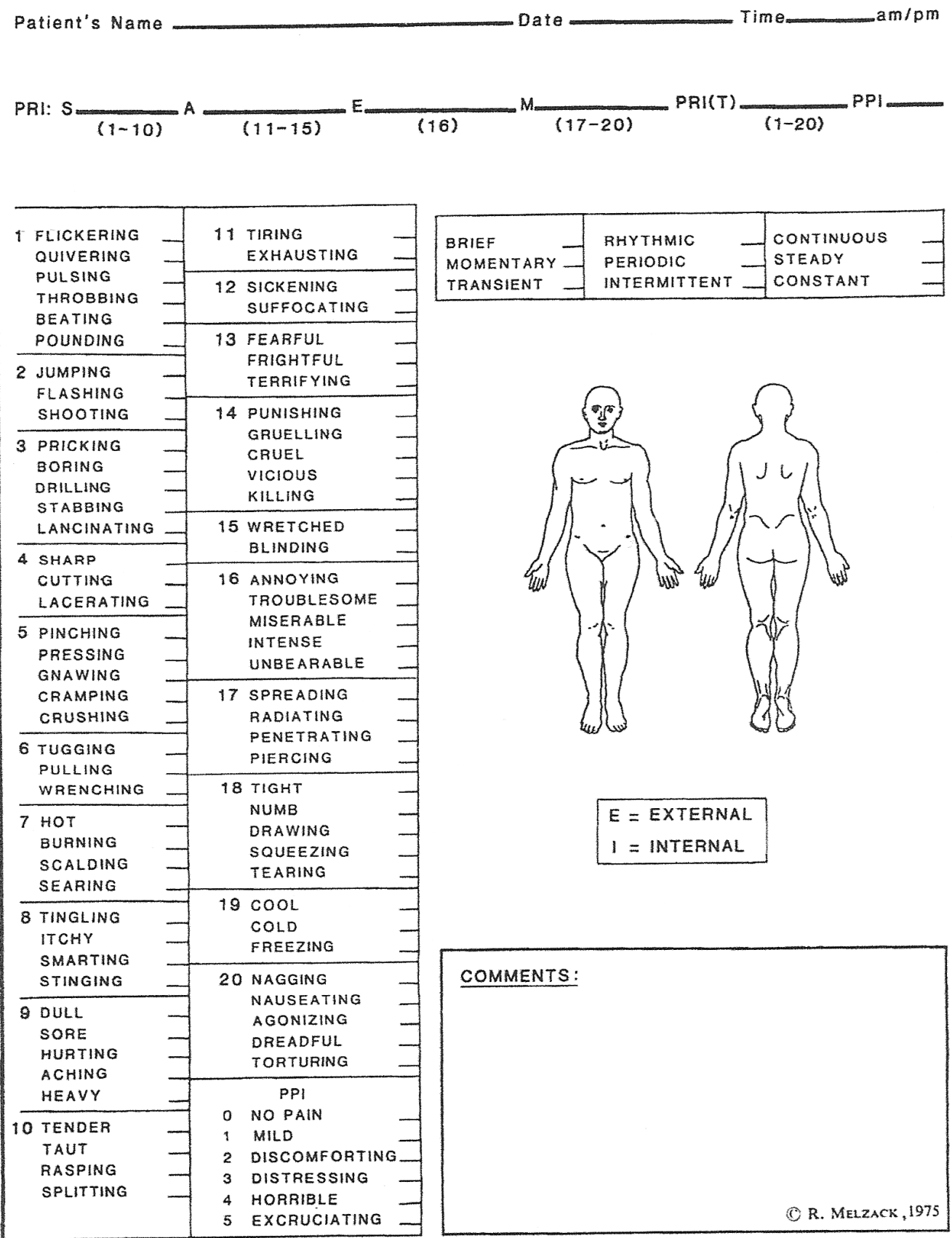

Figure 4 McGill Pain Questionnaire 495

495 Ronald Melzack, "The McGill Pain Questionnaire From Description to Measurement," The Journal of the American Society of Anesthesiologists 103, no. 1 (July 1, 2005): 200. 
MCGILL PAIN QUESTIONNAIRE

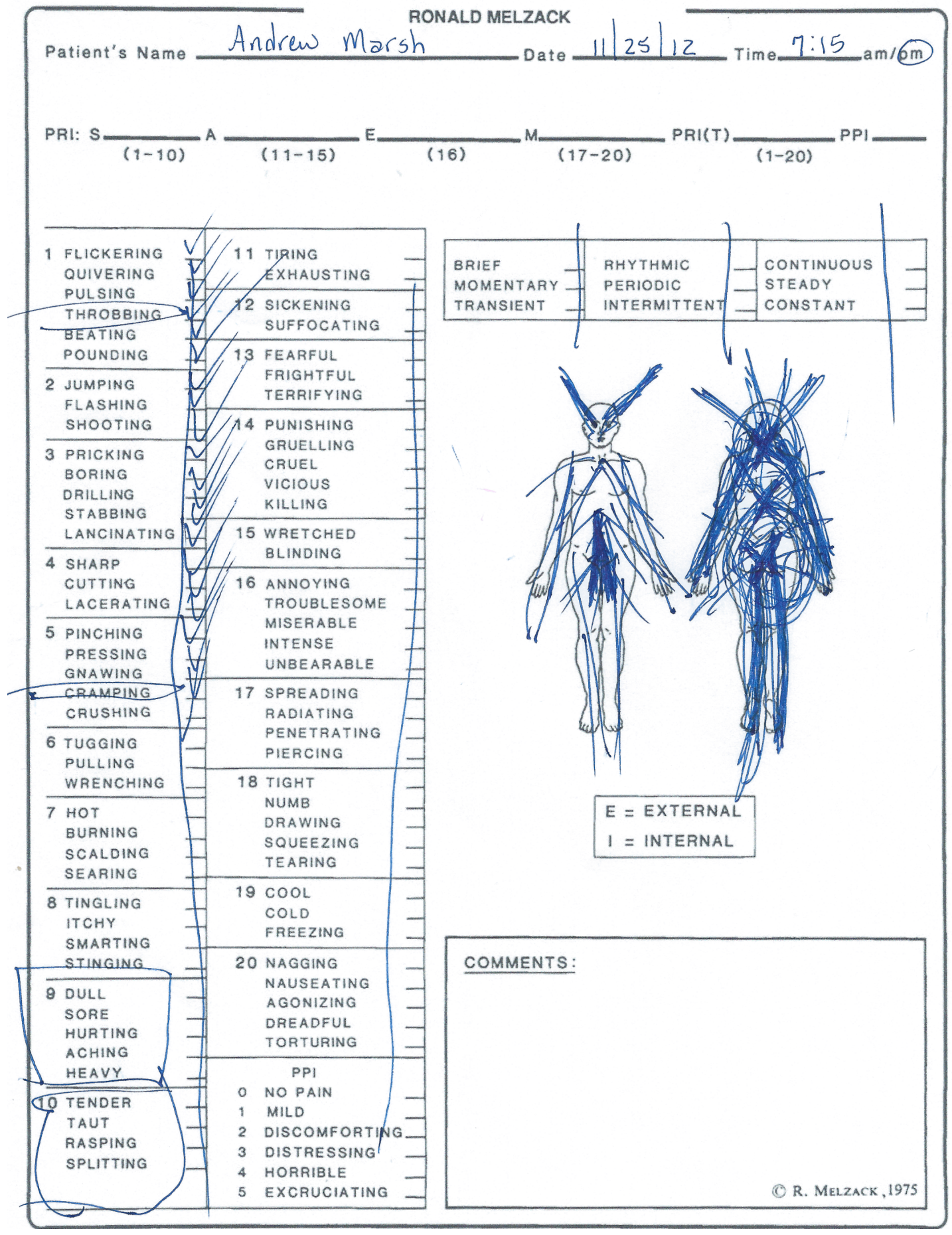

Figure 5, McGill Pain Questionnaire completed by Andrew Marsh on 11/25/12 


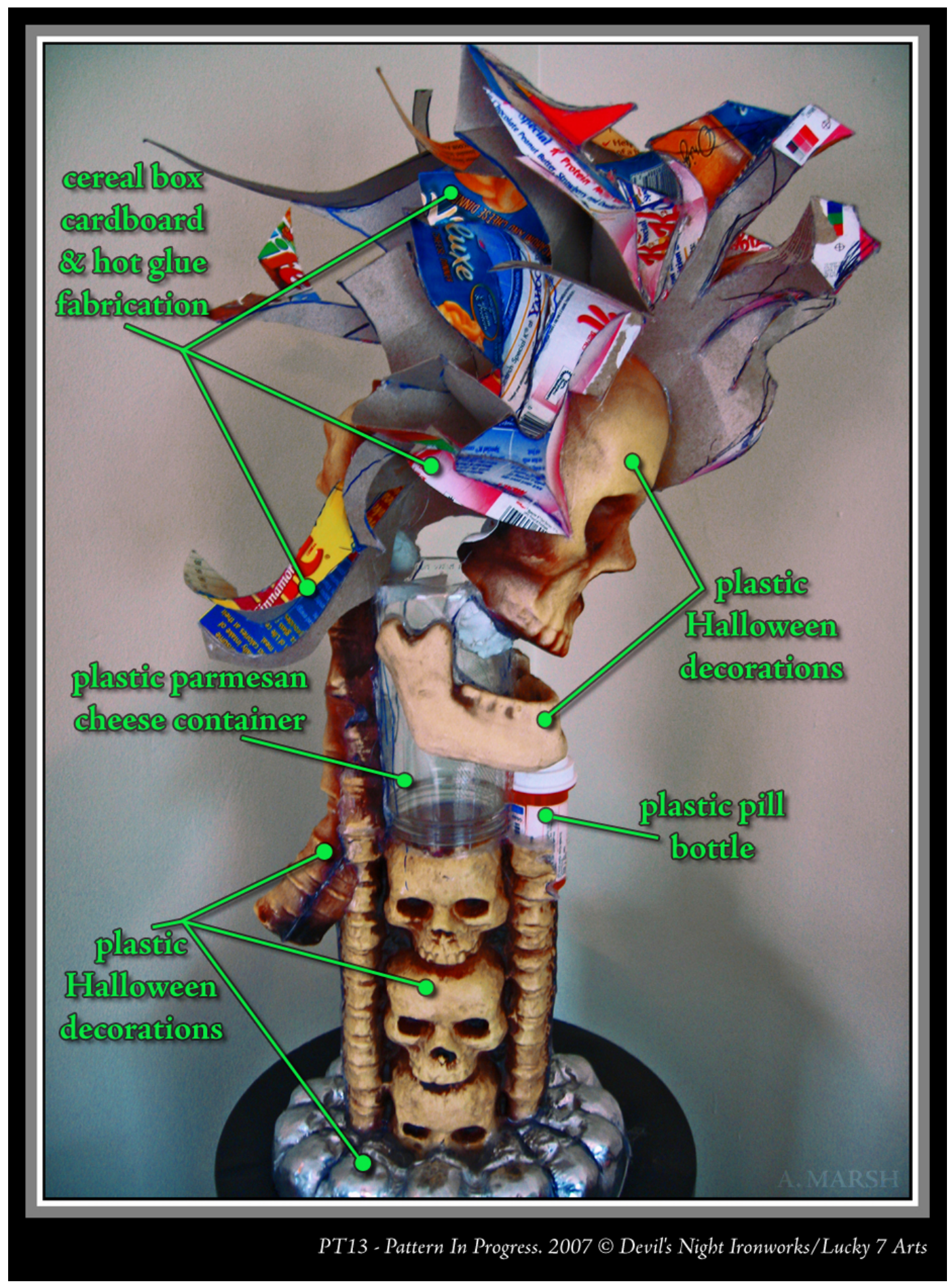

Figure 6 Pain Trophy 13 - Pattern in Progress Andrew Marsh 2007 


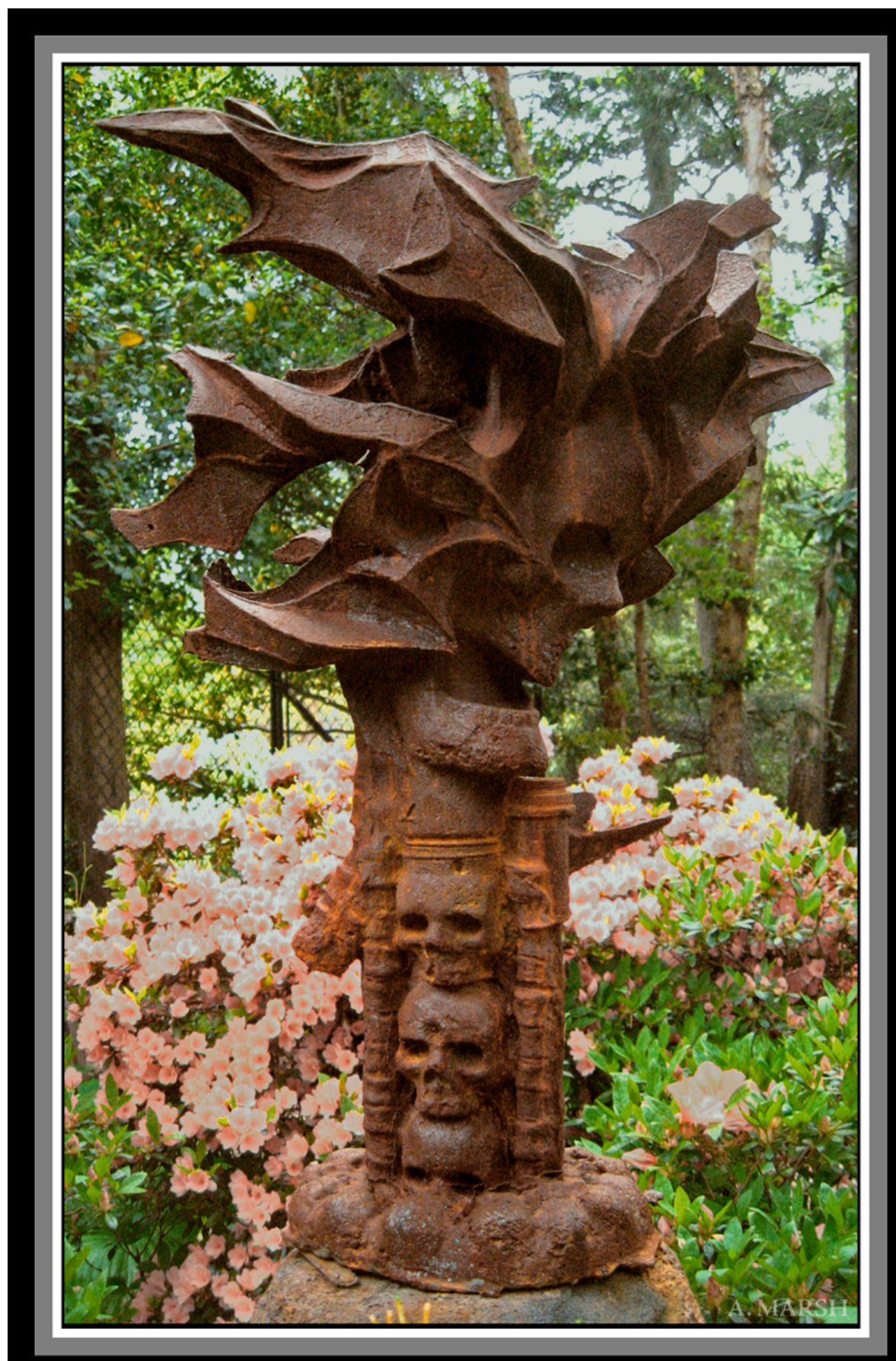

Pain Trophy 13. 2007 ( ) Devil's Night Ironworks/Lucky 7 Arts

Figure 7 Pain Trophy 13 Andrew Marsh 2007 


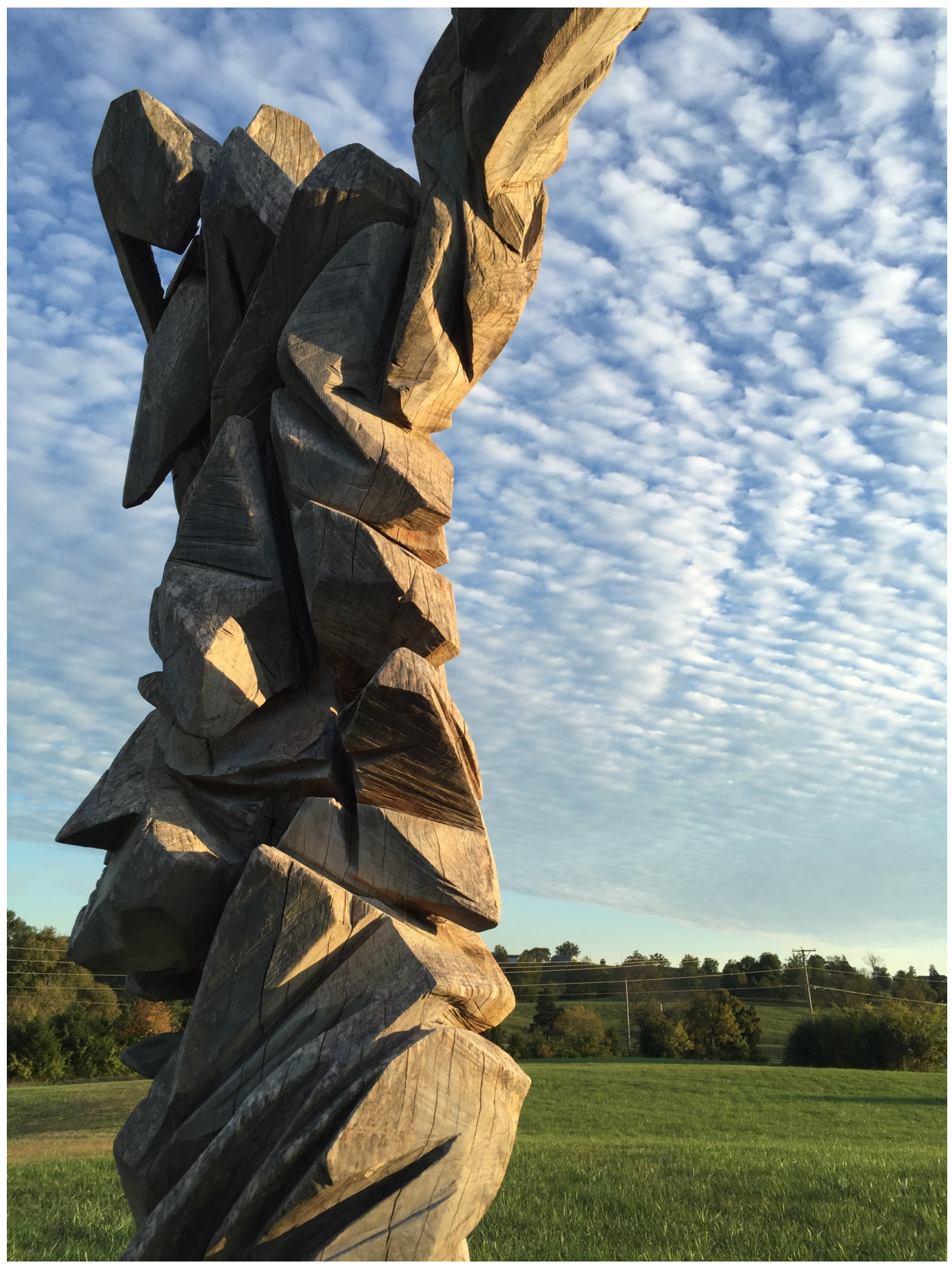

Figure 8 Andrew Marsh 2012 sycamore 13' x 3'x 4' 


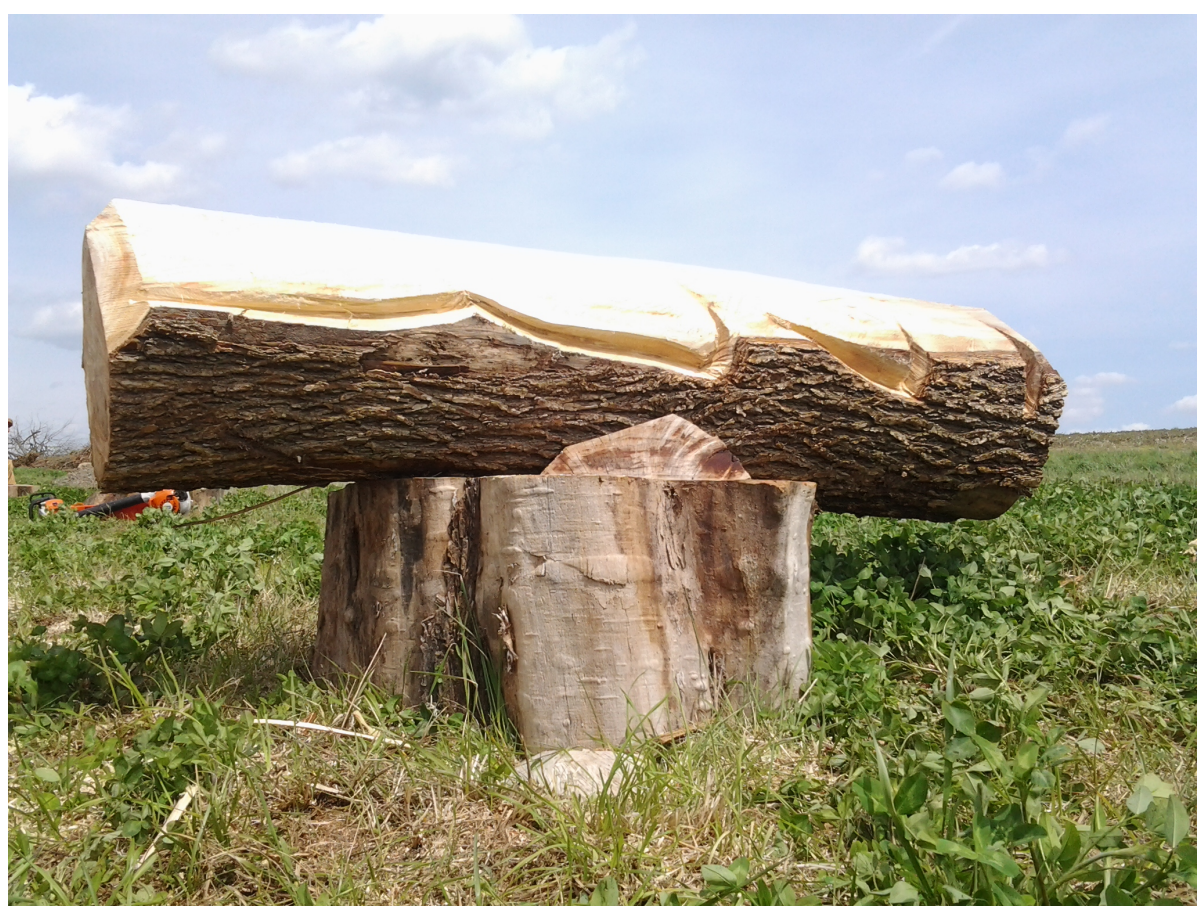

Figure 9 Andrew Marsh, Back Bench, 2013, 7' x 3' x 3', maple \& locust

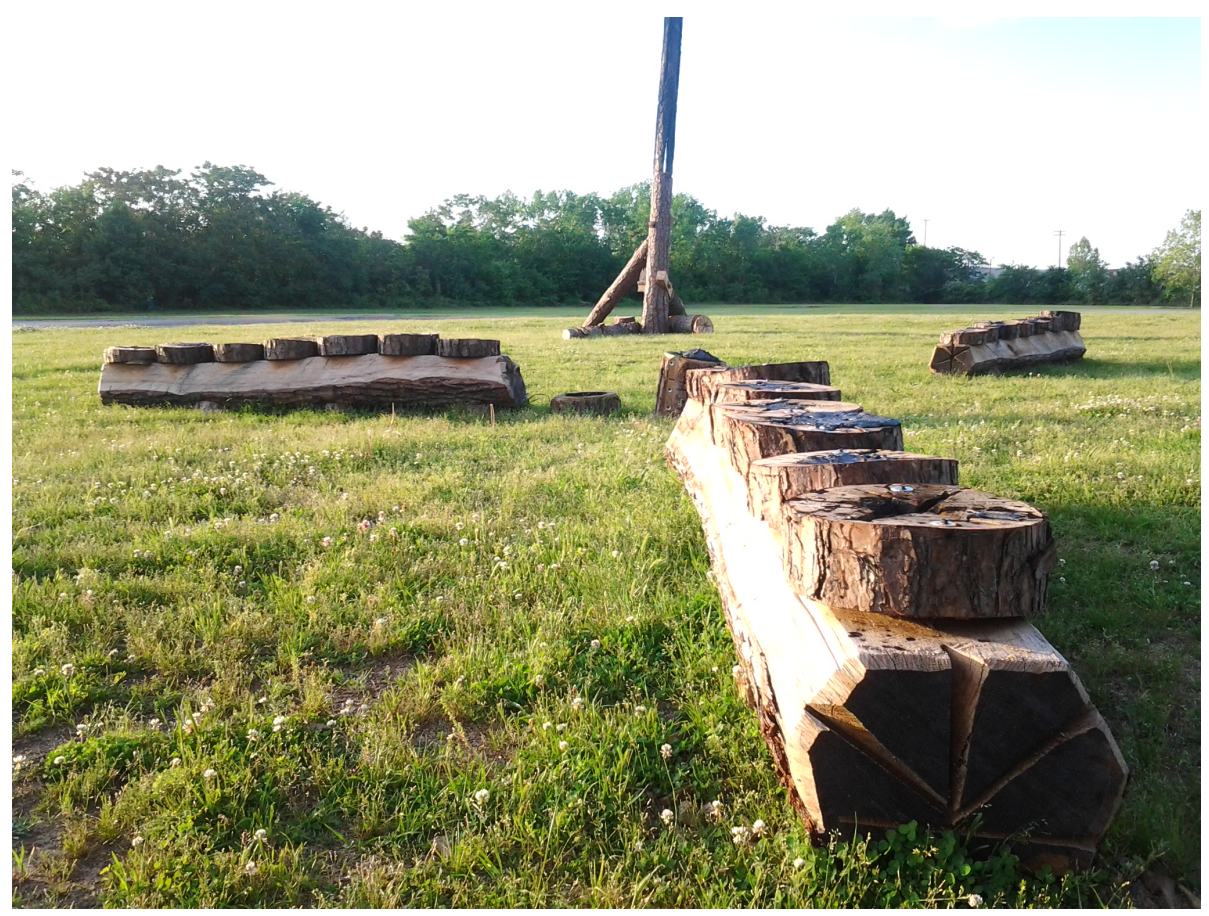

Figure 10 Andrew Marsh, Walking Wounded, 2015, pine, maple, sweet gum, iron 


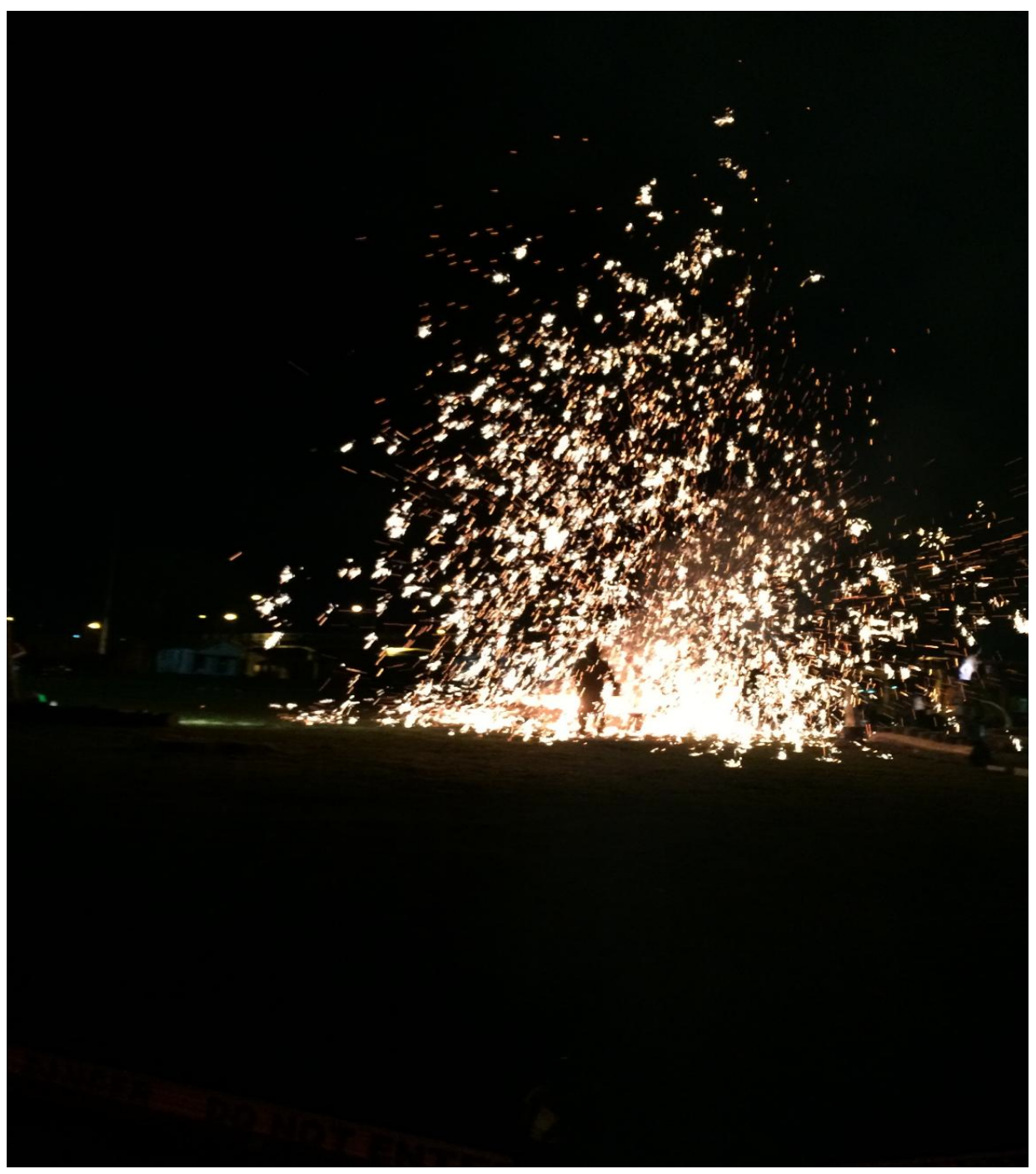

Figure 11

Andrew Marsh (visible at base of explosion)

Walking Wounded Casting Performance 2015 


\section{REFERENCES}

Affleck, Judith. “Commentary.” In Philoctetes. Cambridge Translations from Greek Drama. Cambridge: Cambridge University Press, 2001.

Andre, Judith. "The Medical Humanities as Contributing to Moral Growth and Development." In Practicing the Medical Humanities: Engaging Physicians and Patients, edited by Ronald A. Carson, Chester R. Burns, and Thomas R. Cole, 3969. Hagerstown, MD: University Publishing Group, 2003.

Barr, Donald A. Health Disparities in the United States: Social Class, Race, Ethnicity, and Health. Baltimore: Johns Hopkins University Press, 2008.

Bartel, Roland. "Life and Death in Eudora Welty's 'a Worn Path."' Studies in Short Fiction 14, no. 3 (Summer 1977): 288.

Barthes, Roland. Camera Lucida: Refelctions on Photography. Translated by Richard Howard. New York: Hill and Wang, 1981.

Batt-Rawden, Samantha A., Margaret S. Chisolm, Blair Anton, and Tabor E. Flickinger. "Teaching Empathy to Medical Students." Academic Medicine 88, no. 8 (2013): $1171-77$.

Beauchamp, Tom L., and James F. Childress. Principles of Biomedical Ethics. 6th ed. New York: Oxford University Press, 2009.

Beckman, Howard B., Melissa Wendland, Christopher Mooney, Michael S. Krasner, Timothy E. Quill, Anthony L. Suchman, and Ronald M. Epstein. "The Impact of a Program in Mindful Communication on Primary Care Physicians:” Academic Medicine 87, no. 6 (June 2012): 815-19.

Begley, Ann M. "Facilitating the Development of Moral Insight in Practice: Teaching Ethics and Teaching Virtue." Nursing Philosophy 7, no. 4 (2006): 257-65. 
Belling, Catherine. "Sharper Instruments: On Defending the Humanities in Undergraduate Medical Education.” Academic Medicine June 2010 85, no. 6 (2010): 938-40.

Benjamin, Walter. Illuminations. Edited by Hannah Arendt. Translated by Harry Zohn. New York: Schocken Books, 1969.

Bennett, Jill. Empathic Vision: Affect, Trauma, and Contemporary Art. Stanford: Stanford University Press, 2005.

Bethea, Dean. "Phoenix Has No Coat: Historicity, Eschatology, and Sins of Omission in Eudora Welty’s ‘A Worn Path.” International Fiction Review 28 (2001): 32-41.

Blundell, Mary Whitlock. "The Phusis of Neoptolemus in Sophocles' Philoctetes." Greece and Rome 35, no. 02 (1988): 137-48.

Booth, Wayne. "Forward.” In Literature as Exploration, 5th ed. New York: MLA, 1999.

Brody, Howard. Stories of Sickness. 2nd ed. Oxford: Oxford University Press, 2003.

Brown, Patricia Leigh. "A Doctor For Disease, A Shaman For the Soul: [National Desk].” New York Times, Late Edition (East Coast). September 20, 2009, sec. A.

Bruner, Jerome. "The Narrative Construction of Reality." Critical Inquiry 18, no. 1 (1991): 1-21.

Bryceson A. "Philoctetes' Foot.” Lancet (London, England) 355, no. 9206 (2000): 850.

Burkey, Adam R. "Neuroanatomy and Neurophysiology of Pain.” In Treatment of Chronic Pain by Interventional Approaches: The American Academy of Pain Medicine Textbook on Patient Management, edited by Timothy R. Deer, Michael S. Leong, Asokumar Buvanendran, Philip Kim, and Sunil J. Panchal, 3-12. New York: Springer, 2014.

Burr, Daniel. “Commentary.” Academic Medicine 84, no. 10 (October 2009): 1403.

Burrus, Christina. Frida Kahlo: Painting Her Own Reality. New York: Abrams, 2008.

Carlevale, John. "Education, Phusis, and Freedom in Sophocles' Philoctetes." Arion: A Journal of Humanities and the Classics 8, no. 1 (2000): 26-60.

Carmody, James. "Eastern and Western Approaches to Mindfulness: Similarities, Differences, and Clinical Implications." In The Wiley Blackwell Handbook of Mindfulness, edited by Amanda Ie, Christelle T. Ngnoumen, and Ellen J. Langer, 1st ed., 48-57. Hoboken, NJ: John Wiley \& Sons, 2014.

Cassell, Eric J. The Nature of Suffering and the Goals of Medicine. 2nd ed. Oxford: Oxford University Press, 2004. 
Charon, Rita. "Narrative and Medicine." New England Journal of Medicine 350, no. 9 (February 26, 2004): 862-64.

_ "Narrative Medicine." Classroom visit, Bellarmine University, Louisville, KY, September 22, 2015.

- Narrative Medicine: Honoring the Stories of Illness. Oxford: Oxford University Press, 2006.

Charon, Rita, and Martha Montello, eds. Stories Matter: The Role of Narrative in Medical Ethics. Reflective Bioethics. New York: Routledge, 2002.

Charon, Rita, and Maura Spiegel. "On Conveying Pain/On Conferring Form." Literature and Medicine 24, no. 1 (Spring 2005): vi - ix. doi:10.1353/lm.2005.0019.

Childs, John D., Sara R. Piva, and Julie M. Fritz. "Responsiveness of the Numeric Pain Rating Scale in Patients with Low Back Pain.” Spine 30, no. 11 (June 2005): 1331-34. doi:10.1097/01.brs.0000164099.92112.29.

Clarke, Tom, and Alan Costall. "The Emotional Connotations of Color: A Qualitative Investigation." Color Research and Application 33, no. 5 (October 2008): 40610. doi:10.1002/col.20435.

Coetzee, Siedine Knobloch, and Hester C. Klopper. "Compassion Fatigue Within Nursing Practice: A Concept Analysis." Compassion Fatigue within Nursing Practice: A Concept Analysis. 12, no. 2 (June 2010): 235-43. doi:10.1111/j.14422018.2010.00526.x.

Compton, Wilson M., Maureen Boyle, and Eric Wargo. "Prescription Opioid Abuse: Problems and Responses." Preventive Medicine 80 (November 2015): 5-9. doi:10.1016/j.ypmed.2015.04.003.

Crane, Mark. "Why Burned-out Doctors Get Sued More Often." Medical Economics 75, no. 10 (May 26, 1998): 210-18.

Csikszentmihalyi, Mihaly. Flow: The Psychology of Optimal Experience. New York: Harper Perennial Modern Classics, 2008.

Cudney, Paul. "What Really Separates Casuistry from Principlism in Biomedical Ethics." Theoretical Medicine and Bioethics 35, no. 3 (2014): 205-29. doi:10.1007/s11017-014-9295-3.

Daitz, Ben. "On Navajo Reservation, Poem Helps Broach Topic of End-of-Life Care.” The New York Times, January 24, 2011, sec. Health. http://www.nytimes.com/2011/01/25/health/25navajo.html.

D'Andrade, R., and M. Egan. “The Colors of Emotion.” American Ethnologist 1, no. 1 (February 1974): 49-63. doi:10.1525/ae.1974.1.1.02a00030. 
David, Daniel. "Some Concerns About the Psychological Implications of Mindfulness: A Critical Analysis." Journal of Rational-Emotive \& Cognitive-Behavior Therapy 32, no. 4 (October 15, 2014): 313-24. doi:10.1007/s10942-014-0198-z.

Davis, Mark C. Empathy: A Social Psychological Approach. Social Psychology. Boulder, CO: Westview Press, 1996.

de Botton, Alain, and John Armstrong. Art as Therapy. London: Phaidon, 2013.

DeGrazia, David, Thomas A. Mappes, and Jeffrey Brand-Ballard. Biomedical Ethics. 7th ed. New York: McGraw Hill, 2011.

Dilgen, Regina. "Addressing Ageism through Eudora Welty's 'A Worn Path." Radical Teacher, no. 98 (Winter 2014): 62-63. doi:10.5195/rt.2014.52.

Dobkin, Patricia L., and Tom A. Hutchinson. "Teaching Mindfulness in Medical School: Where Are We Now and Where Are We Going?" Medical Education 47 (2013): 768-79. doi:0.1111/medu.12200.

Donlan, Dan. “'A Worn Path': Immortality of Stereotype.” The English Journal 62, no. 4 (1973): 549-50.

Dubios, Michel Y., Rollin M. Gallagher, and Philipp M. Lippe, eds. "Pain Medicine Position Paper.” Pain Medicine 10, no. 6 (2009): 972-1000. doi:10.1111/j.15264637.2009.00696.x.

Ebert, Roger. "When a Movie Hurts Too Much | Roger Ebert's Journal | Roger Ebert." Accessed November 1, 2015. http://www.rogerebert.com/rogers-journal/when-amovie-hurts-too-much.

Edson, Margaret. W; t. New York: Farber and Farber, 1999.

Edwards, Robert R., and Charles B. Berde. "Pain Assessment." In Essentials of Pain Medicine, edited by Honorio Benzon, Srinivasa N. Raja, Spencer S. Liu, Scott M. Fishman, and Steven P. Cohen, 3rd ed., 28-33. Philadelphia: Saunders, 2011.

Epstein, Ronald M. "Mindful Practice." Journal of the American Medical Association 282, no. 9 (September 1, 1999): 833-39.

- "Mindful Practice in Action (II): Cultivating Habits of Mind." Families, Systems $\&$ Health: The Journal of Collaborative Family HealthCare 21, no. 1 (2003).

Erde, Edmund L. "The Inadequacy of Role Models for Educating Medical Students in Ethics with Some Reflections on Virtue Theory." Theoretical Medicine 18 (1997): 31-45. 
Fadiman, Anne. The Spirit Catches You and You Fall Down: A Hmong Child, Her American Doctors, and the Collision of Two Cultures. New York: Farrar, Straus and Giroux, 2012.

Fernandez-Cano, A., M. Torralbo, M. Vallejo, and I.M. Fernandez-Guerrero. “A Narrative Review of Greek Myths as Interpretative Metaphors in Educational Research and Evaluation." Educational Research Review 7, no. 3 (2012): 238-48.

Fish, Stanley. "Interpreting the Variorum." In The Norton Anthology of Theory and Criticism, 2nd ed., 1974-92. New York: Norton, 2010.

Foucault, Michel. The Birth of the Clinic. Translated by A. M. Sheridan Smith. New York: Vintage Books, 1994.

Frank, Arthur W. Letting Stories Breathe: A Socionarratology. Chicago: University of Chicago Press, 2012.

Frank, Joseph W., Matthew J. Bair, William C. Becker, Erin E. Krebs, Jane M. Liebschutz, and Daniel P. Alford. "Update in Pain Medicine for Primary Care Providers: A Narrative Review, 2010-2012." Pain Medicine 15, no. 3 (March 2014): 425-31. doi:10.1111/pme.12337.

Franklin, Gary, Jennifer Sabel, Christopher Jones, Jaymie Mai, Chris Baumgartner, Caleb J. Banta-Green, Darin Neven, and David J. Tauben. "A Comprehensive Approach to Address the Prescription Opioid Epidemic in Washington State: Milestones and Lessons Learned.” American Journal of Public Health 105, no. 3 (March 2015): 463-69. doi:10.2105/AJPH.2014.302367.

Freedberg, David. The Power of Images: Studies in the History and Theory of Response. Chicago: University of Chicago Press, 1991.

Frey, William J. "Teaching Virtue: Pedagogical Implications of Moral Psychology." Science and Engineering Ethics 16, no. 3 (September 1, 2009): 611-28. doi:10.1007/s11948-009-9164-z.

Gadamer, Hans-Georg. Truth and Method. Translated by Joel Weinsheimer and Donald G. Marshall. 2nd ed. New York: Continuum, 1998.

Gage, John. Color and Meaning: Art, Science, and Symbolism. Berkeley: University of California Press, 1999.

Gardner, Frank L., Zella E. Moore, and Donald R. Marks. "Rectifying Misconceptions: A Comprehensive Response to 'Some Concerns About the Psychological Implications of Mindfulness: A Critical Analysis." Journal of Rational-Emotive \& Cognitive-Behavior Therapy 32, no. 4 (October 1, 2014): 325-44. doi:10.1007/s10942-014-0196-1. 
Gert, Bernard, Charles M. Culver, and K. Danner Clouser. Bioethics: A Systematic Approach. New York: Oxford University Press, 2006.

Gill, Christopher. "Bow, Oracle, and Epiphany in Sophocles' Philoctetes.” Greece and Rome 27, no. 02 (1980): 137-46.

Goldberg, Charlie. "History of Present Illness." A Practical Guide to Clinical Medicine, August 16, 2008. https://meded.ucsd.edu/clinicalmed/history.htm.

Goodwyn, Erik. "Recurrent Motifs as Resonant Attractor States in the Narrative Field: A Testable Model of Archetype." Journal of Analytical Psychology 58, no. 3 (2013): 387-408.

Gottlieb, Richard M. "Refusing the Cure: Sophocles's Philoctetes and the Clinical Problems of Self-Injurious Spite, Shame and Forgiveness ${ }^{1}$." The International Journal of Psychoanalysis 85, no. 3 (2004): 669-90.

Gow, Laura. “Colour.” Philosophy Compass 9, no. 11 (November 2014): 803-13. doi:10.1111/phc3.12173.

Grant, Adam. "Can We End the Meditation Madness?" The New York Times, October 9, 2015. http://www.nytimes.com/2015/10/10/opinion/can-we-end-the-meditationmadness.html.

Grassi W, Farina A, and Cervini C. "The Foot of Philoctetes.” Lancet (London, England) 354, no. 9196 (1999): 2156.

Grohmann, Will. Wassily Kandinsky: Life and Work. Edited by Milton S. Fox. Translated by Norman Guterman. New York: Harry N. Abrams, 1958.

Gupta, Anuj, Kirtipal Kaur, Sheeshpal Sharma, Shubham Goyal, Saahil Arora, and R. S. R. Murthy. "Clinical Aspects of Acute Post-Operative Pain Management \& Its Assessment." Journal of Advanced Pharmaceutical Technology and Research 1, no. 2 (April 2010): 97-108.

Halpern, Jodi. From Detached Concern to Empathy: Humanizing Medical Practice. Oxford: Oxford University Press, 2001.

_. "What Is Clinical Empathy?" JGI Journal of General Internal Medicine 18, no. 8 (2003): 670-74.

Hawker, Gillian A., Samra Mian, Tetyana Kendzerska, and Melissa French. "Measures of Adult Pain: Visual Analog Scale for Pain (VAS Pain), Numeric Rating Scale for Pain (NRS Pain), McGill Pain Questionnaire (MPQ), Short-Form McGill Pain Questionnaire (SF-MPQ), Chronic Pain Grade Scale (CPGS), Short Form-36 Bodily Pain Scale (SF-36 BPS), and Measure of Intermittent and Constant Osteoarthritis Pain (ICOAP)." Arthritis Care and Research 63, no. S1 1 (November 2011): S240-52. doi:10.1002/acr.20543. 
Hawkins, Anne Hunsaker. "Medical Ethics and the Epiphanic Dimension of Narrative." In Stories and Their Limits: Narrative Approaches to Bioethics, edited by Hilde Lindemann Nelson, 153-70. New York: Routledge, 1997.

Herrera, Hayden. Frida: A Biography of Frida Kahlo. New York: Harper Perennial, 2002.

. Frida Kahlo: The Paintings. New York: Harper Collins, 1991.

Hojat, Mohammadreza, Joseph S. Gonnella, Thomas J. Nasca, Salvatore Mangione, Michael Vergare, and Michael Magee. "Physician Empathy: Definition, Components, Measurement, and Relationship to Gender and Specialty." American Journal of Psychiatry 159, no. 9 (September 1, 2002): 1563-69. doi:10.1176/appi.ajp.159.9.1563.

Holmgren, Lindsay, Abraham Fuks, Donald Boudreau, Tabitha Sparks, and Martin Kreiswirth. "Terminology and Praxis: Clarifying the Scope of Narrative in Medicine." Literature and Medicine 29, no. 2 (Fall 2011): 246-73.

Hooper, Crystal, Janet Craig, David R. Janvrin, Margaret A. Wetsel, and Elaine Reimels. "Compassion Satisfaction, Burnout, and Compassion Fatigue Among Emergency Nurses Compared With Nurses in Other Selected Inpatient Specialties." Journal of Emergency Nursing 36, no. 5 (September 2010): 420-27.

Institute of Medicine (IOM). Relieving Pain in America. Washington, DC: National Academies Press, n.d.

Isaacs, Neil D. "Life for Phoenix." In The Critical Response to Eudora Welty's Fiction, edited by Laurie Champion, 37-42. Critical Responses in Arts and Letters 12. Westport, CT: Greenwood Press, 1994.

Jazaieri, Hooria, Kelly McGonigal, Thupten Jinpa, James R. Doty, James J. Gross, and Philippe R. Goldin. "A Randomized Controlled Trial of Compassion Cultivation Training: Effects on Mindfulness, Affect, and Emotion Regulation." Motivation and Emotion 38, no. 1 (February 1, 2014): 23-35.

Johnson, Horton A. "The Foot That Stalled a Thousand Ships: A Controversial Case from the 13th Century BCE." Journal of the Royal Society of Medicine 96, no. 10 (October 1, 2003): 507-8.

Joinson, Carla. “Coping with Compassion Fatigue.” Nursing 22, no. 4 (April 1992): 116, 118-19, 120.

Justman, Stewart. "Bibliotherapy: Literature as Exploration Reconsidered." Academic Questions 23, no. 1 (February 18, 2010): 125-35. doi:10.1007/s12129-009-91471 .

Kabat-Zinn, Jon. Coming to Our Senses. New York: Hyperion, 2005. 
- Mindfulness for Beginners: Reclaiming the Present Moment and Your Life. Boulder, CO: Sounds True, 2012.

- Wherever You Go, There You Are: Mindfulness Meditation in Everyday Life. New York: Hyperion, 2005.

Kandinsky, Wassily. "Collection Online | Vasily Kandinsky. Blue Painting (Blaues Bild). January 1924 - Guggenheim Museum.” Accessed October 12, 2015. http://www.guggenheim.org/new-york/collections/collectiononline/artwork/1943.

- Concerning the Spiritual in Art. Translated by M. T. H. Sadler. New York: Dover, 1977.

Kapplinger, Eunice, and Susan Ray-Degges. "Can Ethics Be Taught or Is It Too Late?" Journal of Interior Design 24, no. 1 (1998): 48-54.

Keen, Suzanne. "A Theory of Narrative Empathy." Narrative 14, no. 3 (October 2006): $207-36$.

Kettenmann, Andrea. Frida Kahlo: Pain and Passion. Los Angeles: Taschen, 1992.

Keys, Marilyn. ““A Worn Path': The Way of Dispossession.” Studies in Short Fiction 16, no. 4 (Fall 1979): 354.

Kharkhurin, Anatoliy V. "Is Triangle Really Yellow? An Empirical Investigation of Kandinsky's Correspondence Theory." Empirical Studies of the Arts 30, no. 2 (July 2012): 167-82. doi:10.2190/EM.30.2.d.

Kidd, Michael R, and Deborah C Saltman. "Case Reports at the Vanguard of 21st Century Medicine." Journal of Medical Case Reports 6, no. 156 (January 2012): 1-3. doi:doi:10.1186/1752-1947-6-156.

"Koru Mindfulness - Meditation for College Aged Students." Koru Mindfulness. Accessed October 1, 2015. http://korumindfulness.org/.

Krasner, Michael S., Ronald M. Epstein, Howard Beckman, Anthony L. Suchman, Benjamin Chapman, and Timothy E. Quill. "Association of an Educational Program in Mindful Communication with Burnout, Empathy, and Attitudes Among Primary Care Physicians." Journal of the American Medical Association 302, no. 12 (September 2009): 1284-93.

Kuper, Ayelet. "Literature and Medicine: A Problem of Assessment." Academic Medicine Academic Medicine 81, no. Suppl (2006): S128-37.

Larson, Eric B., and Xin Yao. "Clinical Empathy as Emotional Labor in the PatientPhysician Relationship.” JAMA 293, no. 9 (March 2005): 1100-1106. 
López-Pérez, B., and T. Ambrona. "The Role of Cognitive Emotion Regulation on the Vicarious Emotional Response." Motivation and Emotion 39, no. 2 (2014): 299308. doi:10.1007/s11031-014-9452-z.

Marmot, M. G. "Status Syndrome: A Challenge to Medicine." JAMA 295, no. 11 (March 15, 2006): 1304-7. doi:10.1001/jama.295.11.1304.

Marsh, Andrew. "Paper,” December 5, 2012.

—. Personal Interview, November 25, 2012.

—. Personal Interview, December 2, 2012.

—. Personal interview, October 24, 2015.

Martensen, Robert. "Thought Styles among the Medical Humanities: Past, Present, and Near-Term Future.” In Practicing the Medical Humanities: Engaging Physicians and Patients, edited by Ronald A. Carson, Chester R. Burns, and Thomas R. Cole, 99-122. Hagerstown, MD: University Publishing Group, 2003.

Martinelli, Debra Levy. “Medicine and Literature.” Sooner Magazine, Fall 2005.

McGrath, Charles. "Margaret Edson, Author of 'Wit,' Loves Teaching." The New York Times, February 16, 2012. http://www.nytimes.com/2012/02/19/theater/margaretedson-author-of-wit-loves-teaching.html.

McIntosh, Peggy. "White Privilege: Unpacking the Invisible Knapsack." Independent School 49, no. 2 (Winter 1990): 31.

McLellan, Faith. "W; T.” Annals of Internal Medicine 131, no. 9 (November 2, 1999): 718-19. doi:10.7326/0003-4819-131-9-199911020-00030.

Melzack, Ronald. "The McGill Pain Questionnaire.” Anesthesiology 103 (2005): 199202.

—. "The McGill Pain Questionnaire From Description to Measurement." The Journal of the American Society of Anesthesiologists 103, no. 1 (July 1, 2005): 199-202.

Miall, David S., and Don Kuiken. "A Feeling for Fiction: Becoming What We Behold." Poetics 30, no. 4 (2002): 221-41.

Miller, Joshua, and Ann Marie Garran. Racism in the United States: Implications for the Helping Professions. Belmont, CA: Thompson Brooks/Cole, 2008.

Mitchell, W. J. T. “What Do Pictures 'Really’ Want?” October, no. 77 (1996): 71-82.

Morgan, Peter. "Health Care Workers' Experiences of Mindfulness Training: A Qualitative Review." Health Care Workers' Experiences of Mindfulness 
Training: A Qualitative Review 6, no. 4 (201508): 744-58. doi:10.1007/s12671014-0313-3.

Mulvey, Laura. "Visual Pleasure and Narrative Cinema." In The Norton Anthology of Theory and Criticism, 2nd ed., 2084-95. New York: Norton, 2010.

Nelson, Hilde Lindemann. Stories and Their Limits: Narrative Approaches to Bioethics. New York: Routledge, 1997.

Neumann, Melanie, Friedrich Edelhauser, Diethard Tauschel, Martin R. Fischer, Markus Wirtz, Christiane Woopen, Aviad Haramati, and Christian Scheffer. "Empathy Decline and Its Reasons: A Systematic Review of Studies With Medical Students and Residents." Academic Medicine August 2011 86, no. 8 (2011): 996-1009.

Nichols, Mike. Wit. DVD. Burbank: HBO Films, 2010.

Nussbaum, Martha. “Consequences and Character in Sophocles' Philoctetes." Philosophy and Literature 1, no. 1 (1976): 25-53. doi:10.1353/phl.1976.0004.

Nussbaum, Martha Craven. 'Invisibility and Recognition: Sophocles' Philoctetes and Ellison's Invisible Man.” Philosophy and Literature 23, no. 2 (1999): 257-83.

Orr, Elaine. "Unsettling Every Definition of Otherness: Another Reading of Eudora Welty's 'A Worn Path.'” South Atlantic Modern Language Association 57, no. 2 (May 1992): 57-72.

Owen, Jim. "Phoenix Jackson, William Wallace, and King MacLain: Welty's Mythic Travelers." Southern Literary Journal 34, no. 1 (Fall 2001): 29.

Parham SF. "Philoctetes' Wound.” Literature and Medicine 9 (1990): 12-20.

Payne-Murphy, Jessica C., and Abbie O. Beacham. "Revisiting Chronic Pain Patient Profiling: An Acceptance-Based Approach in an Online Sample." Clinical Psychology and Psychotherapy 22, no. 3 (June 2015): 240-48. doi:10.1002/cpp.1886.

Pellegrino, Edmund. "Toward a Reconstruction of Medical Morality." The American Journal of Bioethics 6, no. 2 (2006): 65-71.

Pellegrino, Edmund D. "Toward a Virtue-Based Normative Ethics for the Health Professions." Kennedy Institute of Ethics Journal 5, no. 3 (1995): 253-77. doi:10.1353/ken.0.0044.

Pellegrino, Edmund D., and David C. Thomasma. The Virtues in Medical Practice. Oxford: Oxford University Press, 1993. 
Peppin, John F., Martin D. Cheatle, Kenneth L. Kirsh, and Bill H. McCarberg. "The Complexity Model: A Novel Approach to Improve Chronic Pain Care." Pain Medicine 16, no. 4 (April 2015): 653-66. doi:10.1111/pme.12621.

Powlson, Mark. "Philoctetes." Journal of the Royal Society of Medicine 97, no. 2 (February 1, 2004): 99-100.

Raphel, Adrienne. "Adult Coloring Books and the Rise of the 'Peter Pan' Market." The New Yorker. Accessed September 24, 2015.

http://www.newyorker.com/business/currency/why-adults-are-buying-coloringbooks-for-themselves.

Ricard, Matthieu. Why Meditate: Working With Thoughts and Emotions. Translated by Sherab Chödzin Kohn. Carlsbad, CA: Hay House, 2010.

Richardson, Brian. "Beyond the Poetics of Plot: Alternative Forms of Narrative Progression and the Multiple Trajectories of Ulysses." In A Companion to Narrative Theory, edited by James Phelan and Peter J. Rabinowitz, 167-80. Malden, MA: Blackwell Publishing, 2005.

Ricoeur, Paul. Time and Narrative. Translated by Kathleen McLaughlin and David Pellauer. Vol. 1. 3 vols. Chicago: University of Chicago Press, 1983.

Rimmon-Kenan, Shlomith. "The Story of 'I': Illness and Narrative Identity." Narrative 10, no. 1 (2002): 9-27.

Rocha, Tomas. "The Dark Knight of the Soul.” The Atlantic, June 25, 2014. http://www.theatlantic.com/health/archive/2014/06/the-dark-knight-of-thesouls/372766/.

Roesler C. "Are Archetypes Transmitted More by Culture than Biology? Questions Arising from Conceptualizations of the Archetype." The Journal of Analytical Psychology 57, no. 2 (2012): 223-46.

Rosenblatt, Louise M. Literature as Exploration. 5th ed. New York: MLA, 1999.

Sacks, Oliver. A Leg to Stand On. Touchstone. New York: Touchstone, 1998.

Said, Edward W. Orientalism. New York: Vintage Books, 1979.

Saunders, James Robert. ““A Worn Path': The Eternal Quest of Welty's Phoenix Jackson." The Southern Literary Journal 25, no. 1 (1992): 62-73.

Scarry, Elaine. The Body in Pain: The Making and Unmaking of the World. Oxford: Oxford University Press, 1985. 
Schatman, Michael E. "The Medical-Industrial Complex and Conflict of Interest in Pain Education." Pain Medicine 12 (December 2011): 1710-12. doi:10.1111/j.15264637.2011.01284.x.

Schofferman, Jerome. "The Medical-Industrial Complex, Professional Medical Associations, and Continuing Medical Education." Pain Medicine 12, no. 12 (December 1, 2011): 1713-19. doi:10.1111/j.1526-4637.2011.01282.x.

Selzer, Richard. "Imelda.” In Letters to a Young Doctor, 21-36. San Diego: Harvest, 1996.

. "Preface.” In Letters to a Young Doctor, np. San Diego: Harvest, 1996.

Shanafelt, Tait D., Sonja Boone, Litjen Tan, Lotte N. Dyrbye, Wayne Sotile, Daniel Satele, Colin P. West, Jeff Sloan, and Michael R. Oreskovich. "Burnout and Satisfaction With Work-Life Balance Among US Physicians Relative to the General US Population." Archives of Internal Medicine 172, no. 18 (October 8, 2012): 1377-85.

Shapiro, Johanna. "(Re)Examining the Clinical Gaze Through the Prism of Literature." Families, Systems, \& Health Summer 2002 20, no. 2 (2002): 161-70.

Shapiro, Johanna, Lois L. Nixon, Stephen E. Wear, and David J. Doukas. "Medical Professionalism: What the Study of Literature Can Contribute to the Conversation." Philosophy, Ethics \& Humanities in Medicine 10, no. 1 (June 2015): 1-8. doi:10.1186/s13010-015-0030-0.

Smart, Denise, Ashley English, Jennifer James, Marian Wilson, Kenn B. Daratha, Belinda Childers, and Chris Magera. "Compassion Fatigue and Satisfaction: A Cross-Sectional Survey Among US Healthcare Workers." Nursing and Health Sciences 16, no. 1 (March 2014): 3-10. doi:10.1111/nhs.12068.

Smith, Sidonie, and Julia Watson. Reading Autobiography: A Guide for Interpreting Life Narratives. 2nd ed. Minneapolis: University of Minnesota Press, 2010.

Sontag, Susan. Regarding the Pain of Others. New York: Picador, 2003.

Sophocles. Philoctetes. Translated by Judith Affleck. Cambridge Translations from Greek Drama. Cambridge: Cambridge University Press, 2001.

Spiro, Howard M. "Empathy: An Introduction.” In Empathy and the Practice of Medicine, edited by Howard Spiro, Mary G. McCrea Curnen, Enid Peschel, and Deborah St. James, 1-6. New Haven: Yale University Press, 1993.

Spiro, Howard M. "What Is Empathy and Can It Be Taught?" In Empathy and the Practice of Medicine, edited by Howard Spiro, Mary G. Mccrea Curnen, Enid Peschel, and Deborah St. James, 7-14. New Haven: Yale University Press, 1993. 
Spiro, Howard M., Mary G. McCrea Curnen, Enid Peschel, and Deborah St. James, eds. Empathy and the Practice of Medicine: Beyond Pills and the Scalpel. New Haven: Yale University Press, 1993.

Spivak, Gayatri Chakravorty. "Can the Subaltern Speak.” In The Norton Anthology of Theory and Criticism, 2nd ed., 2114-26. New York: Norton, 2010.

Stang, Melissa Deakins. "Parting the Curtain on Lye Poisoning in 'A Worn Path." Eudora Welty Review 1, no. 1 (2009): 13-24. doi:10.1353/ewr.2009.0001.

Stefano, C. "Philoctetes by Sophocles: A Case for Diagnosis." Journal of the Royal College of Physicians of London 23 (1989): 176.

Stein-Parbury, Jane. Patient \& Person: Interpersonal Skills in Nursing. 4th ed. London: Churchill Livingstone, 2009.

Stieve, Ed. "The Medical Essay as an Invitation for Interdisciplinary Exploration." Quadrivium, no. 3 (November 2013).

Sykes, Dennis J. “Welty’s The Worn Path.” Explicator 56, no. 3 (1998).

Tessitore, Aristide. "Justice, Politics, and Piety in Sophocles' 'Philoctetes."' The Review of Politics 65, no. 1 (2003): 61-88.

“The 1999 Pulitzer Prize Winners: Drama.” The Pulitzer Prizes. Accessed September 9, 2015. http://www.pulitzer.org/citation/1999-Drama.

Tyson, Lois. Critical Theory Today: A User Friendly Guide. 2nd ed. New york: Routledge, 2006.

Urso, Carmelo, and Vittoria Farella. “An Inquiry on Philoctetes's Disease.” The AMerican Journal of Dermatopathology 18, no. 3 (1996): 326-29.

Vago, David R. "Mapping Modalities of Self-Awareness in Mindfulness Practice: A Potential Mechanism for Clarifying Habits of Mind." Annals of the New York Academy of Sciences 1307, no. 1 (January 1, 2014): 28-42. doi:10.1111/nyas. 12270 .

Voscopoulos, C., and M. Lema. "When Does Acute Pain Become Chronic?” British Journal of Anaesthesia 105, no. 51 (December 2010): i69-85. doi:10.1093/bja/aeq323.

Warnock, G. J. "The Object of Morality." In Philosophical Ethics: An Introduction to Moral Philosophy, 2nd ed., 29-38. New York: McGraw-Hill, 1991.

Welty, Eudora. “A Worn Path.” In The Collected Stories of Eudora Welty, 142-49. New York: Harcort, 1980. 
Werness, Hope B. The Continuum Encyclopedia of Animal Symbolism in Art. New York: Continuum International, n.d.

White, Lacie. "Mindfulness in Nursing: An Evolutionary Concept Analysis." Journal of Advanced Nursing 70, no. 2 (February 2014): 282-94. doi:10.1111/jan.12182.

Whitfield, T. W. Allan, and Jianne Whelton. "The Arcane Roots of Colour Psychology, Chromotherapy, and Colour Forecasting." Color Research and Application 40, no. 1 (February 2015): 99-106. doi:10.1002/col.21862.

Wiggins, Osborne, October 13, 2015.

Williams, Mark, and Danny Penman. Mindfulness: An Eight-Week Plan for Finding Peace in a Frantic World. New York: Rodale, 2011.

Zamora, Martha. Frida Kahlo: The Brush of Anguish. Translated by Marilyn Sode Smith. San Francisco: Chronicle Books, 1990.

Zuger, Abigail. "When the Patient, Not the Doctor, Becomes the Hero." New York Times 148, no. 51372 (December 15, 1998): F4. 


\title{
CURRICULUM VITA
}

\author{
Lisa Higgins Shugoll
}

lisahshu@aol.com

lhshug01@1ouisville.edu

\section{Education:}

Doctor of Philosophy in Humanities

December 2015

University of Louisville, Louisville, Kentucky

Dissertation: The Pedagogy of Medical Humanities: Using Literature and the Visual Arts to Help Future Caregivers Maintain Their Compassion and Resilience

- Dissertation passed with distinction

November 18, 2015

- Graduate Dean's Citation

Master of Arts in Humanities

University of Louisville, Louisville, Kentucky

August 2010

- Golden Key International Honour Society Member

- Certificate in Medieval/Renaissance Studies

MA Directed Study Project: Designed an undergraduate Medical Humanities course focused on the study and interpretation of illness narratives in art and literature.

Bachelor of Science in Nursing

May 1983

The University of North Carolina, Chapel Hill

Academic \& Teaching Experience:

University of Louisville - Graduate Teaching Assistant

Solo designed and taught all courses

- Humanities 151: Creativity and the Arts - An introduction to the fundamental principles, processes, and styles of the creative arts, both visual and performing.

- Humanities 152: Cultures of America - An interdisciplinary study of the arts and humanities of African, Indigenous, Asian, Latino, and Appalachian cultures within the United States.

- Humanities 361: Humanities and Healthcare - A Medical Humanities course in which literature and the visual arts are used to introduce undergraduate students to the principles of Narrative Medicine, Bioethics, and Mindfulness. 


\section{Exhibitions Curated:}

- 1000 Cuts: An Exhibition of Sculpture by Andrew Marsh University of Louisville, Ekstrom Library Courses taught:

- Medical Law and Ethics - An overview of past and current healthcare legislation and an introduction to the study of biomedical ethics.

- Success Skills for College - An intensive course covering time management, study skills, written and verbal communication techniques - designed for new college students and adults returning to school.

Kentucky Center for the Performing Arts

Summer 2011 Intern - Arts in Healing Program

- Assisted with the development and implementation of Arts in Healing programs at The Nazareth Home and Our Lady of Peace Hospital in Louisville, Kentucky

- Created a video presentation to be used for promotion and education: http://www.youtube.com/watch?v=FaH36JSgAfU

- Presented a research proposal evaluating major pharmaceutical corporations as possible funding sources

Transports de l'Agglomération de Montpellier, Montpellier, France June/July 2008

- Lived and worked in Montpellier, France as an international work exchange student

- Office assistant duties included data entry, filing, and some translation

Conference Presentations:

"Caring for Caregivers: Using Abstraction to Deal with Distraction"

April 11, 2014

Global Alliance for Arts and Healthcare, Houston Texas (CME credit granted for attendance)

"Teaching Medical Humanities to Undergraduates"

February 27, 2014

Humanities Education and Research Association, Washington, DC

"Visual Arts and the Promotion of Empathy in Medical Caregivers,"

June 2012 International Conference on New Directions in the Humanities, Montréal, Canada

"The Rhetoric of Race in Riddle 12 of The Exeter Book,"

March 2011

The Kentucky Philological Association, Frankfort, Kentucky

\section{Nursing Experience:}

Crawford Long Hospital of Emory University, Atlanta, Georgia

- Cared for critically ill patients in a medical/surgical intensive care unit

- Patient teaching included wound and stoma care, diabetic health, nutrition, pulmonary therapies 
- Staff nurse teaching included peritoneal dialysis, decubitus ulcer care, performing physical exams

- Wrote and administered patient care plans, supervised staff nurses, coordinated work assignments

Quality Assurance Coordinator

$1988-1990$

- Chaired Quality Assurance Committee for the Department of Surgery

- Evaluated trends in patient outcomes following surgical procedures

- Monitored patient records for completeness and accuracy

Service:

Association of Humanities Academics, University of Louisville

- Conference organizer

Kentucky Country Day School, Louisville, Kentucky

2010 - present

1996 - 2009

- Diversity Committee member

- Drama Society volunteer for Middle and Upper School theatrical productions

- Library assistant

Habitat for Humanity, Louisville, Kentucky

$1990-1992$

- Site nurse - provided first aid for minor injuries

- Recruited and scheduled volunteers to provide continuous first aid coverage

- Wrote manual for first aid providers and medical volunteers

Memberships:

- Inclusive Teaching Circle, University of Louisville

since 2014

- Association of Humanities Academics

since 2010

- Global Alliance for Arts \& Health

since 2009

- College Art Association

since 2007 